\title{
MICRO SCALE JET IMPINGEMENT COOLING AND ITS EFFICACY ON TURBINE VANES A NUMERICAL STUDY
}

By

Santhiya Jayaraman, B.Eng

Aerospace Engineering

Anna University

\author{
A project \\ Presented to Ryerson University \\ In partial fulfillment of the \\ Requirements for the degree of \\ Masters of Engineering \\ In the program of \\ Aerospace Engineering
}

Toronto, Ontario, Canada, 2013

(C) Santhiya Jayaraman 


\section{Author's Declaration}

I hereby declare that I, Santhiya Jayaraman, am the sole author of this project.

I authorize Ryerson University to lend this project to other institutions or individuals for the purpose of scholarly research.

Santhiya Jayaraman

I further authorize Ryerson University to reproduce this project by photocopying or by other means, in total or in part, at the request of other institutions or individuals for the purpose of scholarly research.

Santhiya Jayaraman 


\section{Abstract}

A numerical analysis of effectiveness of micro-jet impingement cooling on leading edge of a turbine vane is presented. An axisymmetric single round jet was assessed for its ability and consistency as a preliminary study including the investigation of parameters influencing the heat transfer distribution.

The analysis revealed that an increase in Nusselt number was attributed to increase in Reynolds number, decrease in jet diameter and H/D < 3. Significant improvement in heat transfer was observed for tapering nozzle configuration.

The study was then further expanded to 3D analysis of leading edge cooling of turbine vane. Effect of nozzle diameter to micro-scale was studied, which showed $65 \%$ enhancement in the heat transfer rates. 


\section{Acknowledgement}

I would like to express my profound gratitude to my supervisor, Dr. Bassam Jubran, for his exemplary guidance, monitoring and constant encouragement throughout the course of this project. His constant guidance and knowledge sharing made me understand this project and its manifestations in great depths and helped me to complete the assigned tasks.

I would also like to express my gratitude and appreciation to Dr. Francisco Pino Romanville for his support, ideas and motivation during the course of this project.

I take this opportunity to express a deep sense of gratitude to Ryerson University and staff members who provided the vast study materials and the computational resource without which the project would have been a distant reality.

I would like to thank my family for their constant encouragement and support without which this project would not be possible. I also appreciate all those who gave me the possibility to complete this project.

Lastly, I would like to give a special note of thanks to the High Performance Computing Virtual Laboratory for providing the computational resources and best support. 


\section{Contents}

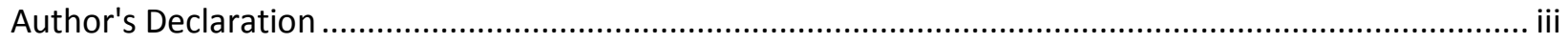

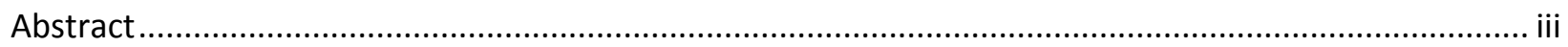

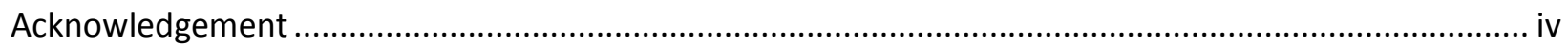

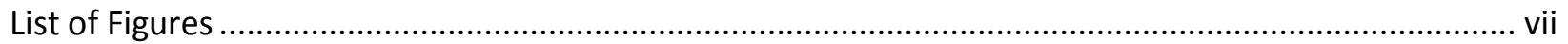

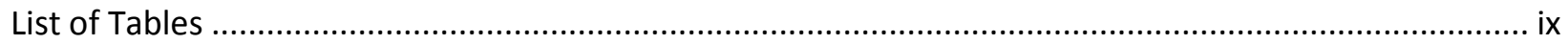

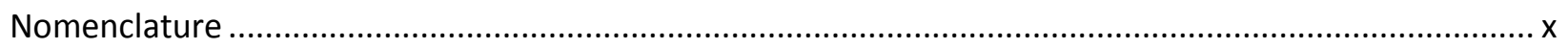

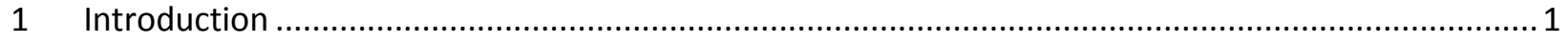

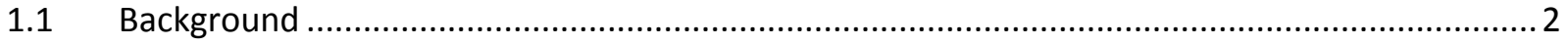

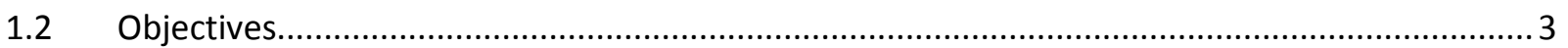

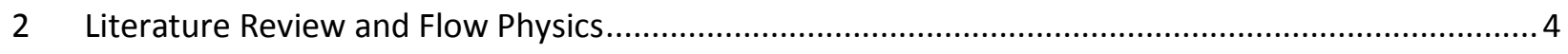

$2.1 \quad H y d r o d y n a m i c s$ of Single Round Jet Impingement ….......................................................... 4

$2.2 \quad$ Jet Impingement Heat Transfer - An analytical review......................................................... 5

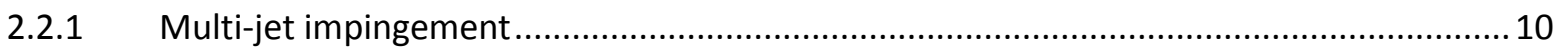

2.2 Impingement Cooling of Curved Surfaces and Turbine vanes .............................................. 12

2.2.3 Impingement Cooling of Turbine vanes .......................................................................... 12

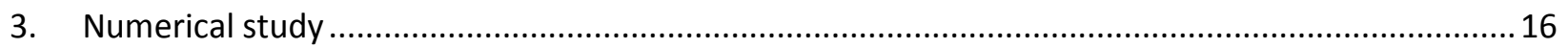

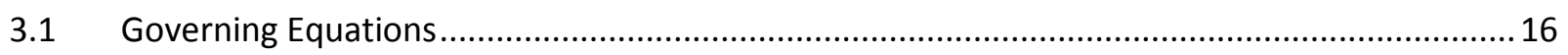

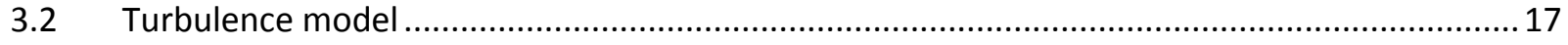

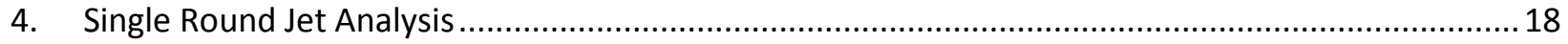

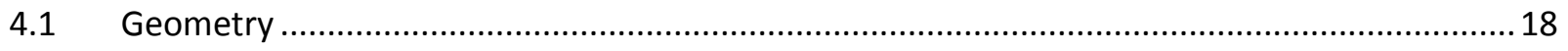

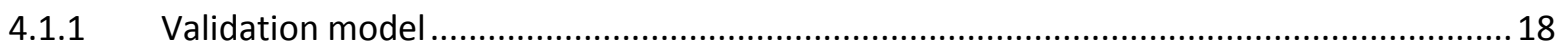

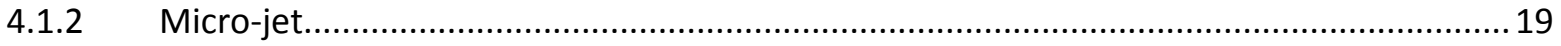

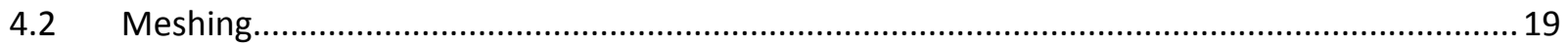

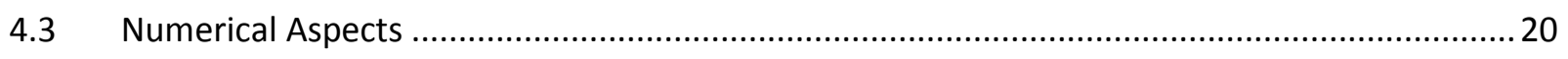

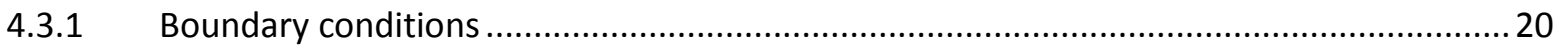

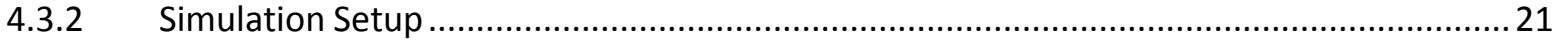

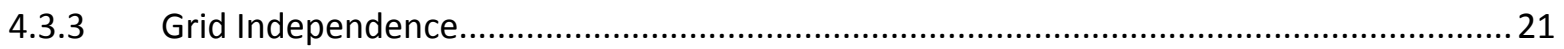

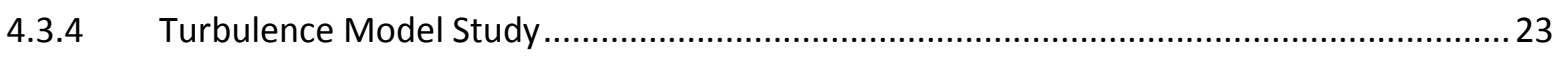

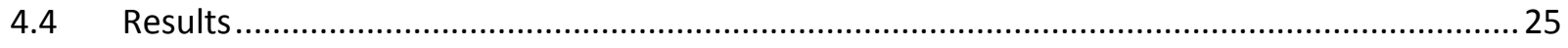




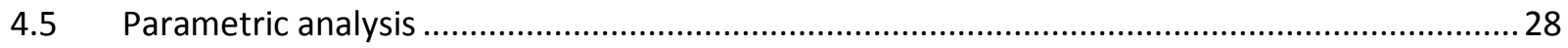

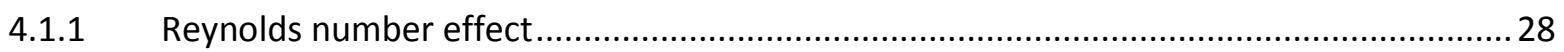

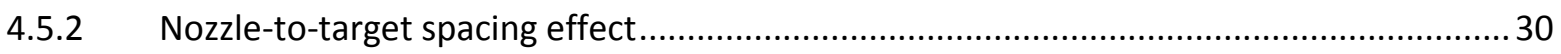

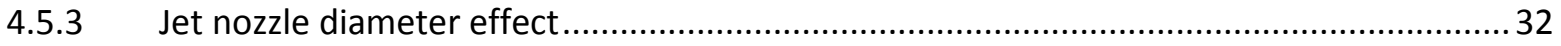

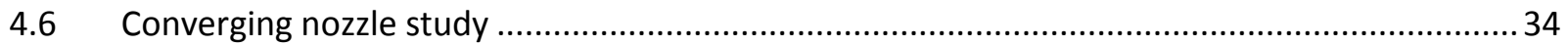

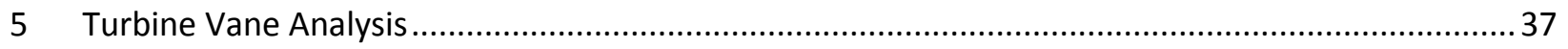

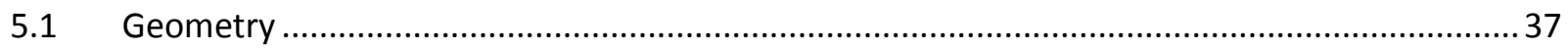

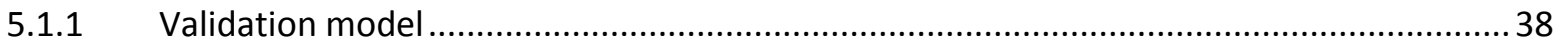

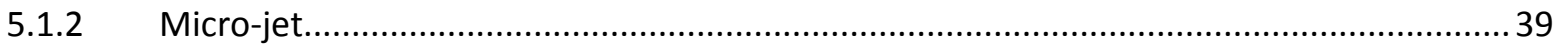

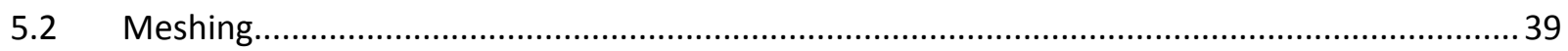

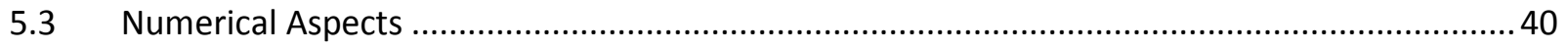

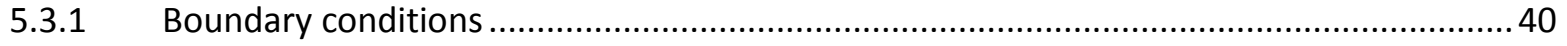

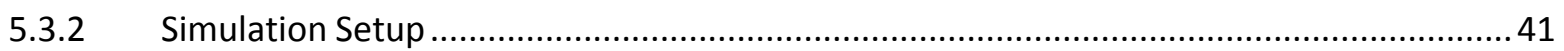

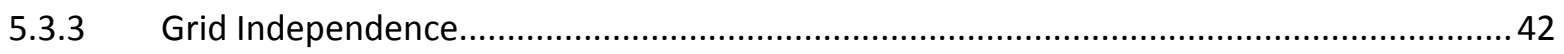

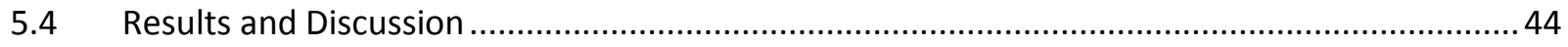

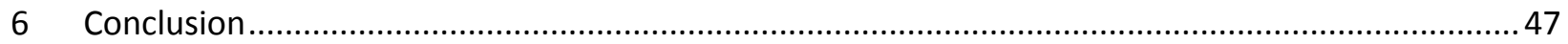

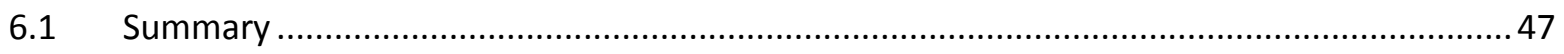

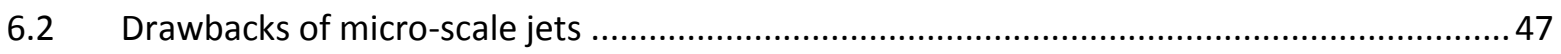

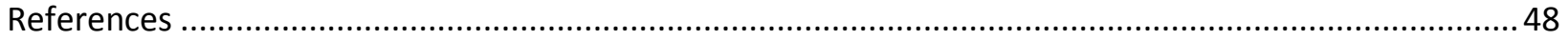




\section{List of Figures}

Figure 1.1: Dependence of TSFC and specific thrust on TIT (Van Treuren [2]) ........................................ 2

Figure 1.2: Growth in cooling technologies .................................................................................... 3

Figure 2.1 Submerged jet; Free surface jet (M.Al-aqal [4]) .................................................................. 4

Figure 2.2 a) unconfined jet; b) Confined jet (M.Al-aqal [4]).............................................................. 4

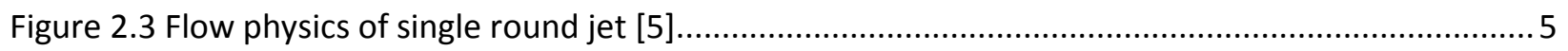

Figure 2.4 Boundary layer formations along the wall (Mirko Bovo [7]) .............................................. 6

Figure 2.5: Radial distribution of Nusselt number ............................................................................... 7

Figure 2.6: Effect of H/D on Nusselt distribution [8] ..................................................................... 8

Figure 2.7: Radial distribution of Nu showing secondary peaks [6] ...................................................... 9

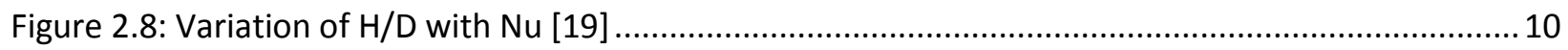

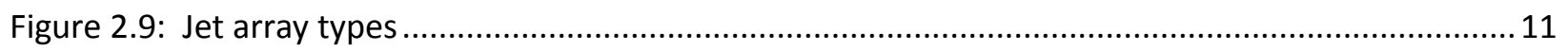

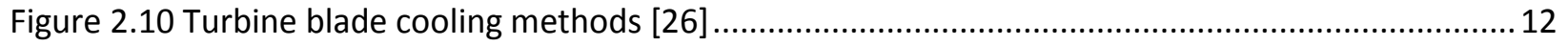

Figure 2.11 Effect of nozzle position (first stage rotor blade) [28] ...................................................... 13

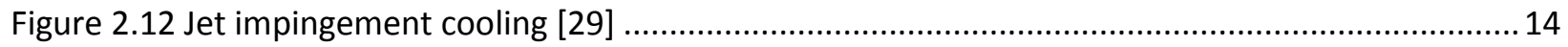

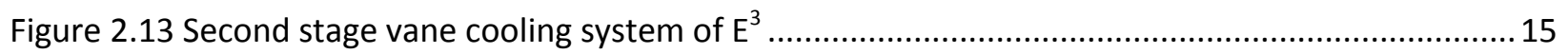

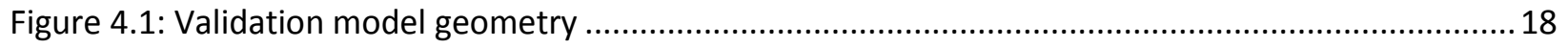

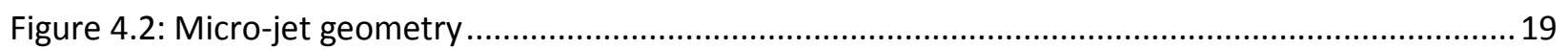

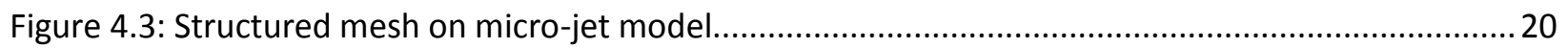

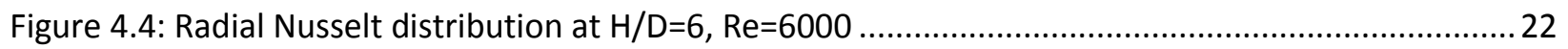

Figure 4.5: Radial Nusselt distribution for three grids ........................................................................ 22

Figure 4.6: Effect of K-Epsilon turbulence models and its variations on $\mathrm{Nu}$............................................2 24

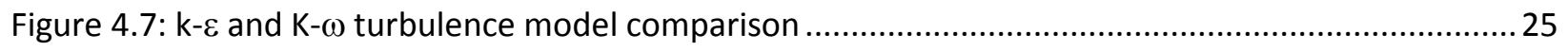

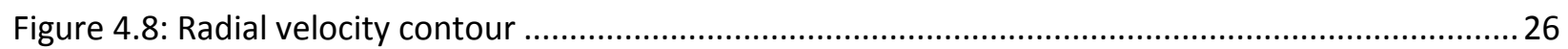

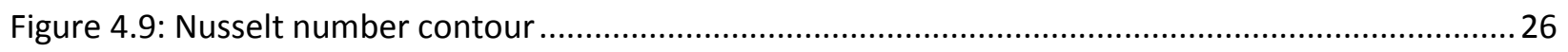

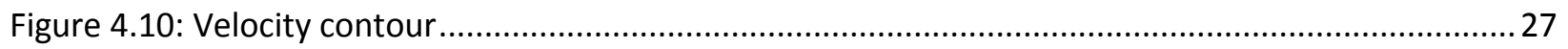

Figure 4.11: 3D model showing fully developed jet ......................................................................... 27

Figure 4.12: Static pressure contour on symmetry plane and target .....................................................28

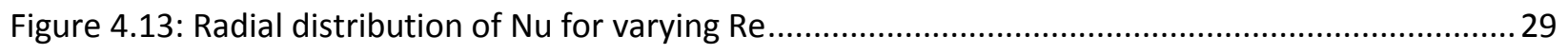

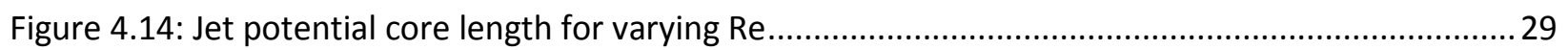

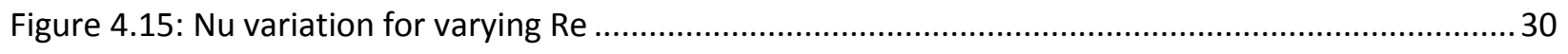

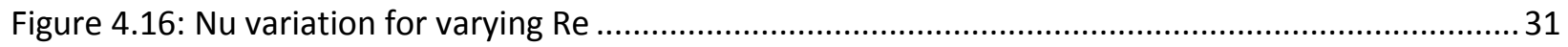

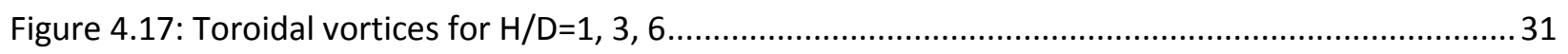

Figure 4.18: Local Nusselt number distribution for varying jet diameters ............................................... 32

Figure 4.19: Centerline mean velocity distribution for varying jet diameters......................................... 33

Figure 4.20: Comparison of diameter effect with the work of Anand [9] ............................................ 33

Figure 4.21: Velocity contours of $D=0.1 \mathrm{~mm}$ (top left), $0.2 \mathrm{~mm}$ (top right), $0.25 \mathrm{~mm}$ (bottom left) and

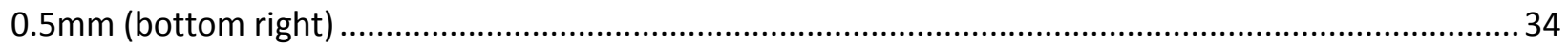


Figure 4.22: Tapering effect on local Nusselt distribution

Figure 4.23: Velocity contour for nozzle taper ratio of 2 (left) in comparison with $0.2 \mathrm{~mm}$ constant diameter nozzle .35

Figure 4.24: Velocity contour (left) and Nusselt contour (right) for nozzle taper ratio of 1.43 ................36

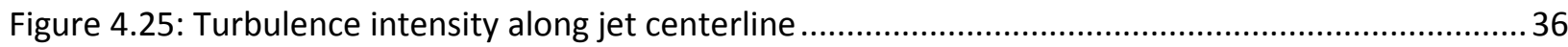

Figure 5.1: Second stage vane -airfoil (left), Generated vane model (right) .......................................... 37

Figure 5.2: Validation model (left), Model showing jet location (right) .................................................. 38

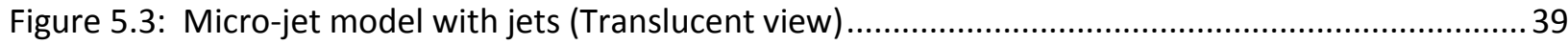

Figure 5.4: Hybrid mesh generated on validation model (left), micro jet model (right) ........................... 40

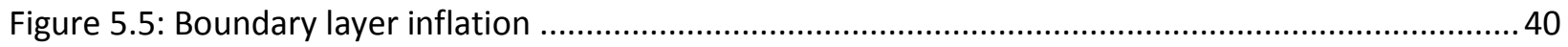

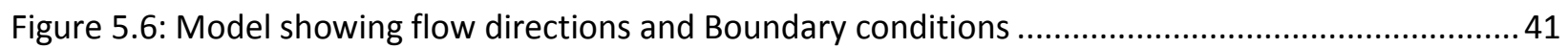

Figure 5.7: Mesh sensitivity of stream wise Nusselt distribution on pressure surface ........................... 42

Figure 5.8: Stream wise nusselt distribution on pressure surface for full vane geometry by [9]............. 43

Figure 5.9: Velocity distribution on the vane mid plane of validation model ........................................ 44

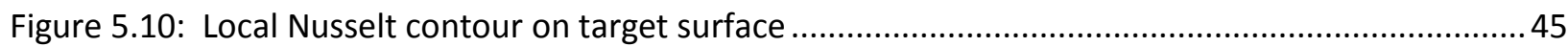

Figure 5.11: Streamlines representing recirculation zones and the cross flow.......................................45

Figure 5.12: Velocity distribution on the vane mid plane of micro-jet model......................................... 46

Figure 5.13: Stream wise Nusselt distribution on pressure surface .......................................................46 


\section{List of Tables}

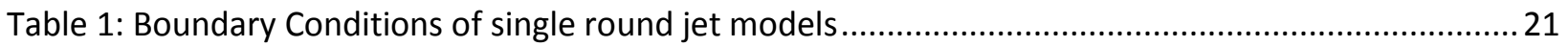

Table 2: Average Nu values for different grids and zero spacing value.................................................23

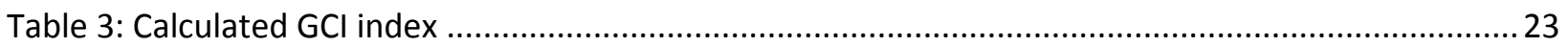

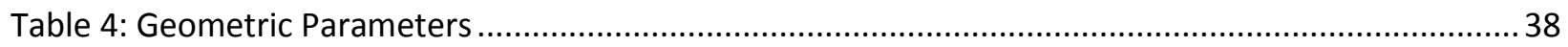

Table 5: Average Nu values for different grids and zero spacing value ................................................... 43

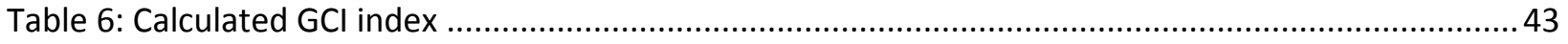




\section{Nomenclature}

\begin{tabular}{|c|c|}
\hline$C_{p}$ & Specific heat at constant pressure \\
\hline$D(o r) d$ & Nozzle Diameter \\
\hline $\mathbf{E}^{3}$ & Energy Efficient Engine \\
\hline $\boldsymbol{h}$ & Convective Heat Transfer Coefficient \\
\hline $\boldsymbol{H}$ & Nozzle to Target Distance \\
\hline $\boldsymbol{k}$ & Thermal Conductivity of fluid \\
\hline $\boldsymbol{L e}_{\text {Turb }}$ & Entrance Length (nozzle pipe) \\
\hline$N u$ & Nusselt Number \\
\hline$N u_{\text {stag }}$ & Stagnation Nusselt Number \\
\hline Pr & Prandt/ number \\
\hline$q$ & Total Heat Surface Heat Flux \\
\hline $\mathbf{r}($ or) $x$ & Radial Distance \\
\hline $\operatorname{Re}$ & Reynolds number \\
\hline c & Chord length \\
\hline$T_{j}$ & Jet Temperature \\
\hline $\boldsymbol{T}_{w}$ & Wall Temperature \\
\hline TIT & Turbine Inlet Temperature \\
\hline $\boldsymbol{V}$ & Velocity of jet \\
\hline G & Mass flow per unit heated area \\
\hline \multicolumn{2}{|l|}{ Greek } \\
\hline$\gamma$ & Ratio of Specific heats \\
\hline $\boldsymbol{\rho}$ & Density \\
\hline $\boldsymbol{\mu}$ & Dynamic Viscosity \\
\hline $\boldsymbol{v}$ & Kinematic Viscosity \\
\hline$\tau_{w}$ & Wall Shear Stress \\
\hline \multicolumn{2}{|l|}{ Ratios } \\
\hline$H / D, Z / d, L / d$ & rget spacing to jet diameter rat \\
\hline$x / D, r / D$ & Radial distance to jet diameter ratio \\
\hline
\end{tabular}




\section{Introduction}

\subsection{Background}

The growing demand for higher performance of turbine engines has pushed the engine technology to increase its cycle efficiency. The cycle efficiency $(\eta)$ of the engine is a function of both pressure ratio( $r)$ and turbine inlet temperature (TIT) (Saravanamuttoo [1])

$$
\begin{gathered}
\eta=1-\left(\frac{1}{r}\right)^{(\gamma-1) / \gamma} \\
\frac{W}{C_{p} T_{1}}=t\left(1-\frac{1}{r^{(\gamma-1) / \gamma}}\right)-\left(r^{(\gamma-1) / \gamma}-1\right)
\end{gathered}
$$

$W$ is the Specific power output and $T_{1}$ is the inlet temperature (ambient).

Increase in TIT provides greater specific thrust while decreasing the fuel consumption since they are inter-dependent with the engine operating temperature (Fig 1.1). Increasing TIT will also greatly increase, the thermal efficiency of the engine, reduce the engine weight and drag, but with the drawback of exposing turbine blades to high temperatures thereby reducing its life and durability. Fig 1.2 shows the growth in TIT over a period of 60 years due to the developments and new findings in cooling techniques. Advanced composites are used to enhance the life expectancy of the blades but this eliminates only fifty percent of the issue. Reducing the blade temperature proved to greatly improve the blade life, thus the cooling methods come into plot.

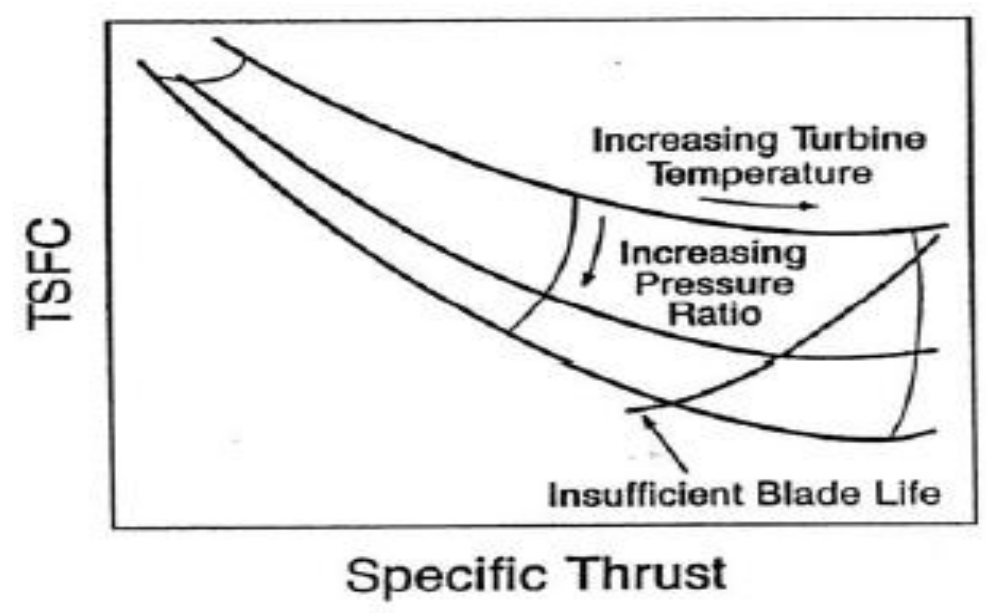

Figure 1.1: Dependence of TSFC and specific thrust on TIT (Van Treuren [2]) 


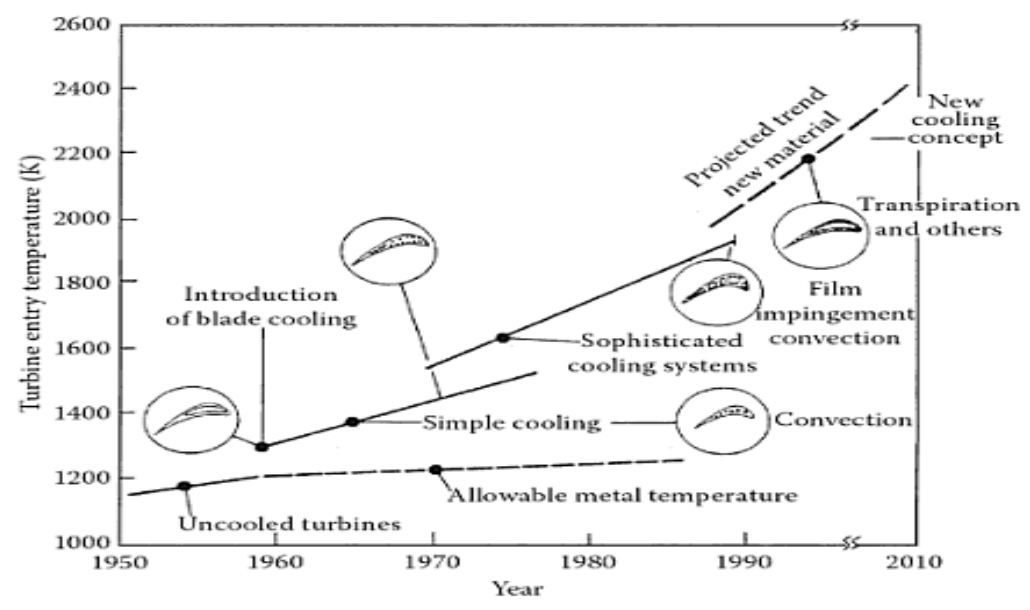

Figure 1.2: Growth in cooling technologies

There are two strategies in cooling blades, internal cooling and external cooling. Internal cooling can be accomplished by jet impingement or pin fin and external by film cooling. The target is to design vanes that use minimal coolant to prevent aerodynamic losses. Accordingly, jet impingement cooling is of greater interest since it is efficient, particularly for localized cooling of surfaces, use of fluid and in situations with restricted spaces. Cooling methods for particular component are chosen based on the material and accepted stress levels of the component.

In this present study, an Eulerian approach is adapted to accomplish an elaborated numerical study on parameters influencing heat transfer rates for single round jet impingement. Focusing on fluid passing through a fixed control volume in space is referred to as Eulerian approach. The acquired understanding and optimized results were used to analyze multi-jet impingement on the leading edge of second stage high pressure turbine vane. The second stage vane used for current study pertains to Energy Efficient Engine $\left(E^{3}\right)$ (Halila et al [3]).

\subsection{Objectives}

The principal objectives of this project are to,

- Study the complex flow structure and analyse the factors influencing the heat transfer involved in jet impingement cooling

- Assess the turbulence models which better predicts the heat transfer characteristics

- Study the jet impingement effectiveness on a realistic turbine vane

- Determine the efficacy of using micro jet impingement on turbine vanes 


\section{Literature Review and Flow Physics}

\subsection{Hydrodynamics of Single Round Jet Impingement}

Jet impingement cooling is a method where the jet flow is directed to impinge on the target surface through a hole or slot. The jet flow may be classified as submerged, free surface, confined and unconfined jet. Submerged jet is characterised as jet with fluid same as the fluid in the surrounding region and different fluid compared to the impinging or surrounding region is referred to as free surface jet (Fig 2.1).The jets which are confined between orifice plate and the target surface are called confined or semi-confined jets (Fig 2.2).
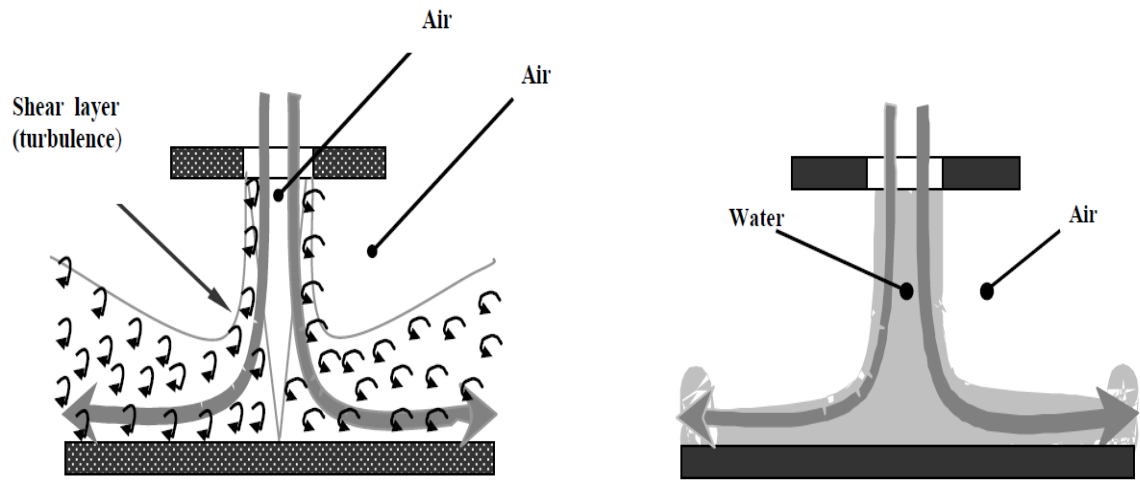

Figure 2.1 Submerged jet; Free surface jet (M.Al-aqal [4])

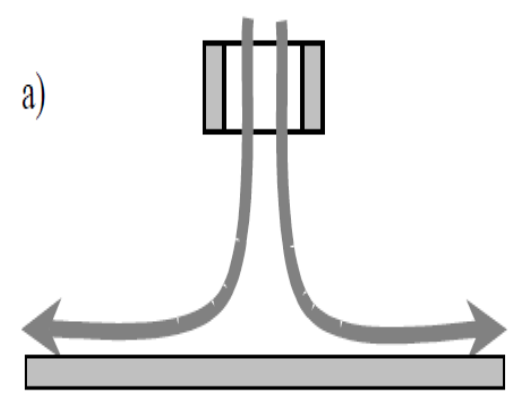

b)

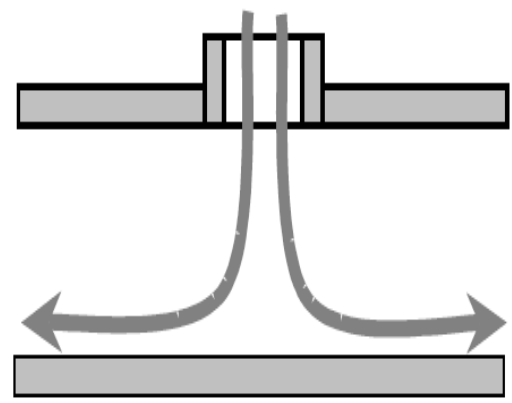

Figure 2.2 a) unconfined jet; b) Confined jet (M.Al-aqal [4])

The various distortions experienced by the flow in the region between the jet exit and the target surface have led to the division of the flow into three regions; free jet, stagnation and wall jet (Fig 2.3). The free jet region is further subdivided into potential core, developing and fully developed zones. Free jet in a developing zone undergoes transfer of momentum from the surrounding, entraining the surrounding mass, momentum and energy into the jet. This result in widening of jet, losing energy along its perimeters leaving a core region called the potential core, where the velocity in the centerline is almost 
equal to the nozzle exit velocity. Potential core length depends on the turbulence intensity of the jet at the nozzle exit. Further entrainment and nozzle to target distances leads to the decay of axial velocity forming the developing zone and fully developed zone when the jet reaches a Gaussian velocity profile. (Jambunathan et al [5]).
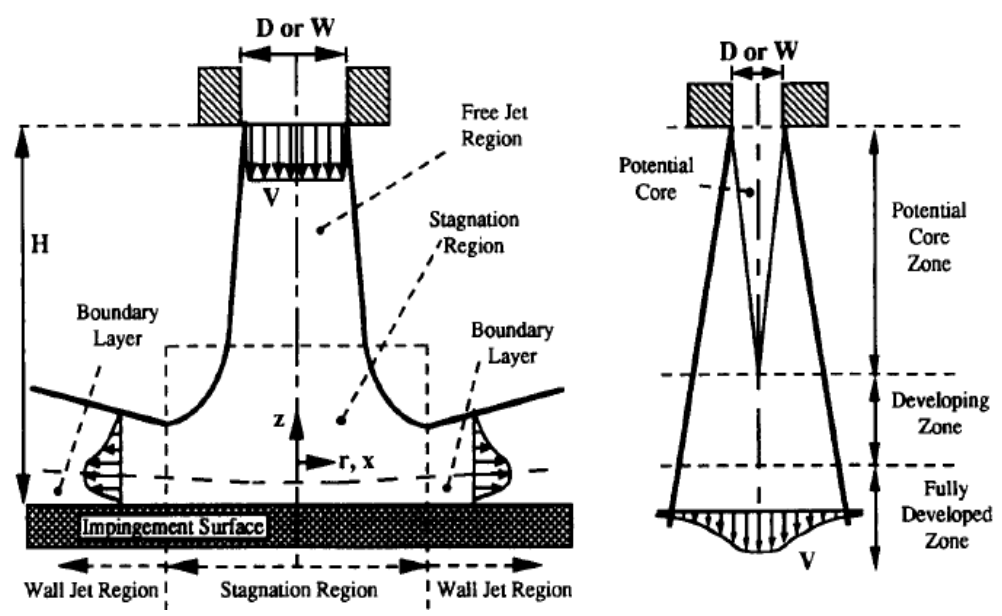

Figure 2.3 Flow physics of single round jet [5]

Approximately 1.2D above the impingement plate is the stagnation region; the flow loses its velocity, builds static pressure and turns in the radial direction (Draksler et al [6]). The region where the flow moves radially outward, parallel to the wall is the wall jet region. Higher heat transfer rates are obtained in the wall jet region due to the turbulence generated by shear between the wall jet and the surrounding air.

\subsection{Jet Impingement Heat Transfer - An analytical review}

An outline of the flow features of an impinging jet was defined in the previous section with focus on velocity of the jet. This section deals with heat transfer aspect of an impingement jet.

The heat transfer characteristic of an impinging jet is mostly assessed by the dimensionless number, Nusselt number $(\mathrm{Nu})$. A maximum of $\mathrm{Nu}$ is obtained at stagnation point and this is due to high turbulent kinetic energy of jet at that region. A reduced value of stagnation Nusselt number will be obtained if the length of potential core is greater than the nozzle-to-target spacing. A laminar boundary layer is formed in the stagnation point which later develops reducing the heat transfer rates and thus the drop of $\mathrm{Nu}$ curve as shown in (Fig 2.4). The laminar boundary layer slowly transforms into turbulent boundary layer which is portrayed by the sudden rise in $\mathrm{Nu}$ in the transition region. The $\mathrm{Nu}$ value then decays monotonically as the jet spreads radially to conserve the momentum. 


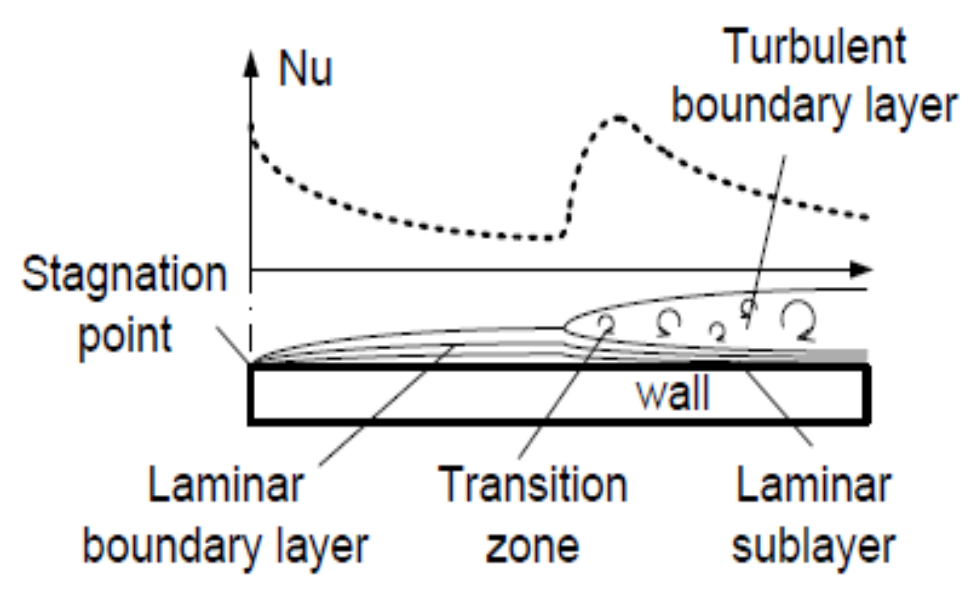

Figure 2.4 Boundary layer formations along the wall (Mirko Bovo [7])

The convective heat transfer occurring in the region bounded by nozzle exit and target surface is estimated from convective heat transfer coefficient given by,

$$
h=\frac{q}{\left(T_{w}-T_{j}\right)}
$$

A non-dimensional parameter, Nusselt number is defined for calculating the heat transfer coefficient,

$$
N u=h D / k
$$

Jambunathan et al [5] did a detailed study on the available single round turbulent jet heat transfer literatures and reported the below simple correlation for local heat transfer coefficient,

$$
\mathrm{Nu}=f(\operatorname{Re}, z / D, x / D, P r)
$$

Where $z / D$ is jet-target spacing to jet diameter ratio, $x / D$ is radial distance to jet diameter ratio and

$$
R e=\frac{\rho V D}{\mu}
$$

Several other correlations were given from detailed investigations by researchers. San and Shiao [10] have proposed a correlation for stagnation Nusselt number $\left(\mathrm{Nu}_{\mathrm{stag}}\right)$ based on their experimental data.

$$
N u_{\text {stag }}=0.426 R e^{0.638}\left(\frac{H}{d}\right)^{-0.3} e^{-\left[0.044\left(\frac{w}{d}\right)+0.011\left(\frac{L}{d}\right)\right]}
$$


For $10,000 \leq \operatorname{Re} \leq 30,000 ; 1 \leq H / d \leq 6 ; 4.17 \leq H / d \leq 41.17 ; 5.5 \leq L / d \leq 166.7$

Hence expressing Nu as,

$$
N u=f\left(R e, \frac{H}{d}, \frac{w}{d}, \frac{L}{d}, \frac{x}{d}, \frac{y}{d}\right)
$$

Where,

$\mathrm{H} / \mathrm{d}$ - plate spacing to jet diameter ratio

$\mathrm{W} / \mathrm{d}$ - jet plate width-to-jet diameter ratio

$\mathrm{L} / \mathrm{d}$ - jet plate length-to-jet diameter ratio

$\mathrm{x} / \mathrm{d}$ - radial distance to jet diameter ratio

$y / d$ - axial distance to jet diameter ratio

Goldstein and Behbahani [11] investigated the effect of circular air jet, with and without cross flow for different jet blowing rates at jet-to-plate spacing of 6D, 12D and observed a decrease in maximum Nusselt number with increasing cross flow for $L / D=12$ and increase in maximum Nusselt number with moderate cross flow for $L / D=6$. They approximated the relation between $\mathrm{Nu}$ and $\mathrm{Re}$ as

$$
N u \propto R e^{n}
$$

Where $n$ depends on parametric variation such as nozzle-to-target spacing (L/D).

It is observed from the literatures that the heat transfer coefficient tends to increase with nozzle-totarget spacing for up to $6 \mathrm{D}$ distances and then decreases. Secondary peaks are seen to occur at relatively high Reynolds number and low H/D ratios.

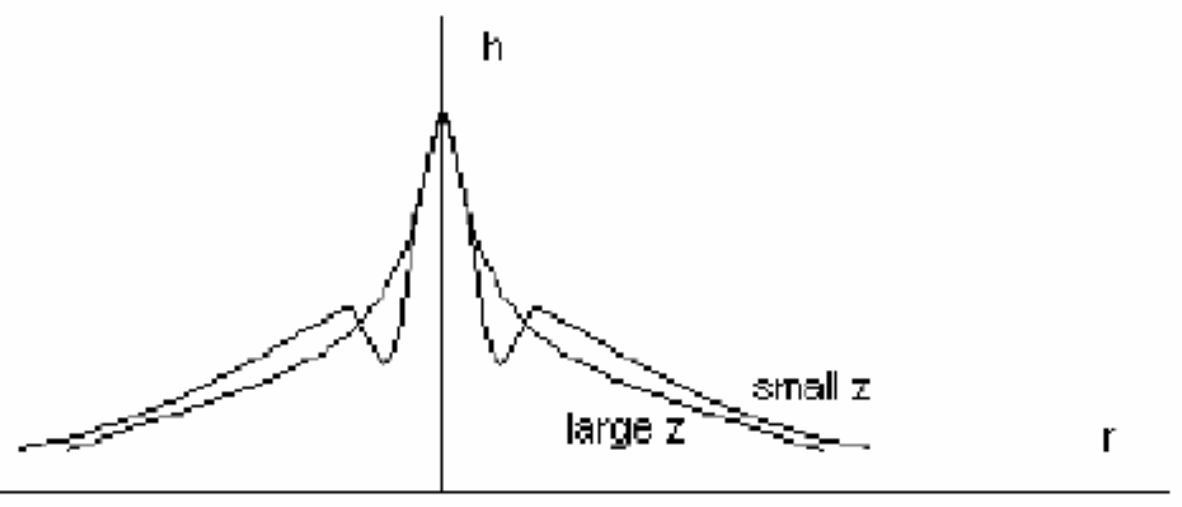

Figure 2.5: Radial distribution of Nusselt number 
Lytle and Webb [8] performed an elaborated study on low nozzle-to target spacings. From the trends obtained, it is perceived that secondary peaks occur for $H / D<6$ and the maxima of the peak keeps increasing with decreasing $H / D$ ratios. The first peak is located at $r / D \approx 0.5$ and it is noticed to be diminishing with increase of H/D (Fig 2.6). They also emphasized the fact that increase in heat transfer coefficient under low spacings lead to significant pressure drop in the system.

Here,

r/D - radial distance to jet diameter ratio

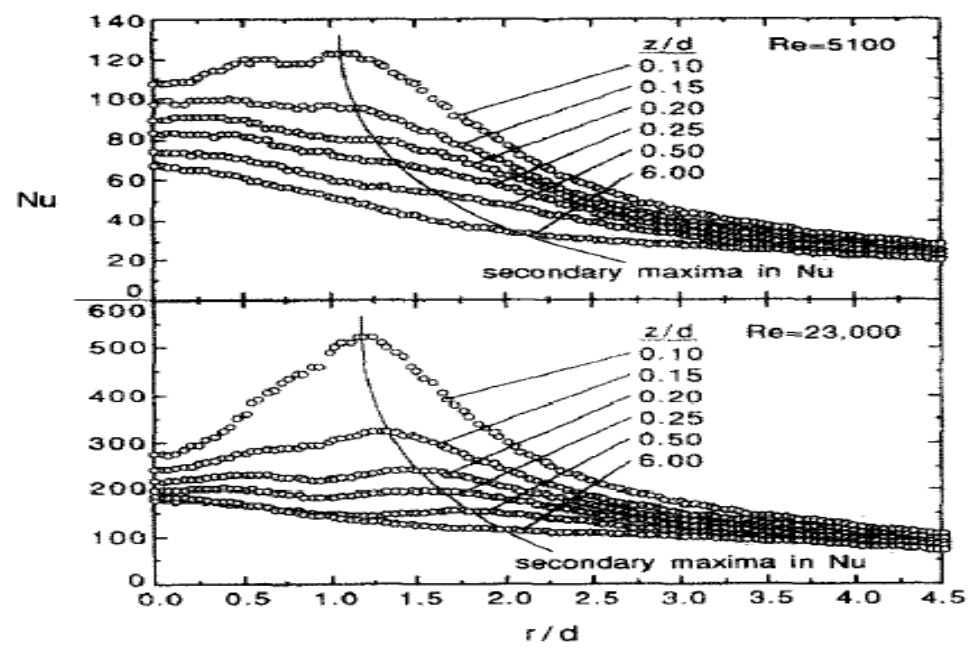

Figure 2.6: Effect of H/D on Nusselt distribution [8]

San and Shiao [10] performed experimental study on confined circular jet impinging on flat plate. They studied the effects of jet plate size and nozzle-to-target spacing. They showed the occurrence of two peaks, one at $x / D \approx 1$ pertaining to the transition from impingement to wall jet and the second peak at $x / D \approx 2.4$ indicating strong turbulence. They also showed that the stagnation Nusselt number decreases with increase of $\mathrm{H} / \mathrm{d}$ and this is due to increase in the mixing area, in turn effecting the mixing of the flow.

Lee and Lee [12] did a detailed experimental study of three different nozzle exit configurations for an axisymmetric converged jet. They found that the sharp edged orifice nozzle gives higher heat transfer rates compared to standard edged and square edged. They also observed secondary peaks in Nusselt number distribution along radial direction corresponding to transition from laminar to turbulent boundary layer and the peaks were more prominent for lower H/D ratios. 
Draksler and Koncar [6] numerically analysed the effects of nozzle shape and different turbulence models on turbulent impinging jet. They also observed secondary peaks indicating the transition of jet to fully turbulent (Fig 2.7). The local heat transfer coefficient of different nozzle inlet shapes showed two peaks and a local minimum stagnation point with rectangular nozzle having the highest heat transfer coefficient.

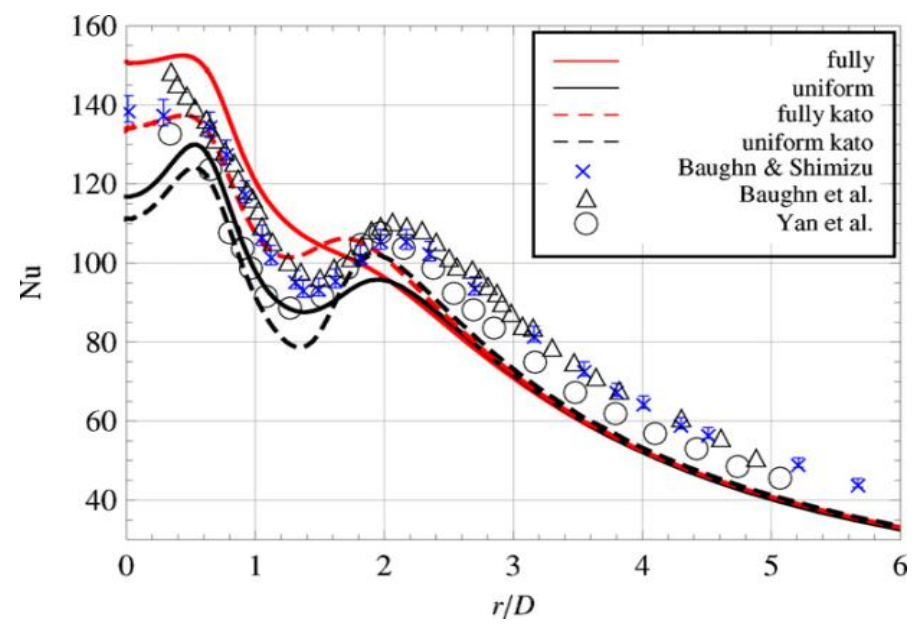

Figure 2.7: Radial distribution of Nu showing secondary peaks [6]

Uddin et al [13] performed numerical simulation to observe the vortical structures on heat transfer of an impinging jet. They used large eddy simulations to explore the flow physics in stagnation and developing wall jet zone. It shows that the reason for occurrence of secondary peak is the acceleration of flow in the developing region.

Secondary peaks were also reflected in the work of Frost et al [14] and the distribution of Nusselt number along radial direction shows the location of secondary maximum to be $r / d \approx 1.5$

Katti and Prabhu [15] performed an experimental analysis of circular jet impinging on flat surface. They found the occurrence of secondary peaks at $\mathrm{r} / \mathrm{d}=1.7$ and came up with an expression for local Nusselt number of the form,

$$
\frac{N u}{\operatorname{Re}^{1 / 2} \operatorname{Pr}^{1 / 3}}=a_{1}\left(\frac{Z}{d}\right)^{-0.11}\left(1-\frac{\left(\frac{r}{d}\right)^{2}\left(\frac{z}{d}\right)^{-0.2}}{b_{1}}\right)^{1.2}
$$

Where $a_{1}$ and $b_{1}$ are constant for different jet-to-target spacing and the equation reduces to stagnation point Nusselt number when $r / d=0$. They also defined a correlation for wall jet region Nusselt number.

$$
N u=0.0436 \operatorname{Re}^{0.8} \operatorname{Pr}^{0.333}\left(\frac{z}{d}\right)^{0.0976}\left(\frac{r}{d}\right)^{-1.0976}
$$


Goldstein and Seol [16] investigated the heat transfer from a row of circular, submerged impinging jets on a flat surface and observed that the recovery factor is independent of jet Reynolds number and dependent on jet-to-plate spacing (L/D).

$$
\text { recovery factor }=\left(T_{w}-T_{j}\right) /\left(\frac{V^{2}}{2 C_{p}}\right)
$$

Glynn et al [17] used compressed air supply to impinge on a uniform wall flux target surface through single submerged and confined jets of $0.5,1$ and $1.5 \mathrm{~mm}$ diameters. They observed that the area averaged heat transfer increases with decreasing jet diameter. This could be accounted to the increase in air flow velocity.

Lee et al [18] investigated the effects of nozzle diameter on impinging jet heat transfer. They experimentally analysed the effects of L/D ratios ranging from 2 to 14 and showed that maximum $\mathrm{Nu}$ occurs at $L / D=7$. They also inferred that potential core length is directly proportional to the nozzle diameter.

Behnia et al [19] studied both confined and unconfined configurations and noted that for $H / D$ ratios greater than unity, confinement has no effect on heat transfer rate. (Fig 2.8)

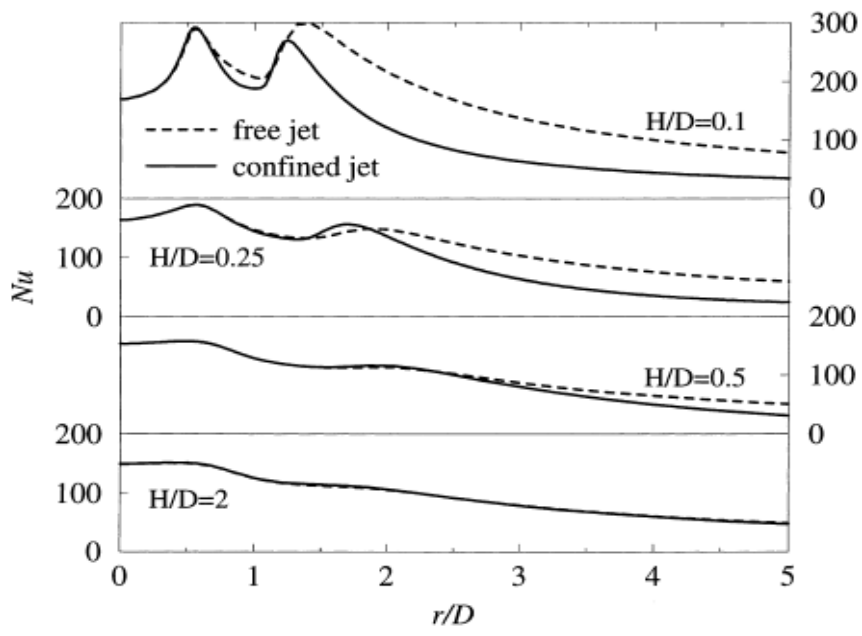

Figure 2.8: Variation of $\mathrm{H} / \mathrm{D}$ with $\mathrm{Nu}$ [19]

\subsubsection{Multi-jet impingement}

A multi-jet or array of jets involves more complex flow structure since the jet from one hole is affected by neighbouring jets. Factors that influence the heat transfer of jet arrays include wall-jet interaction, jet-jet interaction, cross flow and the flow features is similar to a single jet with free jet, stagnation and 
wall jet regions. Jet arrays may be positioned either inline or staggered. (Fig 2.9) shows inline and staggered arrangement of jets.

The flow physics of multiple jets is studied in detail by Geers et al [20]. Leland and Ponnappan [21] experimentally evaluated the micro jet array impingement with cross flow and reported an increase of heat transfer with decrease in jet-to-target spacing which is also reported by Miao et al [22] work. The following correlation is obtained by [21] for local Nusselt number in terms of wall-to-inlet temperature ratio.

$$
N u_{d}=1.136 R e_{d}^{0.16} \exp \left(\frac{R e_{d}}{637}\right)^{1 / 3} \operatorname{Pr}\left(\frac{\mathrm{T}_{\mathrm{w}}}{\mathrm{T}_{\mathrm{i}}}\right)^{0.055}
$$

Where

$\mathrm{Nu}_{d}$-average Nusselt number, $\mathrm{Re}_{d}$ - Reynolds number, $\mathrm{T}_{w}$ - average wall temperature, $\mathrm{T}_{\mathrm{i}}-$ inlet static temperature

They also reported the higher efficacy of inline round jet arrays with cross flow than staggered jets due to the fact that the spent air gets accumulated upstream and hence the flow rate increases when it reaches downstream.

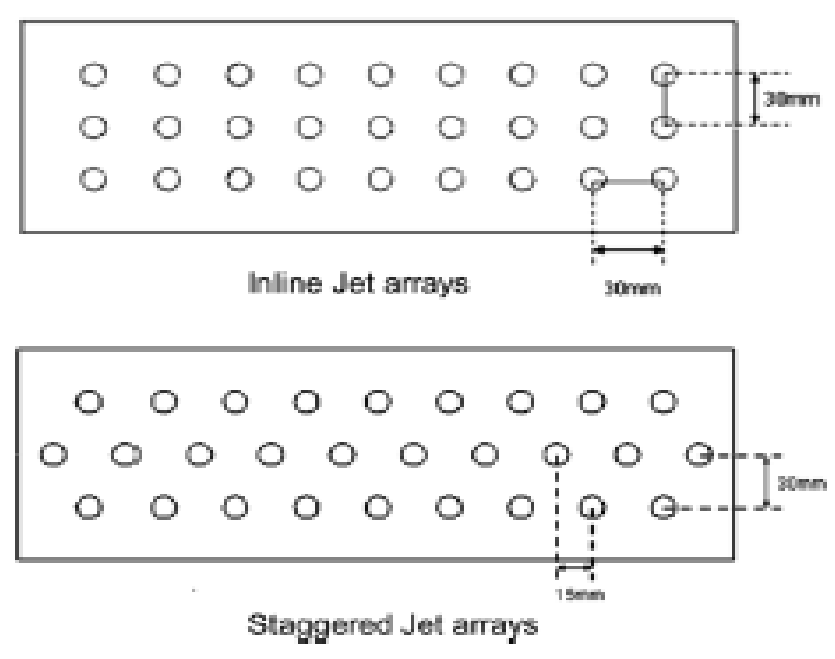

Figure 2.9: Jet array types

Uysal et al [23] studied the heat transfer of an array of impinging jets on internal surfaces of a rectangular channel and observed that the varying diameter alleviates the influence of cross flow. 


\subsection{Impingement Cooling of Curved Surfaces and Turbine vanes}

Though there is a vast data on impingement cooling of flat surfaces, analysis of jet impingement cooling on curved surfaces is very limited. Surface curvature effect comes into play for jet impingement on curved surfaces.

Lee et al [18] investigated the local heat transfer from a convex surface impinging jet. A general trend of increasing Nusselt number with Re and surface curvature is noted due to acceleration of flow for increased curvature, which is also reported by Yang and Hwang [24].

Numerical study of slot jet impingement on concave surface was carried out by Souris et al [25] and a higher Nusselt number was noted for $\mathrm{H} / \mathrm{B}=6$.

Where,

$\mathrm{H} / \mathrm{B}$ is nozzle exit- to- nozzle slot jet width

\subsubsection{Impingement Cooling of Turbine vanes}

Impingement cooling of turbine vanes is achieved by impingement of fluid jets on the inner surface of the vanes after passing through the inner cooling passages of the vane. Other types of cooling include film cooling and transpiration cooling. Je-chin Han [26] did a detailed study on the types of turbine blade cooling and its recent developments. (Fig 2.10) shows the basic cooling techniques used in the turbine blades.

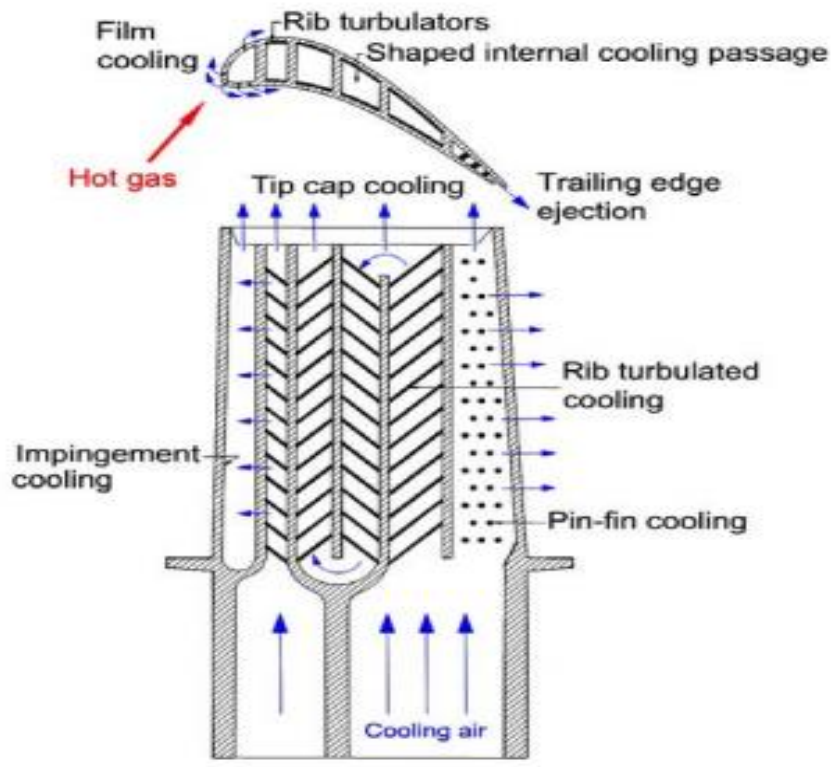

Figure 2.10 Turbine blade cooling methods [26] 
The need for turbine blade cooling dates back to 1950's. Ainley [27] was one of the first to give a methodical cooling design procedure of blades. A simplified assumption to analyse the problem where span wise heat conduction on blade is negligible and the chord wise blade metal temperature is uniform was used by him. This one dimensional approach made a fairly close approach with reality but with a hitch of using it only for a single pass system and that failure occurs when average chord wise temperature reaches a critical value. Liu and Feng [28] numerically investigated the impingement cooling on leading edge of first stage rotor blade of $\mathrm{Ge}-\mathrm{E}^{3}$ engine. They studied the effect of nozzle position in the leading edge and observed that the reduced distance between jet nozzle center and pressure side increases the area weighted average Nusselt number and the side entry jet better enhances impingement cooling (Fig 2.11).

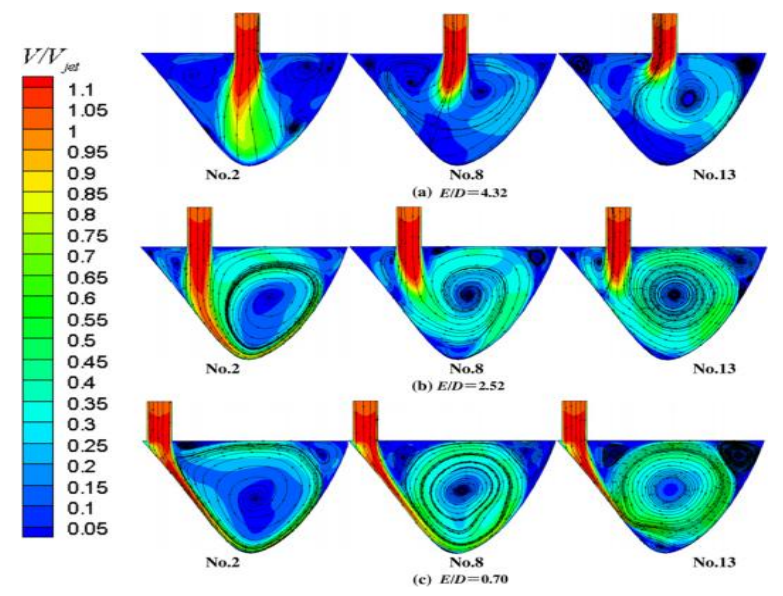

Figure 2.11 Effect of nozzle position (first stage rotor blade) [28]

Chupp et al [29] investigated the heat transfer coefficient for impingement cooling on a curved surface experimentally. The basic functional relationships for heat transfer coefficient are,

$$
\begin{gathered}
h=h(\text { flow rate, properties, location, geometry }) \\
N u=N u(r e, \text { Pr, geometry, location })
\end{gathered}
$$

And the value of $h$ varies chord wise around the leading edge. He showed that Nusselt number varies exponentially with $\mathrm{I} / \mathrm{d}$ ratio. He obtained the below empirical relation for stagnation Nusselt number and average Nusselt number for $3000<\operatorname{Re}<15,000,4<\mathrm{s} / \mathrm{d}<16,1<\mathrm{l} / \mathrm{d}<10$, and $1.5<\mathrm{D} / \mathrm{d}<16$.

$$
N u_{\text {stag }}=0.44 R e^{0.7}\left(\frac{d}{s}\right)^{0.8} \times \exp \left[-0.85\left(\frac{l}{d}\right)\left(\frac{d}{s}\right)\left(\frac{d}{D}\right)^{0.4}\right]
$$




$$
N u_{\text {avg }}=0.63 R e^{0.7}\left(\frac{d}{s}\right)^{0.6} \times \exp \left[-1.27\left(\frac{l}{d}\right)\left(\frac{d}{s}\right)^{0.5}\left(\frac{d}{D}\right)^{1.2}\right]
$$

Showing stagnation Nusselt number as a function of,

$$
N u=f\left(\operatorname{Re}, \frac{l}{d}, \frac{s}{d}, \frac{d}{D}\right)
$$

Where,

$\mathrm{l} / \mathrm{d}$ - nozzle to leading edge spacing - to - hole diameter.

$\mathrm{d} / \mathrm{s}$ - hole diameter to hole spacing

$d / D$ - hole diameter to leading edge diameter
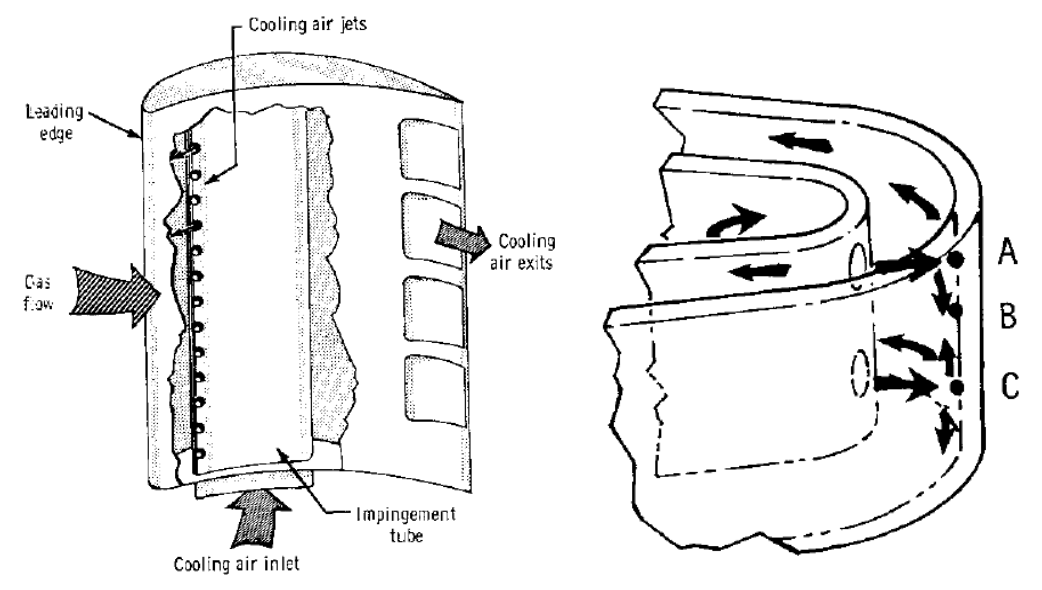

Figure 2.12 Jet impingement cooling [29]

A realistic model of turbine vane using impingement cooling is the second stage high pressure turbine vane of Energy Efficient Engine [3]. Fig 2.13 is the replica of cooling system used in stage 2 vane of $\mathrm{E}^{3}$. Convection cooling with single impingement insert is used and the cooling system involves impingement of $1.85 \%$ of core flow on the inner surface of the vane through the holes of diameter $0.51 \mathrm{~mm}$ which are at $4 \& 12$ diameters spacing. $0.75 \%$ of bleed air after impingement is used to purge the inter-stage seal and only $1.1 \%$ of air is discharged through the pressure side bleed slots in the trailing edge. 


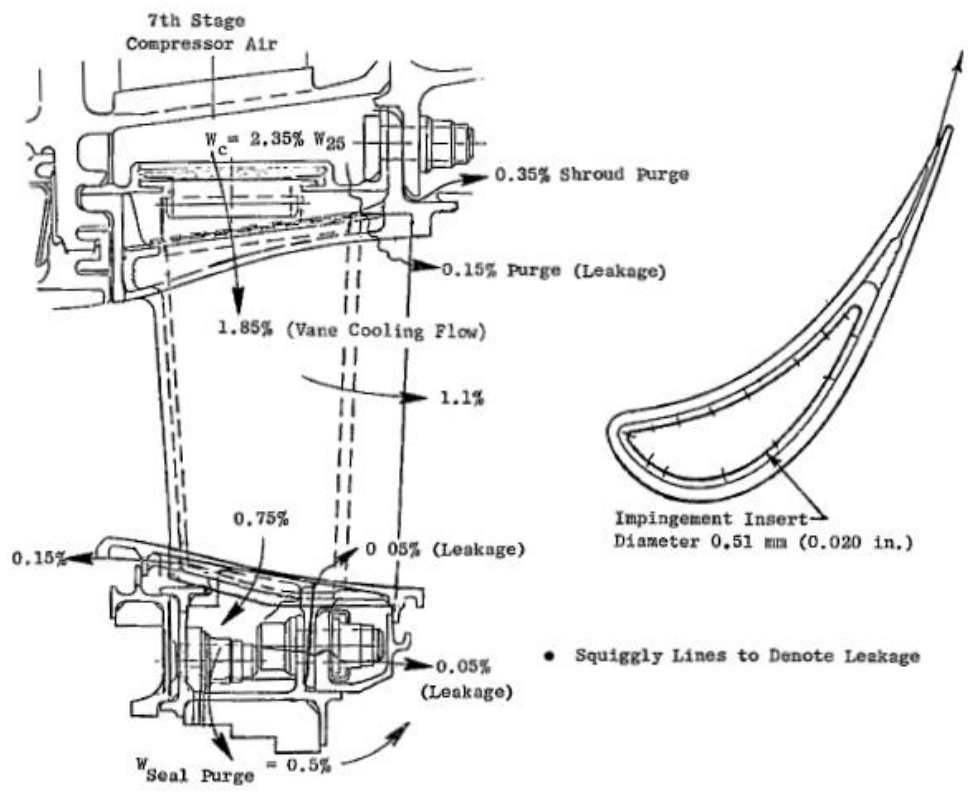

Figure 2.13 Second stage vane cooling system of $E^{3}$

Despite all the experiments and numerical analysis performed till date, a general theory for flow characteristics of jet impingement heat transfer is yet to be determined. Hence an attempt has been made to understand and study its flow feature and heat transfer characteristics. 


\section{Numerical study}

\subsection{Governing Equations}

The equations which describe the motion of incompressible fluid are continuity, momentum and energy. The momentum equation with Newtonian fluid assumption is referred to as Navier-Stokes equations.

The continuity equation for incompressible fluid in tensor notation is given by, (I. G. Currie [30])

Navier-Stokes equation is given by,

$$
\frac{\partial u_{k}}{\partial x_{k}}=0
$$

$$
\frac{\partial u_{j}}{\partial t}+\frac{\partial}{\partial x_{k}}\left(u_{k} u_{j}\right)=-\frac{1}{\rho} \frac{\partial P}{\partial x_{j}}+v \frac{\partial^{2} u_{j}}{\partial x_{i} \partial x_{i}}
$$

This equation can be written in non-dimensional form by assigning $t=t * D_{0} / V_{0}, u=u^{*} V_{0}, x=x^{*} D_{0}$ where $\mathrm{D}_{0}$ and $\mathrm{V}_{0}$ is the characteristic length scale and velocity of the flow respectively.

$$
\begin{gathered}
\frac{\partial u_{j}}{\partial t}+\frac{\partial}{\partial x_{k}}\left(u_{k} u_{j}\right)=-\frac{\partial P}{\partial x_{j}}+\frac{1}{R e} \frac{\partial^{2} u_{j}}{\partial x_{i} \partial x_{i}} \\
R e=V_{0} D_{0} / v
\end{gathered}
$$

Re is the Reynolds number and $v$ is the kinematic viscosity of the fluid.

Energy equation in dimensional form is given by,

$$
\rho \frac{\partial e}{\partial t}+\rho u_{k} \frac{\partial e}{\partial x_{k}}=-P \frac{\partial u_{k}}{\partial x_{k}}+\frac{\partial}{\partial x_{j}} k\left(\frac{\partial T}{\partial x_{j}}\right)+\lambda\left(\frac{\partial u_{k}}{\partial x_{k}}\right)^{2}+\mu\left(\frac{\partial u_{i}}{\partial x_{j}}+\frac{\partial u_{j}}{\partial x_{i}}\right) \frac{\partial u_{j}}{\partial x_{i}}
$$

Where $\lambda$ is the viscosity coefficient and the final two terms in the above equation is collectively referred as dissipation function [30].

Another factor to be mentioned is the wall shear stress defined by,

Where,

$$
\tau_{w}=\mu\left(\frac{\partial u}{\partial y}\right)
$$

$\frac{\partial u}{\partial y}$ is the wall normal derivative of the flow velocity parallel to the wall. 


\subsection{Turbulence model}

The turbulence models in focus for this study are K- $\varepsilon$ RNG and K- $\omega$ SST model. Various researchers have reported varied opinion on the effectiveness of different turbulence models for jet impingement heat transfer. Jet impingement cooling involves complex flow features which are hard to predict by the available turbulence models. Continuous research is carried out for the accurate prediction of flow variables involved in impingement heat transfer.

The performance of turbulence models reported by few of authors is discussed below.

Angiloletti et al [31] analysed submerged and unconfined jets both experimentally and numerically hence validating different turbulence models. It shows better prediction of the complex flow variables by K- $\omega$ SST model near the stagnation region particularly for low Re whereas results of K- $\varepsilon$ RNG showed a smoothed out plot in the stagnation region. A contrasting phenomenon is seen for higher Re where K$\varepsilon$ RNG better predicts the local distribution of Nusselt number in the stagnation region.

Behnia et al [19] used $v^{2}-f$ model to evaluate the heat transfer rates of submerged and unconfined jet impingement. $v^{2}-f$ model is claimed to excellently predict the flow features. K- $\varepsilon$ Model is marked by poor performance for over predicting the cooling effect.

Chougule et al [32] numerically investigated different turbulence models for multi-jet impingement on flat plate. The results indicated that k- $\omega$ SST turbulence model yielded better heat transfer results with Nusselt number prediction error of $2.1 \%$.

Based on the various experimentations and assessment by researchers, it is concluded that the turbulence models for impingement heat transfer studies depends on particular case, turbulence and the flow structure involved.

The focus on turbulence models in the present study is narrowed down to K- $\omega$ SST and K- $\varepsilon$ RNG, based on comparative better performance and consistency portrayed by these models in heat transfer analysis.

K- $\varepsilon$ Model uses two transport equations, hence solving for kinetic energy $\mathrm{k}$ and turbulent dissipation, $\varepsilon$. The modification of standard K- $\varepsilon$ to RNG includes the effects of small scale motions. (Fluent [37])

K- $\omega$ Model solves for kinetic energy and turbulent frequency. K- $\omega$ SST uses standard K- $\omega$ Model at near walls and standard K- $\varepsilon$ Model in the rest of space using blending function thereby demonstrating good prediction capabilities.

The use of wall functions defines a fully developed turbulent boundary layer which helps in reducing the grid nodes needed to capture flow characteristics in near the wall region. 


\section{Single Round Jet Analysis}

\subsection{Geometry}

This study is confined to single axisymmetric round jet impinging normal to the target surface in a semiconfined space. The jet issued is a submerged jet. These criteria were chosen to get a clear understanding of the general flow structure between the nozzle exit and impingement surface.

\subsubsection{Validation model}

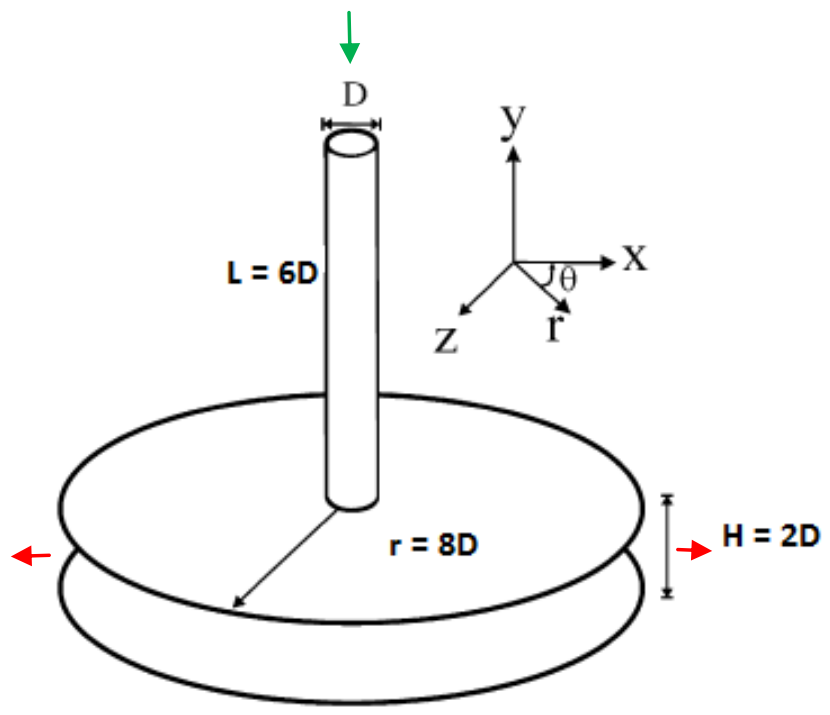

Figure 4.1: Validation model geometry

The computational domain chosen for validation is based on the experimental work of Cooper et al [33] which involves a long circular pipe of 6D length and a 16D X 2D cylindrical region between the nozzle exit and impingent surface. The diameter of the jet is $26 \mathrm{~mm}$. The confinement at the top and the bottom impingement surfaces are the walls and the jet is allowed to spread outward radially. The impingement surface is a no-slip wall with constant heat flux of $1000 \mathrm{~W} / \mathrm{m}^{2}$. Direction of flow inlet and outlet are depicted by green and red arrows respectively. (Fig 4.1)

This validation model is chosen to do an elaborate turbulence model study and to gain confidence by comparing with experimental results. 


\subsubsection{Micro-jet}

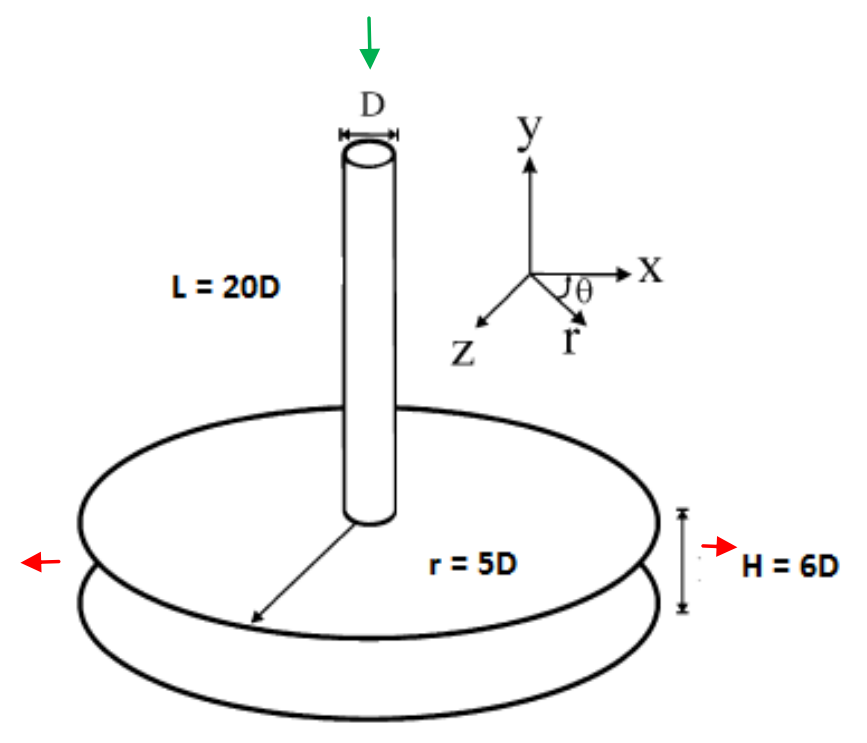

Figure 4.2: Micro-jet geometry

The computational domain used for micro-scale jet impingement study is shown in (Fig 4.2). A jet diameter of $0.2 \mathrm{~mm}$ is analysed in this study. A prior study on $0.5 \mathrm{~mm}$ jet diameter is done for comparison with the works of Leon De Paz [34] and Anand [9]. Direction of flow inlet and outlet are depicted by green and red arrows respectively. Here the length of the nozzle pipe is chosen based on the entrance length for fully developed flow equation, White [35],

$$
\frac{L e_{T u r b}}{D}=4.4 R e^{1 / 6}
$$

\subsection{Meshing}

The computational domain of both validation and micro jet are modeled and meshed using Gambit software. Only one half of the model is meshed due to axisymmetric nature of jet. The domain is divided into three volumes and structured mesh of cooper scheme is generated in all three volumes using C-grid topology with hexahedral cells. The number of nodes on validation model and micro jet model is $4 \mathrm{E}+5$ and $1.52 \mathrm{E}+5$ respectively. 

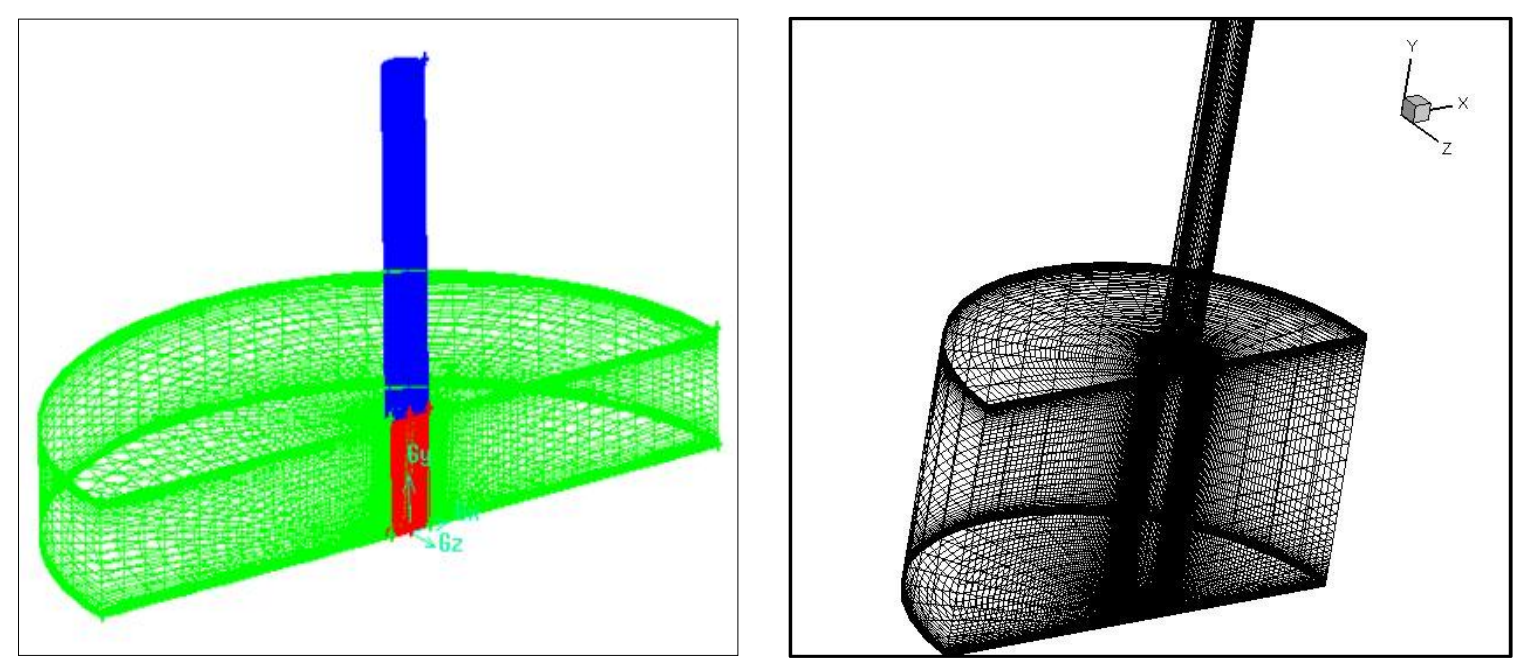

Figure 4.3: Structured mesh on micro-jet model

The major regions of interest are stagnation region and near wall region where the flow structure is complex. The near wall region is categorized into, (Berdberg [36])

- Viscous sub-layer where the viscous effects play a major role with negligible turbulence

- Buffer layer-influenced by both turbulence and viscous effects

- And inertial sub-layer with negligible viscous effects

Hence a fine mesh is generated near the impingement surface with $\mathrm{y}^{+}<1$ to capture the flow features and resolve viscous sub layer.

\subsection{Numerical Aspects}

\subsubsection{Boundary conditions}

The numerical results are strongly bounded to the mesh, discretization scheme and boundary conditions used. Henceforth, correct boundary conditions have to be set to get accurate results.

The boundary condition for both validation and micro-jet models is as mentioned in Table 1 . The impingement surface at the bottom is considered no-slip wall with a constant temperature/heat flux. The top confinement wall and the pipe wall are given an adiabatic, no-slip wall condition. The inlet boundary condition is set to velocity inlet and outlet to pressure outlet. The jet and ambient temperature were left at 300K. 


\begin{tabular}{|l|l|}
\hline Validation model & Micro-jet model \\
\hline Jet inlet - Velocity Inlet $(\mathrm{Re}=\mathbf{2 3 , 0 0 0 )}$ & Jet inlet - Velocity Inlet (Re=6000) \\
\hline Outlet - Pressure outlet & Outlet - Pressure outlet \\
\hline Top confinement wall: Adiabatic wall, 300 K & Top confinement wall: Adiabatic wall, $300 \mathrm{~K}$ \\
\hline $\begin{array}{l}\text { Impingement surface: constant temperature, } 1000 \\
\mathrm{~W} / \mathrm{m}^{2}\end{array}$ & Impingement surface: constant heat flux, $600 \mathrm{~K}$ \\
\hline Nozzle Pipe wall - Adiabatic wall, 300K & Nozzle Pipe wall - Adiabatic wall, $300 \mathrm{~K}$ \\
\hline
\end{tabular}

Table 1: Boundary Conditions of single round jet models

\subsubsection{Simulation Setup}

Numerical simulations of all cases were carried out using Fluent 6.3 and the simulations were run using parallel solvers with a total of 12 processors. Fluent uses Finite volume method for solving the governing equations.

The flow in this case is considered axisymmetric and incompressible with constant properties; hence constant density was set for all cases. SIMPLE scheme of pressure-velocity coupling was used which calculates the initial velocity components from an assumption of pressure and then updates the values after correction satisfying continuity equation. Second order upwind scheme was used to discretize momentum and energy equations for higher accuracy and the convergence level for all residuals apart from energy equation was set to $10^{-4}$. Energy equation was set at $10^{-6}$. These levels of convergence were set to ensure that the variables of interest have reached a stable value and imbalances are below $1 \%$. Specification of turbulence was defined by turbulence intensity and hydraulic diameter for both cases. Turbulence intensity (I) was calculated based on formula defined in Fluent [37].

$$
I=0.16 R e^{-1 / 8}
$$

\subsubsection{Grid Independence}

Grid independent solution is a major requirement for a robust CFD simulation. A good mesh saves lot of time in post processing and analysis.

Grid independence study was carried out for both validation and micro case models. Four grids of different densities were generated with a refinement factor of 1.5. 
The Fig (4.4) shows the radial distribution of Nusselt number for the validation model compared with experimental results of Baughn et al [38] and Yan et al [39]. It shows an error of $3 \%$ compared with experimental values. The under prediction of peaks in this study compared to experimental results is due to turbulence models and would be discussed in detail under turbulence model section. It is explicit from the curves that as the mesh density increases the error decreases. A variation in stagnation Nusselt number, secondary peak and wall jet Nusselt values is observed in coarse grid whereas fine and medium grid merges well showing that the mesh is independent. Hence the study was carried on with medium mesh for all later cases to minimize computational space and time.

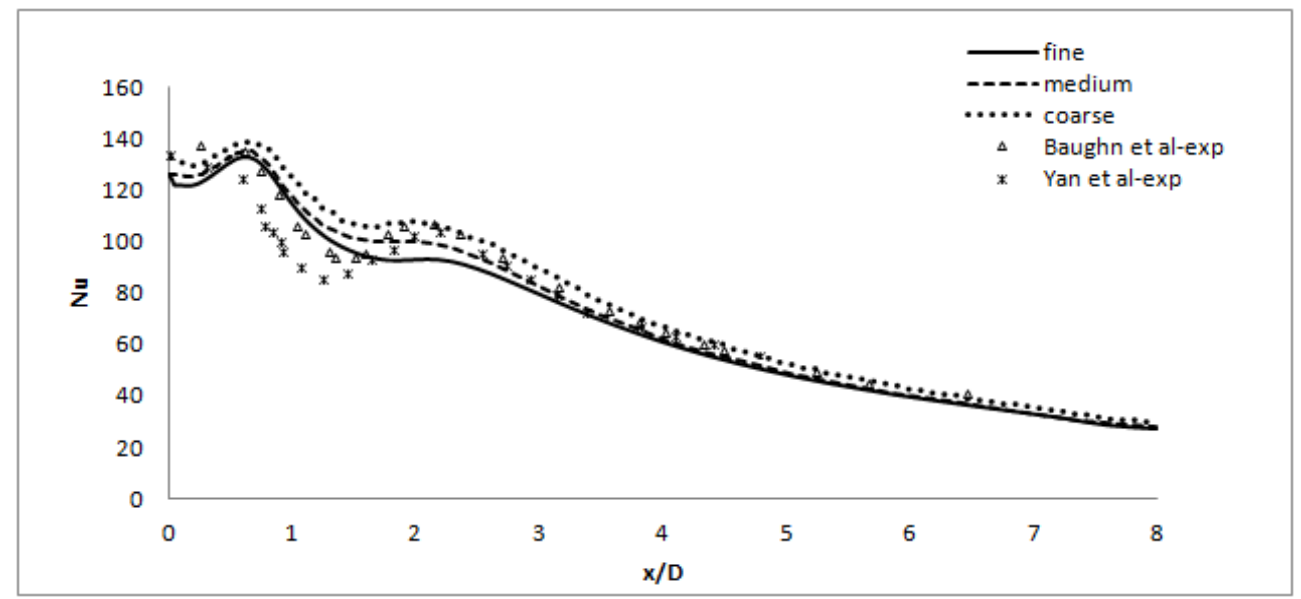

Figure 4.4: Radial Nusselt distribution at $H / D=6, R e=6000$

Grid sensitivity analysis for micro scale jet model performed for three different densities of grid revealed a smooth curve with slight difference in secondary peaks between fine and medium grids (Fig 4.5). This is reasoned to be large nozzle-to-target spacing effect. It is also apparent from the plot that the coarse grid shows a significant variation along the radial distance and the rest two grid densities merge well. Hence medium grid is used for further case studies.

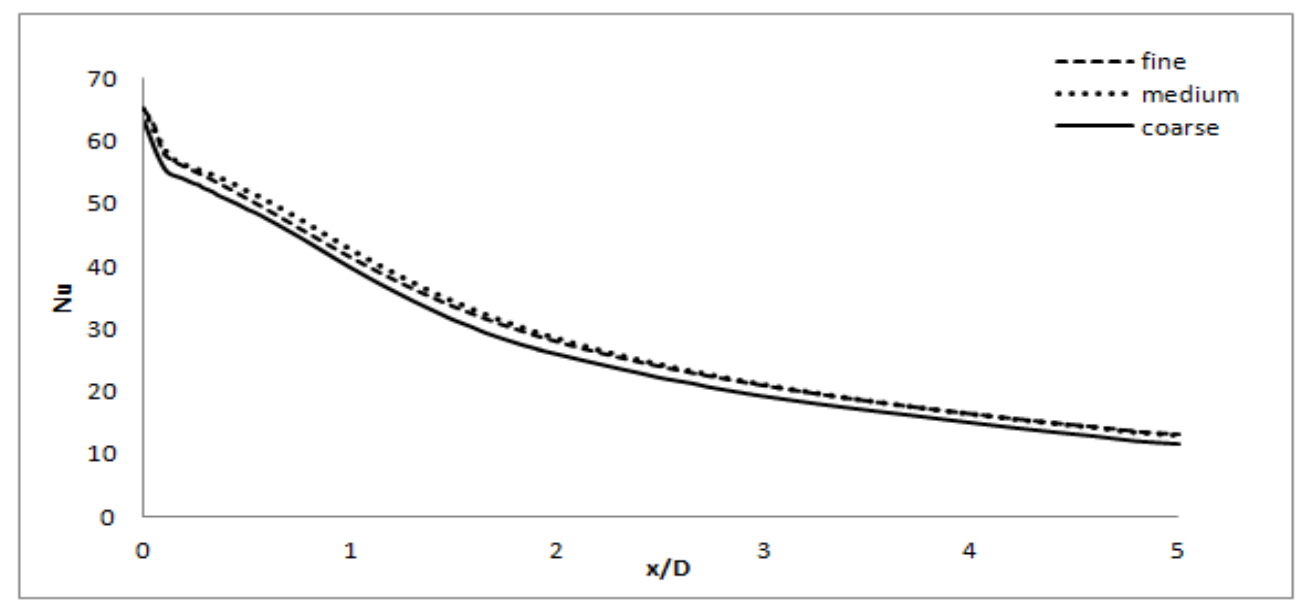

Figure 4.5: Radial Nusselt distribution for three grids 
Further to this, grid sensitivity analysis based on the method proposed by Roache [45] was carried on for micro jet case with three grids to determine the Grid convergence index $(\mathrm{GCl})$. Table 2 shows the average Nusselt values of three grids and the calculated zero spacing value

\begin{tabular}{|l|c|c|}
\hline \multicolumn{1}{|c|}{ Grid } & $\bar{N} \bar{u}$ & Zero Spacing Nu Value \\
\hline Coarse & 34.62 & \\
\cline { 1 - 2 } Medium & 38.77 & \multirow{2}{*}{41.48} \\
\hline Fine & 39.67 & \\
\hline
\end{tabular}

Table 2: Average Nu values for different grids and zero spacing value

Table 3 shows the order of convergence obtained and the Grid convergence index for the grids. It reveals that the average Nusselt number can be predicted with a maximum discretization error of $0.028 \%$.

\begin{tabular}{|l|l|}
\hline Order of convergence & 3.7 \\
\hline $\mathrm{GCl}$ Coarse (\%) & 0.13 \\
\hline $\mathrm{GCl}$ Fine (\%) & 0.028 \\
\hline
\end{tabular}

Table 3: Calculated GCI index

\subsubsection{Turbulence Model Study}

An elaborate study was carried out to evaluate different turbulence models and was validated based on experimental results of Baughn et al [38] and Yan et al [39]. Firstly variations of k-epsilon model such as Standard, Renormalization group (RNG) and Realizable were evaluated with different wall functions on the validation model.

A very fine mesh with $y+<1$ near the impingement surface (wall) which is highly influenced by turbulence and viscous effects is required to resolve the flow features. This need of very fine mesh inflates the computational time. Wall functions used by computational schemes surpass this issue by defining fully turbulent region near the wall. Hence, the study 


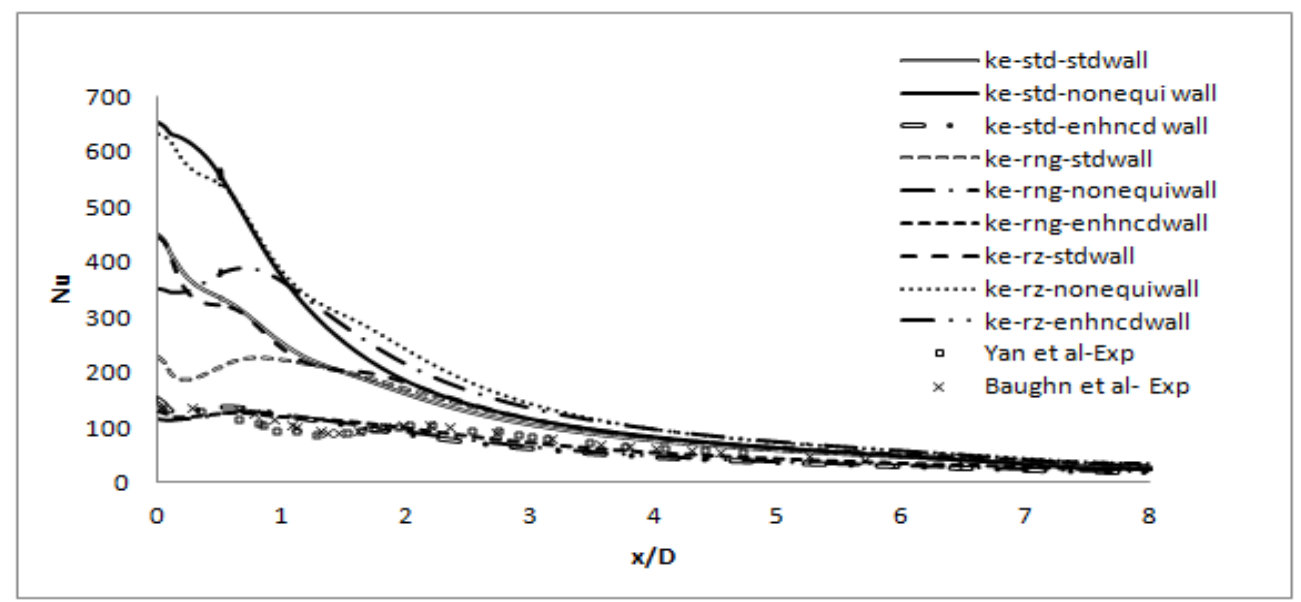

Figure 4.6: Effect of K-Epsilon turbulence models and its variations on $\mathrm{Nu}$

Radial distribution of Nusselt number is plotted for this study. It is clear from the plot that nonequilibrium wall function and standard wall function for all variations of k-epsilon model over predicts the Nusselt number in the stagnation region (Figure 4.6). Enhanced wall functions better predict the Nusselt values at stagnation and wall jet region but with minor under prediction of peaks. It is observed that none of the turbulence models emulate the secondary peaks as in experimental plot.

The Nusselt distribution along the wall jet region is seen less affected by the variance in models. Predictions by k-epsilon RNG, Realizable and Standard models are approximately close with slightly higher prediction of stagnation Nusselt number by standard form of k-epsilon and under prediction by realizable form of k-epsilon model. From the knowledge gained, the focus in narrowed down to kepsilon models with enhanced wall function.

Further analysis was carried out for $\mathrm{k}-\omega$ SST model and compared with experimental and previous narrowed down models. It is observed that the stagnation Nusselt number is well predicted by both kepsilon RNG and k- $\omega$ SST models but the smooth flat maxima is not captured by either of the models.

Apparently, k- $\omega$ SST model shows a better trace of secondary peak which is slightly off (away from jet centerline) compared to experimental values. K-epsilon RNG model with enhanced wall function also shows a slight trace of secondary peak which is located slightly ahead compared with experimental peak values (Fig 4.7 ). 


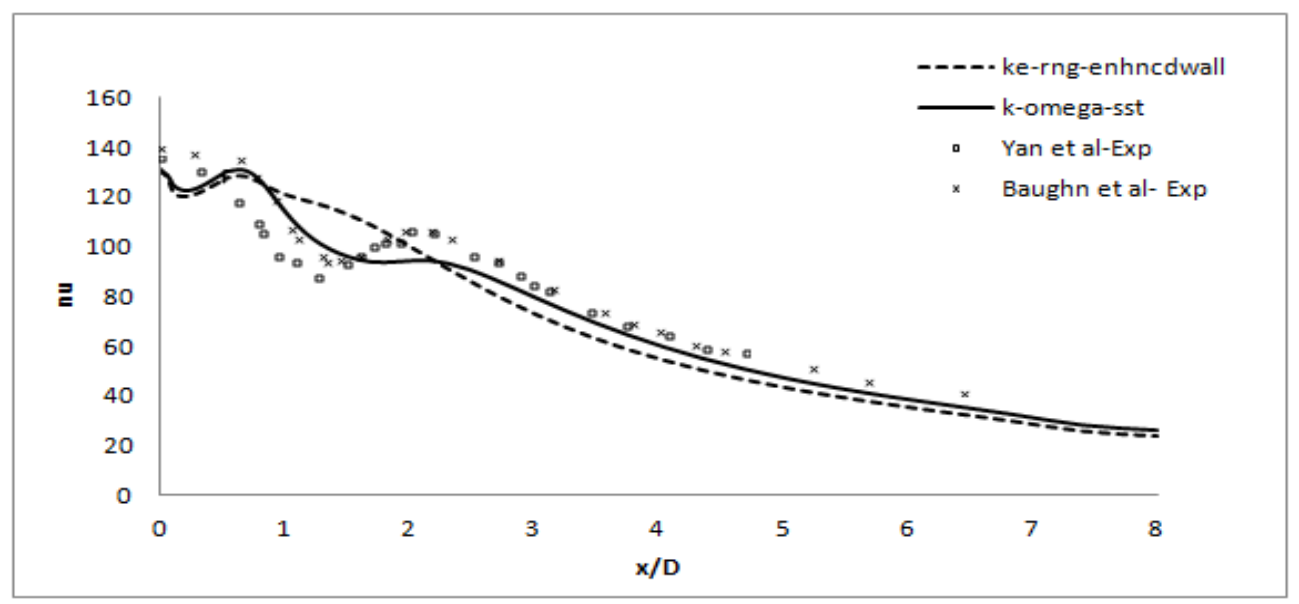

Figure 4.7: $k-\varepsilon$ and $K-\omega$ turbulence model comparison

In a nutshell, both k- $\omega$ SST and K-epsilon RNG model can be used for the present study. Furthermore, it is inferred from various literatures and work of [34] that the turbulence models are also hooked to a particular case and flow conditions. Considering all facts, conditions and the consistency of results of kepsilon RNG model, the same is applied for the numerical study of semi-confined micro case model.

\subsection{Results}

The plots for various flow variables are shown for a basic understanding of the flow characteristics involved in the case studied $(H / D=6$ and $R e=6000)$. Figure 4.8 and 4.9 clearly depicts the decay of the Nusselt values radially from its peak at the stagnation point. Slowing down of the jet in the axial direction and acceleration of jet in the radial direction conserving the momentum is also shown. Maximum heat transfer is reached in regions with high velocity which also explains previous figure. The decrease in radial velocity far downstream of the stagnation region is also seen which causes the reduction of heat transfer rates in that region. 

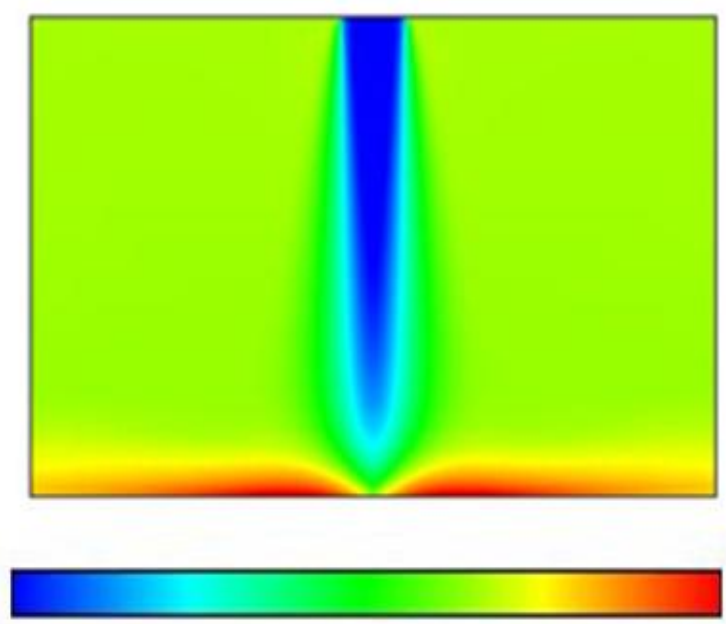

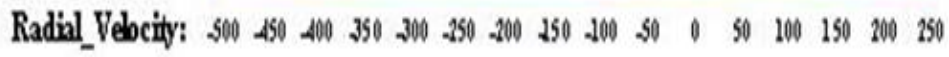

Figure 4.8: Radial velocity contour

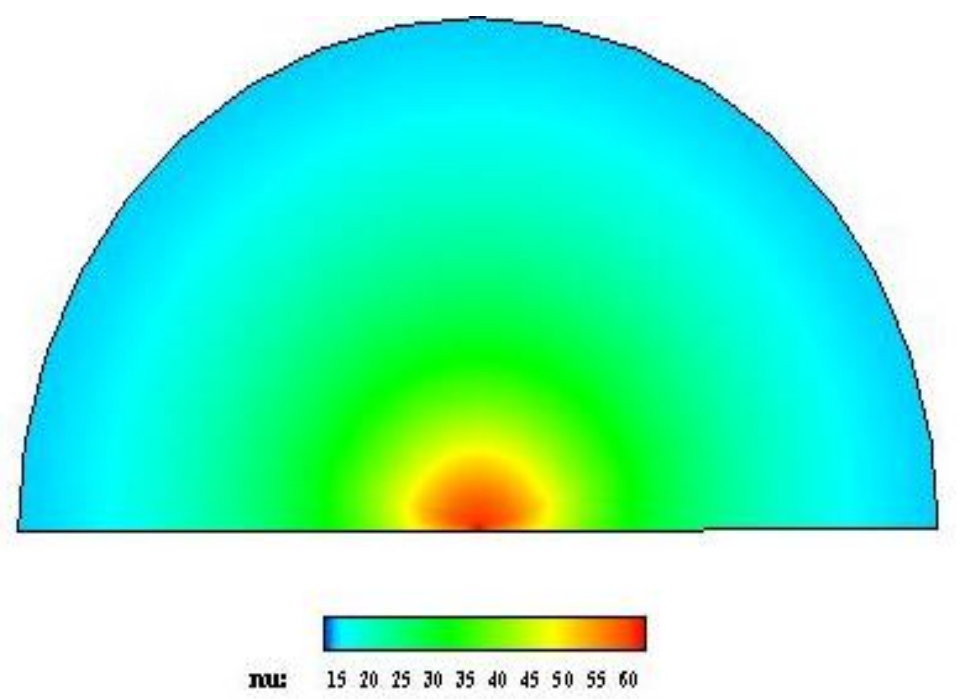

Figure 4.9: Nusselt number contour

Degradation of velocity along the boundary of the jet as it accelerates from the nozzle exit is shown Figure 4.10. The radial spread of the jet and the approximate length of potential core could also be visualized from the figure.

Figure 4.11 shows the whole 3D model with the fully developed jet and its entry into the confined region. 


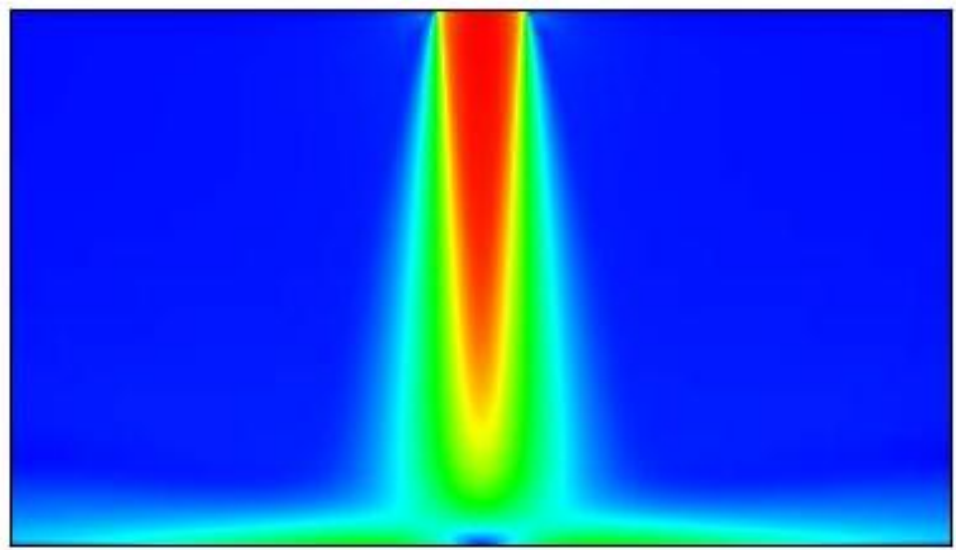

VelocinyMagnitude

$50 \quad 100 \quad 150 \quad 200 \quad 250 \quad 300 \quad 350 \quad 400 \quad 450 \quad 500$

Figure 4.10: Velocity contour

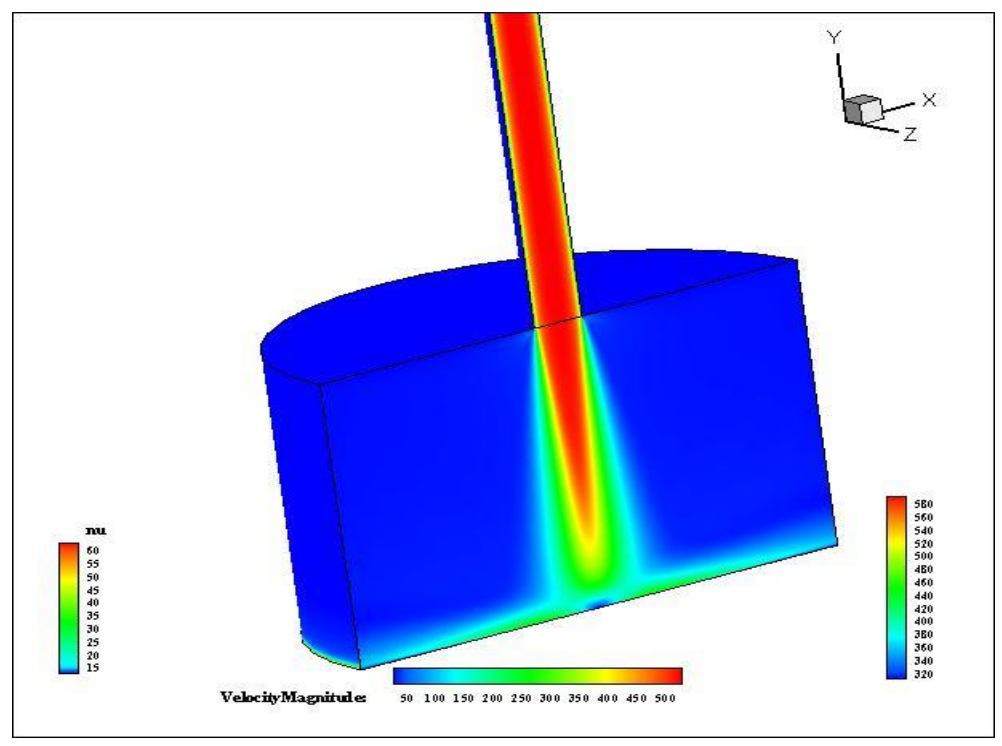

Figure 4.11: 3D model showing fully developed jet

The static pressure rise in the stagnation region due to decrease of axial velocity is shown in Fig 4.12. Thus the stagnation region is marked by high static pressure and Nusselt number. 


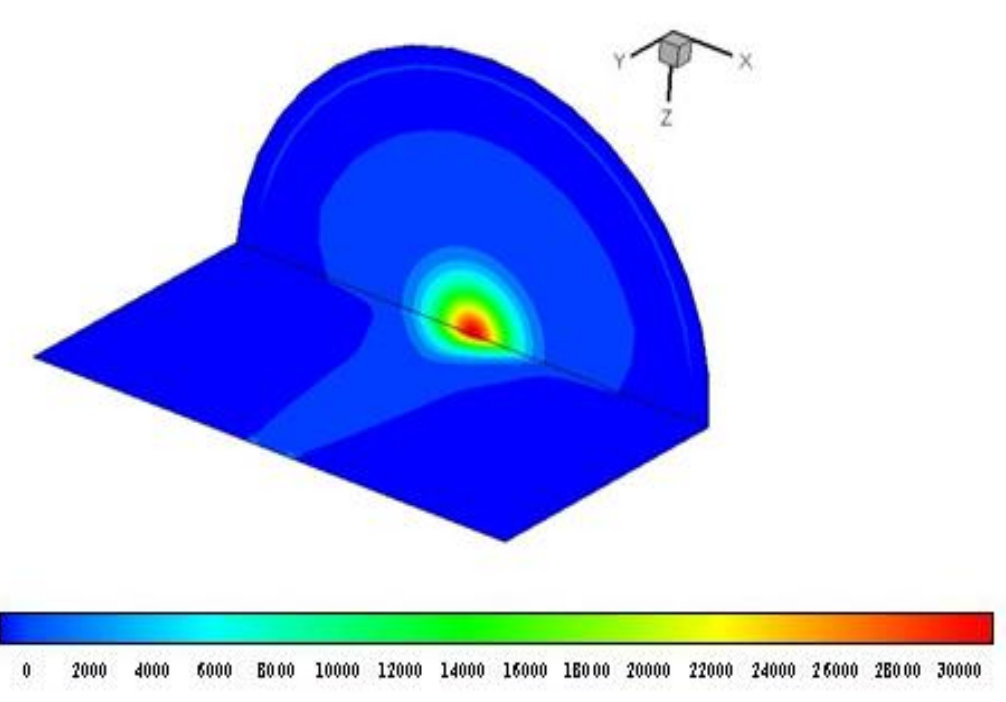

Figure 4.12: Static pressure contour on symmetry plane and target

\subsection{Parametric analysis}

Numerous investigations both experimental and numerical were carried out by researchers, to acquire better cooling at an optimum trade-off between performance and durability. The effectiveness of jet impingement cooling is interdependent on parameters such as nozzle to target spacing, Reynolds number and jet nozzle geometry. For a clear understanding of the flow characteristics, the effects of those parameters are studied and an analysis of the same was made to get optimized parameters for effective cooling.

\subsubsection{Reynolds number effect}

The influence of Reynolds number on the heat transfer characteristics of the impingement jet is studied for a wide range of Reynolds numbers starting with 2000 in an arithmetic progression with a common difference of 2000 . The H/D ratio and nozzle diameter were kept constant at 6 and $0.2 \mathrm{~mm}$ respectively.

A general trend of Reynolds number effect is that the Nusselt number increases with increase in Reynolds number as given by Eqn [2.7]. A similar trend has been reported by [5], [15], [12]and [17].

Figure 4.13 shows the radial distribution of Nusselt number for varied Reynolds number. It is observed that maximum value of Nusselt number is reached at the stagnation point. The steep curve following the stagnation Nusselt number depicts decrease of Nusselt number up to $x / D=0.5$ and then a slight bump is seen showing transition from laminar to turbulence region which is then followed by monotonically decreasing Nusselt values. This is due to decrease of radial velocity along the wall jet region. 


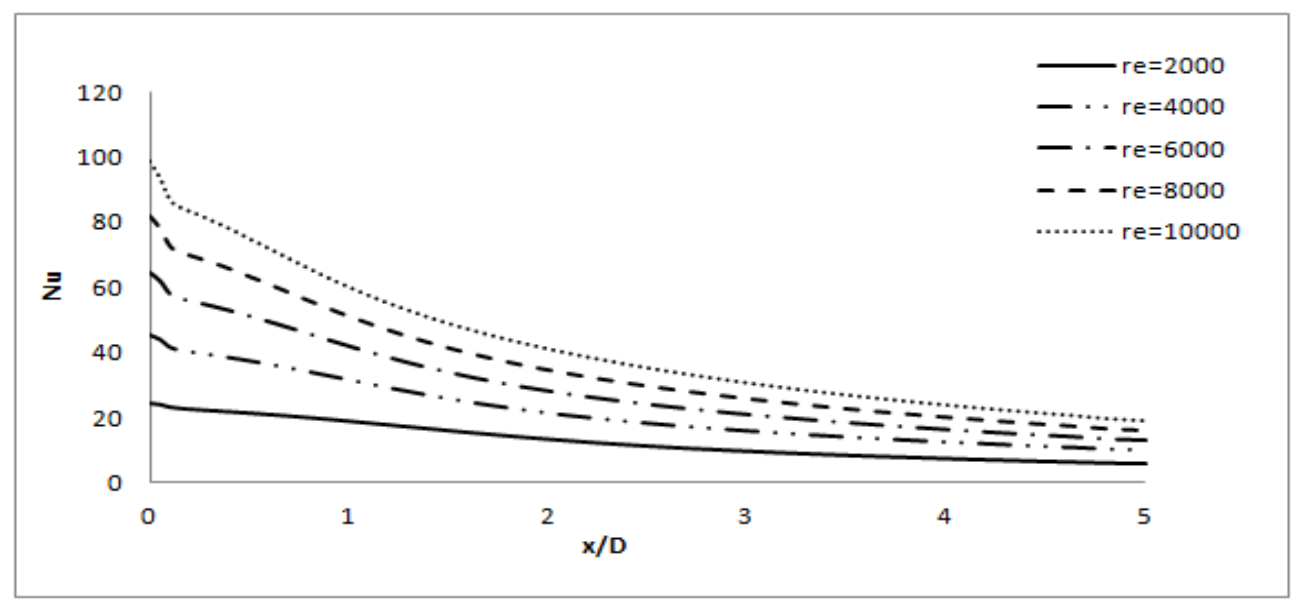

Figure 4.13: Radial distribution of Nu for varying Re

The velocity contours shown in figure 4.14 gives a clear visual interpretation of the jets exiting from the nozzle which widens as a result of mixing and entrainment of surrounding air for the varied Reynolds number. At lower Reynolds number, the jet exiting from the nozzle is dominated by the surrounding air due to transfer of momentum, thereby weakening the potential core which is reported to be extending 6-7D from nozzle exit [40]. As the jet nears the impingement surface its velocity decreases with increasing pressure, creating high static pressure at the stagnation and thereby reducing the heat transfer rate. It is also noticed that as Reynolds number increases the length of potential core also increases causing higher heat transfer rates at the stagnation point.

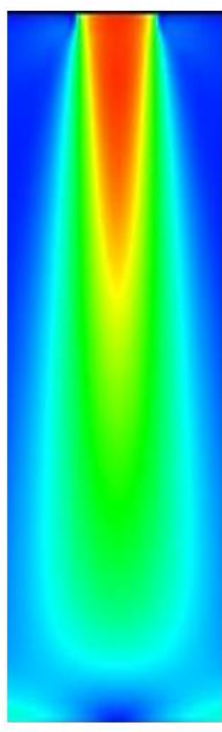

$\operatorname{Re}=\mathbf{2 0 0 0}$

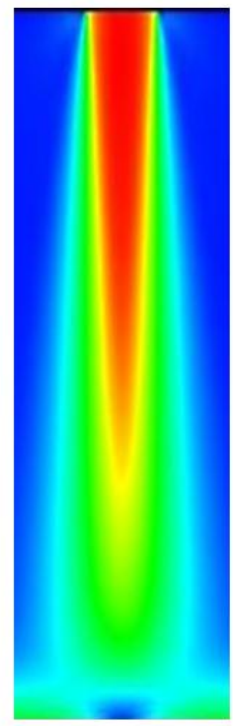

$\operatorname{Re}=\mathbf{4 0 0 0}$

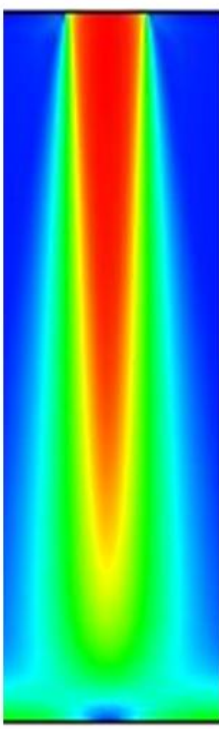

$\mathrm{Re}=6000$

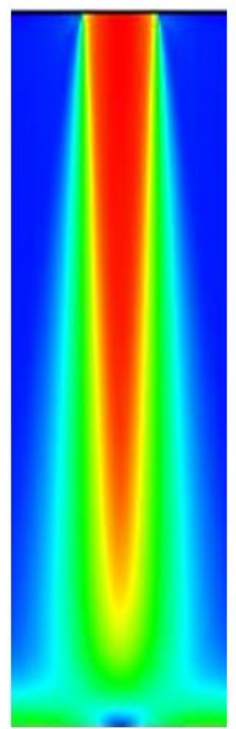

$\operatorname{Re}=\mathbf{8 0 0 0}$

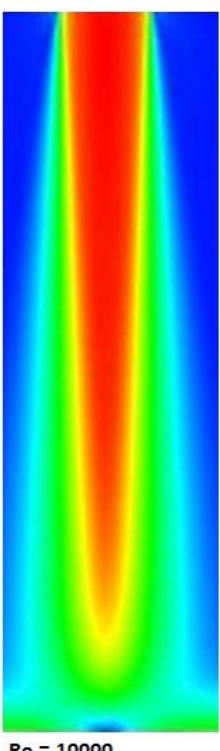

$\operatorname{Re}=10000$

Figure 4.14: Jet potential core length for varying $R e$ 
Increase in Reynolds number also shifts the recirculation zone away from jet centerline radially. This has also been observed by Goldstein and Bouchez [41].

Nusselt number contours have been plotted for all Reynolds number (Fig 4.15) which demonstrates high $\mathrm{Nu}$ values for higher Reynolds number. It also shows enhancement of Nusselt values along the radial direction with increasing Reynolds number.

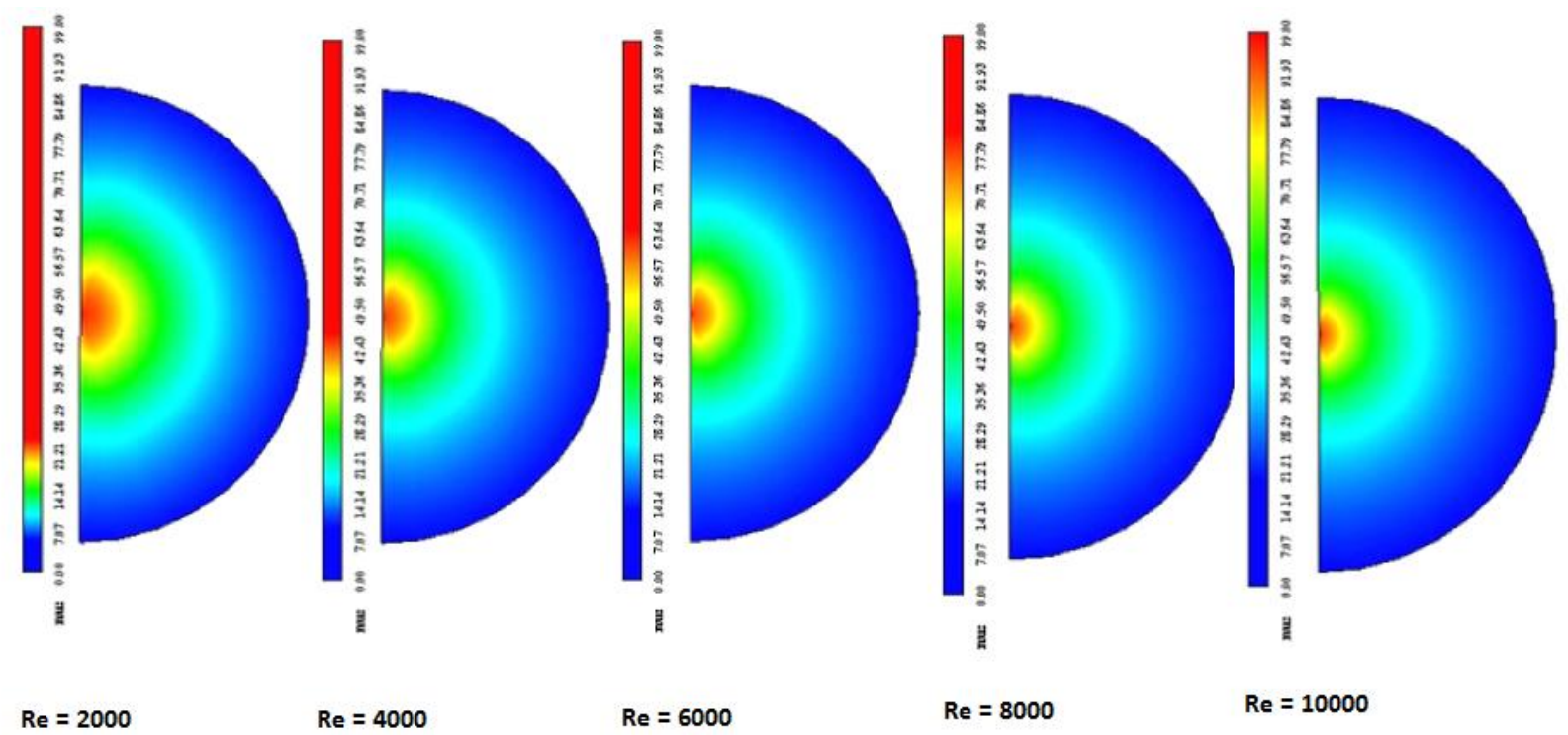

Figure 4.15: Nu variation for varying Re

\subsubsection{Nozzle-to-target spacing effect}

The analysis of nozzle-to-target spacing effect was carried on for a wide range of H/D ratios. This was done by varying only the H/D ratio with constant Reynolds number of 6000 and nozzle diameter of $0.2 \mathrm{~mm}$. Figure 4.16 illustrates the Nusselt number plot for $\mathrm{H} / \mathrm{D}$ ratios ranging from 1 to 10 . The Nusselt number at the stagnation point keeps increasing up to H/D ratio of 3 and then decreases. A general trend of high Nusselt number at stagnation and monotonous decreasing of the Nusselt values along the wall region is seen.

A similar trend is shown by Lytle and Webb [8].

Highest value of Nusselt number is obtained for $H / D=3$ and the lowest for $H / D=10$. Higher the Nusselt number, steeper is the curve. For $H / D<2$, secondary peak is more prominent, this is due to the transition and hence the formation of recirculation zone influenced by top confinement wall. This secondary peak for $H / D=2$ is located at $x / D$ of 0.5 from the jet centerline and observed to shift radially outward for decreasing H/D ratios. This shift could be explained as the shift of toroidal vortices for decreasing $H / D$ ratios. A contrasting result was reported by Liping et al [42] 
The Nusselt values along the wall region shows only a slight variation except for $H / D=1$ and lower, which may be accounted for reduced radial velocity and less mixing of turbulence. Thus the influence of $H / D$ ratios tends to either increase or decrease the stagnation Nusselt values with very slight variation along the wall jet region.

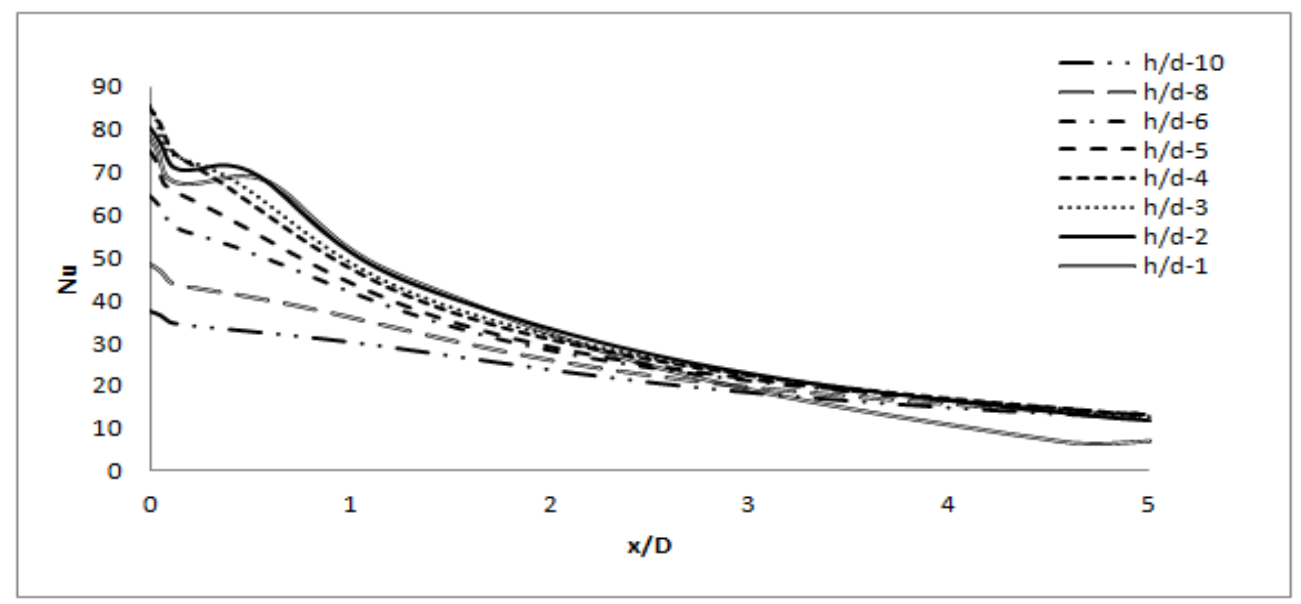

Figure 4.16: Nu variation for varying $\mathrm{Re}$

Figure 4.17 shows the velocity contour and the corresponding toroidal vortices for $H / D=1,3,6$. A shift of toroidal vortices radially outward from the stagnation point is observed with increase in nozzle-to-plate spacing at constant Re of 6000 . Similar trend has been reported by Leon De Paz [34]. This recirculation zone can be attributed to the turbulence of the jet and the confined geometry effects.

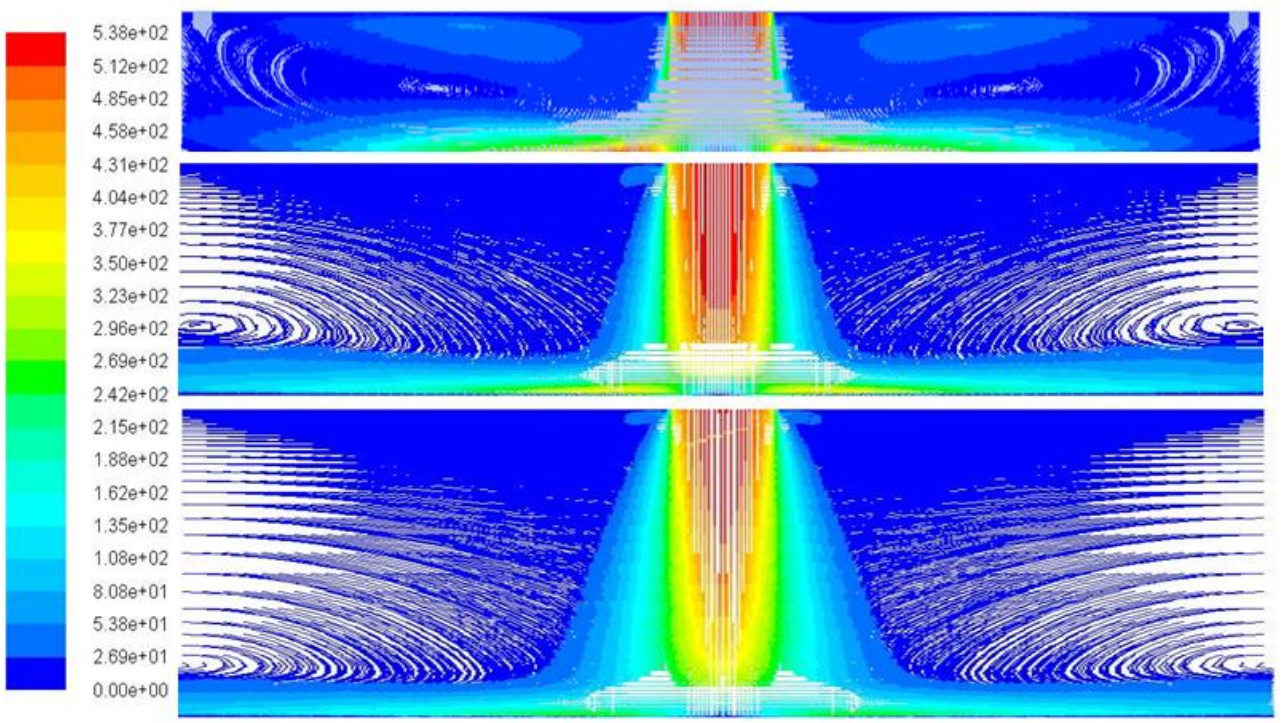

Figure 4.17: Toroidal vortices for $H / D=1,3,6$ 


\subsubsection{Jet nozzle diameter effect}

From the general relation between area and velocity, it could be said that velocity increases as area decreases. An increase in velocity is accompanied by an increase in heat transfer rates as explained in the prior sections. This concept has lead to the analysis of effect of nozzle diameter on the heat transfer characteristics of the impinging jet. Results in favour of this have been obtained by Glynn and Murray [17]. His experimental investigation showed an increase in heat transfer coefficient with decrease of jet diameter for constant Re. Increase in velocity of jets due to decreasing diameter enhances the heat transfer.

This effect has also been studied by Lee et al [18]; a contradictory trend of increasing Nu number with increasing jet diameter to the above concept has been noted. This trend is explained to be the result of increase in mass flow rate and turbulence intensity with jet diameter. The maximum Nu values are found to occur at $H / D \approx 7$ and the wall jet Nusselt number values seem to be unaffected by the change in jet diameters. The same trend has been reported by Garimella et al [43] who experimentally investigated, confined liquid jet impingement and studied the effect of various parameters such as nozzle diameter on the local heat transfer distribution.

In the current study, this effect of nozzle diameter is validated by assuming constant mass flow rate of $0.00982 \mathrm{~g} / \mathrm{s}\left(\mathrm{G}=0.5 \mathrm{~kg} / \mathrm{m}^{2} \mathrm{~s}\right)$ at the inlet. Three models are generated with same H/D and control volume as in the micro-jet model except for the jet diameters which are modified to be of $0.5 \mathrm{~mm}, 0.25 \mathrm{~mm}$ and $0.1 \mathrm{~mm}$. Jet diameter of $0.25 \mathrm{~mm}$ and $0.5 \mathrm{~mm}$ is also analysed to compare the results with Anand [9].

Figure 4.18 shows significant increase of Nusselt number as the jet diameter is decreased. As explained above the wall jet region is less affected by change in nozzle diameter for a diameter change of $0.05 \mathrm{~mm}$ which is not reflected in the Nu plot of [9] but significant change has been noted for a change of $0.1 \mathrm{~mm}$. These variations may be due to turbulence fluctuations. $52.5 \%$ increase in Nu value is obtained by decreasing the nozzle diameter to $0.1 \mathrm{~mm}$.

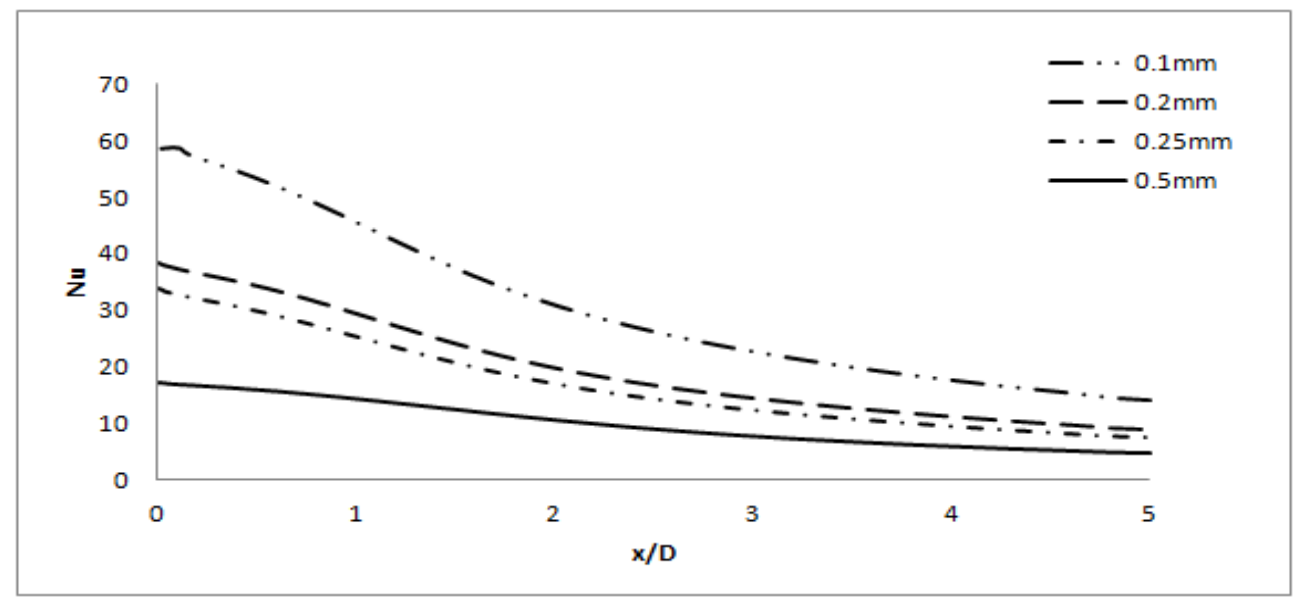

Figure 4.18: Local Nusselt number distribution for varying jet diameters 


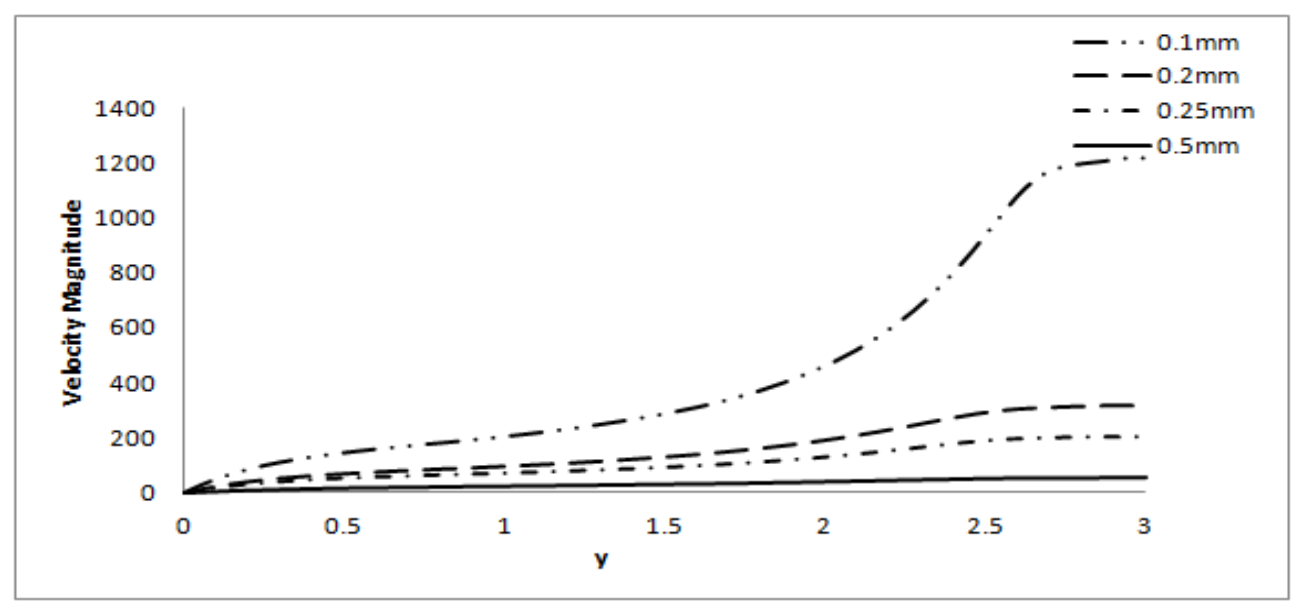

Figure 4.19: Centerline mean velocity distribution for varying jet diameters

Figure 4.19 shows the mean velocity distribution in the jet centerline. The jet with diameter of $0.1 \mathrm{~mm}$ shows the highest nozzle exit velocity and axial velocity till it reaches the target surface. Plot of all diameters depicts the increase in velocity with decrease in jet diameter. Figure 4.20 shows the comparison with the work of Anand [9].

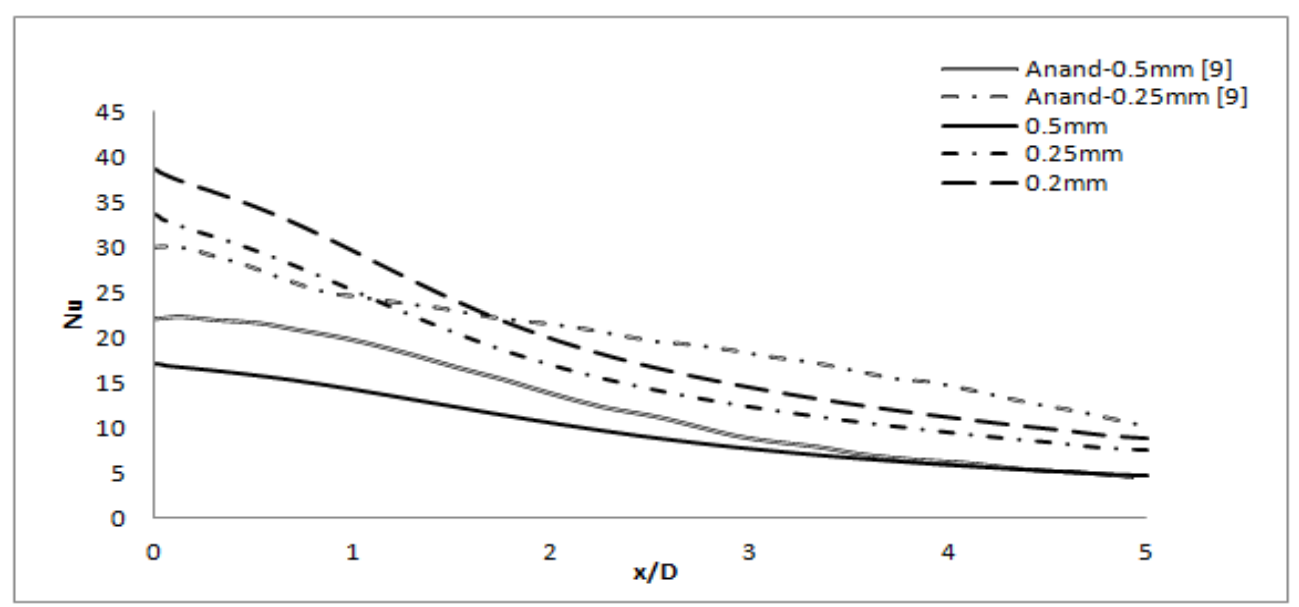

Figure 4.20: Comparison of diameter effect with the work of Anand [9] 

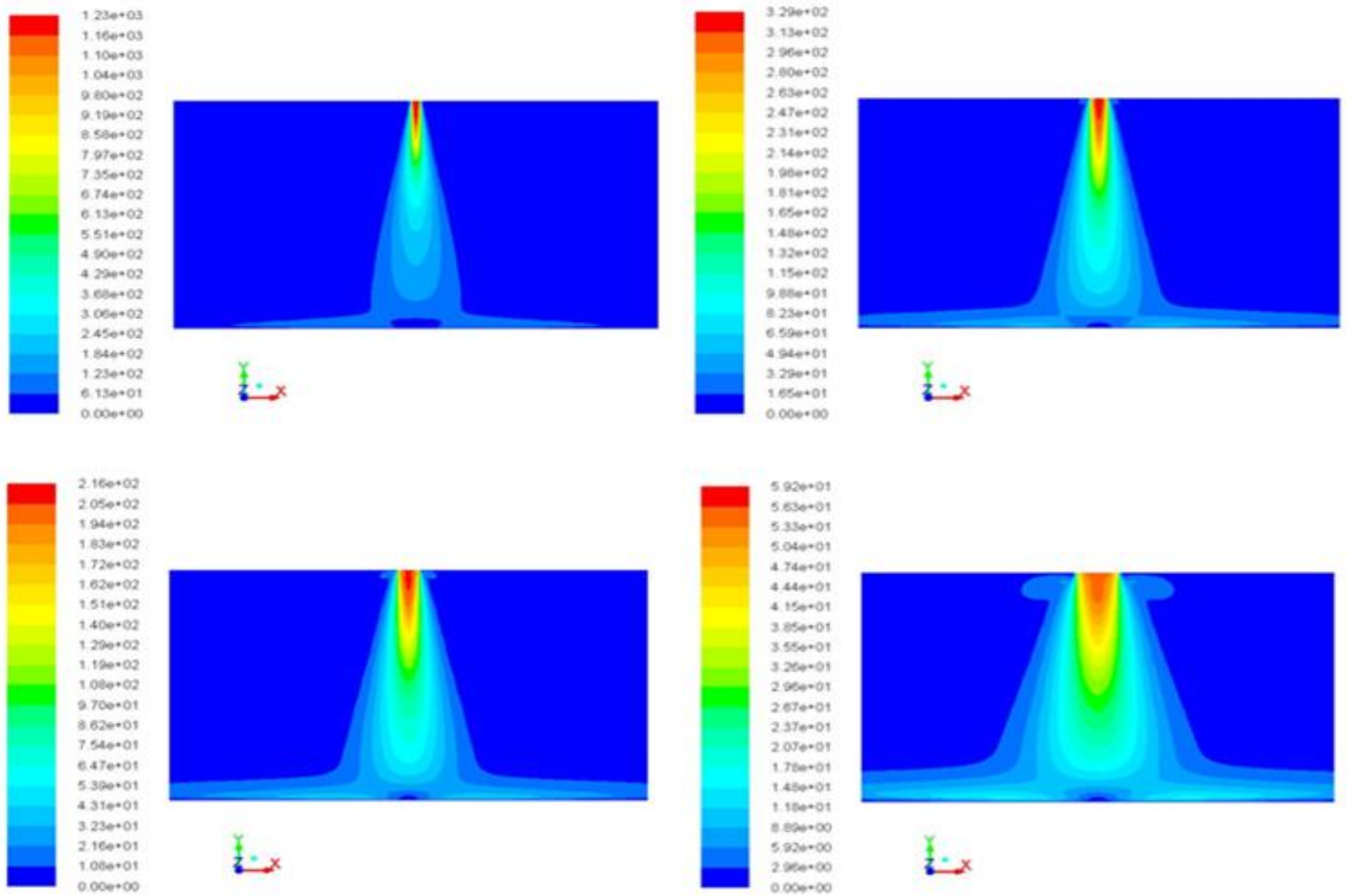

$\infty$

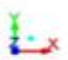

Figure 4.21: Velocity contours of $D=0.1 \mathrm{~mm}$ (top left), $0.2 \mathrm{~mm}$ (top right), $0.25 \mathrm{~mm}$ (bottom left) and $0.5 \mathrm{~mm}$ (bottom right)

Figure 4.21 shows the radial spread of jets with increasing diameters which in turn reduces the jet intensity, velocity and thereby the nusselt number.

\subsection{Converging nozzle study}

A study on effect of change in nozzle contours has been carried out in order to define an effective impinging jet and also in a view of finding a solution to prevent blockage in micro jet diameters.

A tapered nozzle model with inlet to exit diameter ratio of 2 and 1.43 have been generated for this study. The model and flow conditions are the same as in micro-jet case $(H / D=6$ and $R e=6000)$. The results obtained show the increase of local heat transfer distribution with increasing taper ratio. But this tapering effect comes with limits due to manufacturing complexity and structural strength of the component.

The plot (figure 4.22) indicates $38 \%$ increase in Nu for a tapering ratio of 1.43 and $75 \%$ increase for a ratio of 2 from the standard value. 


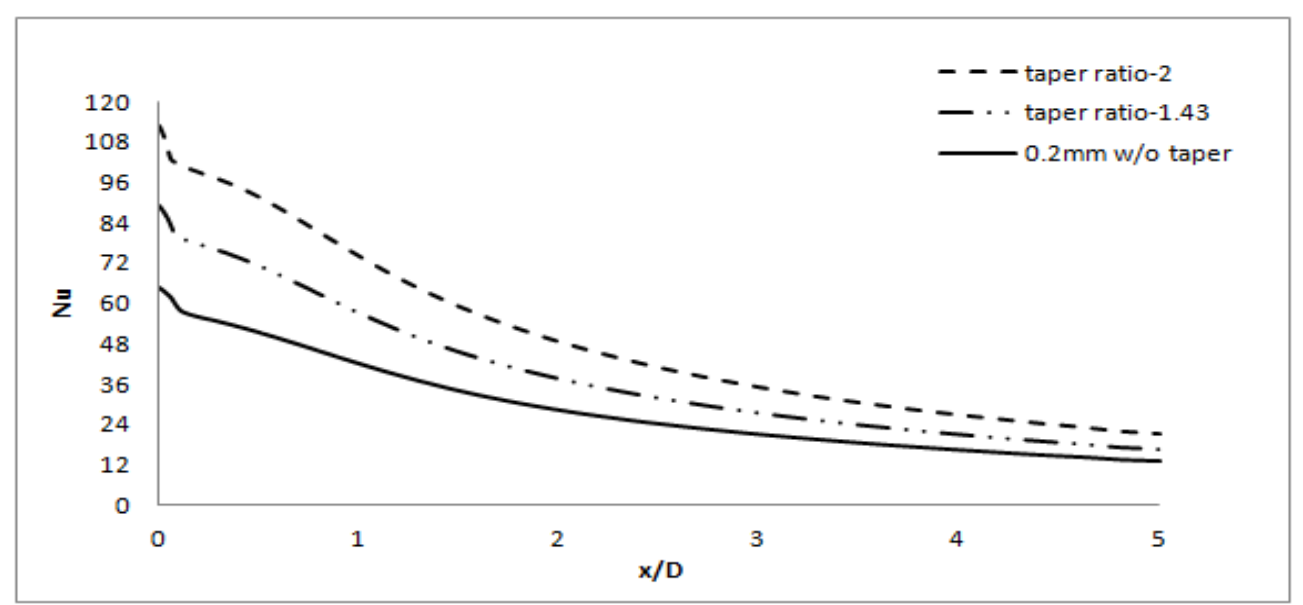

Figure 4.22: Tapering effect on local Nusselt distribution

The velocity contour of the tapering nozzle configuration with a taper ratio of 2 shows the intensity of the potential core and increase in velocity compared to constant diameter nozzle geometry of $0.2 \mathrm{~mm}$ (Fig 4.23).
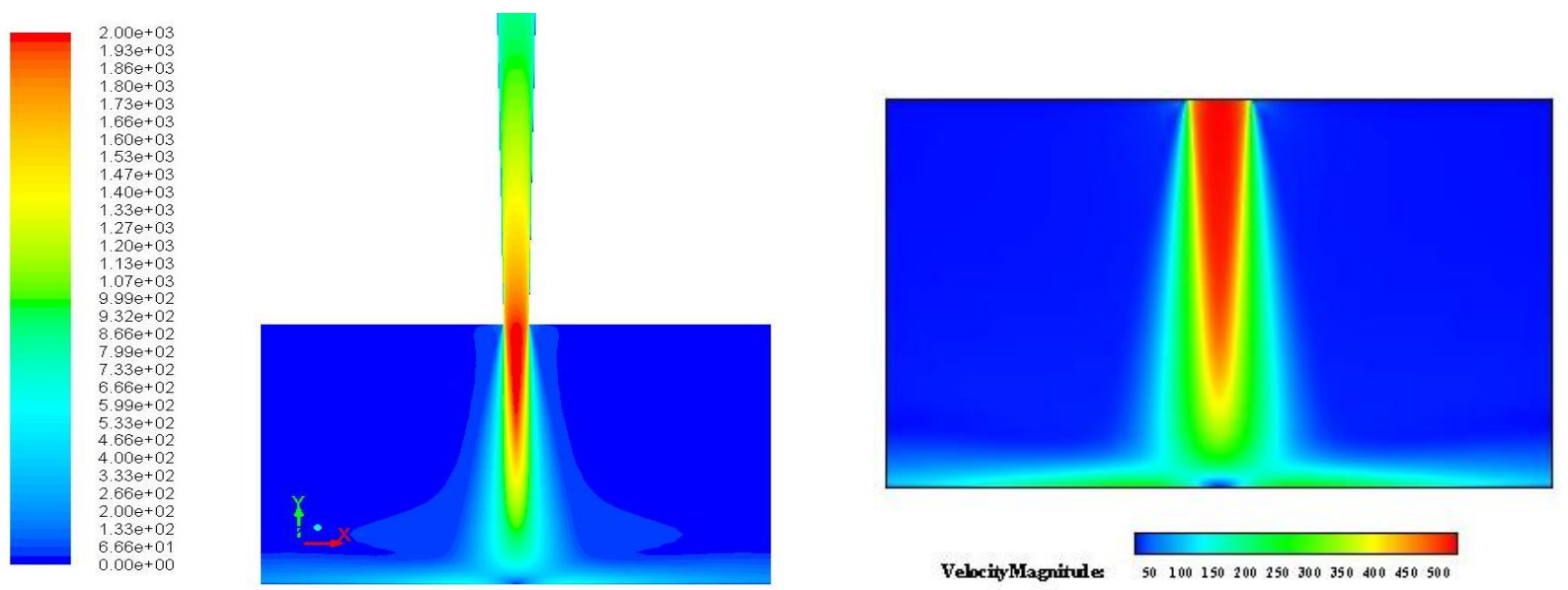

Figure 4.23: Velocity contour for nozzle taper ratio of 2 (left) in comparison with $0.2 \mathrm{~mm}$ constant diameter nozzle

Figure 4.24 (left) shows the velocity contour of the model with tapering ratio of 1.43, the penetration of the jet with high velocity is seen due to decreasing area of the nozzle. Maximum heat transfer in the stagnation point is depicted by the high Nusselt value seen in the center (right). 

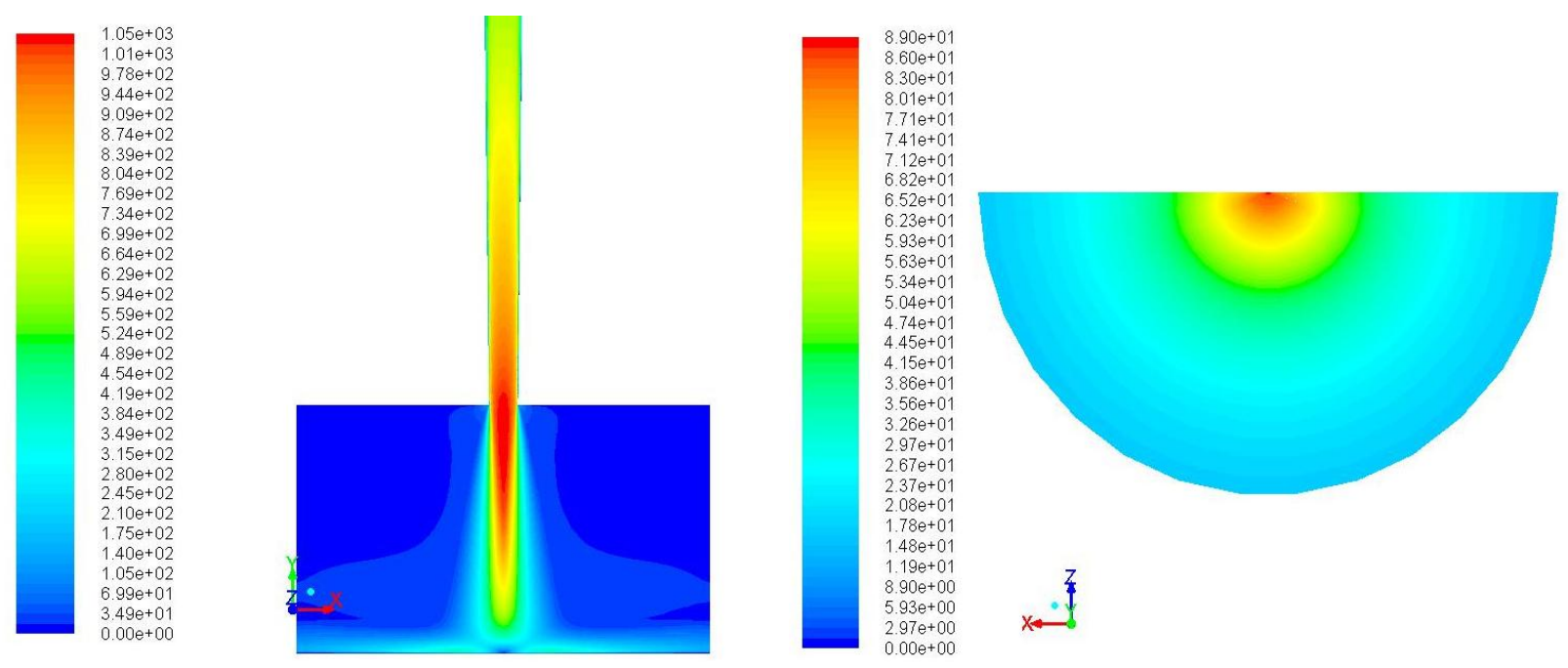

Figure 4.24: Velocity contour (left) and Nusselt contour (right) for nozzle taper ratio of 1.43

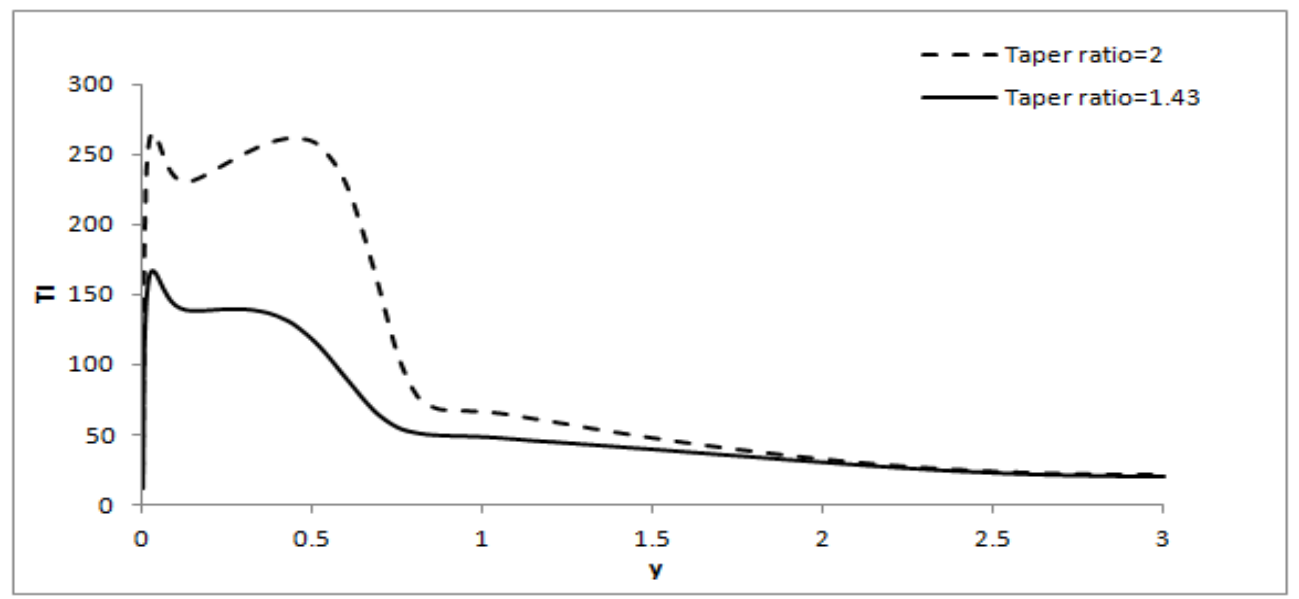

Figure 4.25: Turbulence intensity along jet centerline

Figure 4.25 shows the increase of turbulence intensity as the jet nears the wall region and hence high turbulence intensity is seen around the stagnation region 


\section{Turbine Vane Analysis}

The previous study of single round jet impingement and the factors influencing its heat transfer distribution provided a wide knowledge on the behaviour of flow between the nozzle exit and impingement surface. Though the basic flow physics of jet arrays is same as the single jet, there are additional effects such as cross flow and neighbour jet interactions which makes the jet arrays even more complex. As the operating temperature of turbine vanes are very high, single jets are not sufficient for cooling, hence arrays of jets are used. Impingement jets are mostly used in the leading edge of the turbine blades and vanes due to structural limits.

\subsection{Geometry}

The model used for the current study is the second stage vane of Energy Efficient Engine (Fig 5.1). The cooling system of this vane is detailed in chapter 2 .

This vane is selected for a realistic approach of jet impingement study. The model was generated using CATIA V5 with the mid span airfoil coordinates provided by Timko [44]. Only the leading edge of the model is analysed in this study. The mid span airfoil coordinates of the second stage HPT vane form the outer vane surface, while the plenum chamber and interior surface are modeled by scaling the outer airfoil coordinates. The model consists of a plenum chamber (blue), impingement chamber and a target surface (red) (Fig 5.1). The impingement chamber is bounded between the interior surface where the jets exit from the nozzle and the target surface.
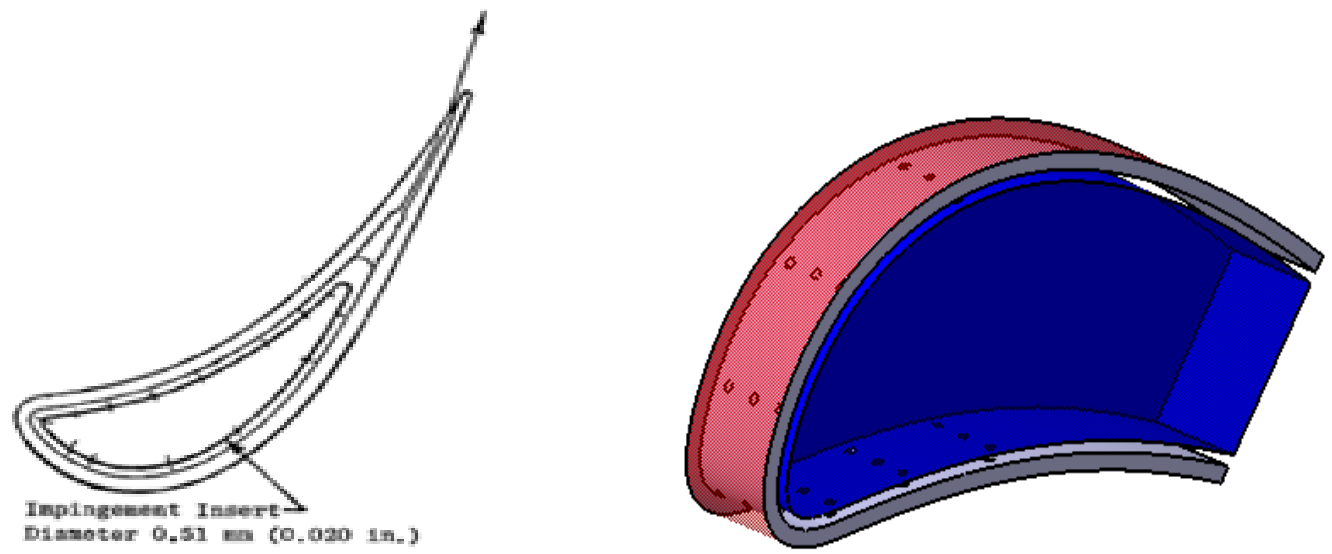

Figure 5.1: Second stage vane -airfoil (left), Generated vane model (right) 
First the validation model is simulated with jet arrays and the results are analysed which is then proceeded with the study of effect of smaller jet diameters.

\subsubsection{Validation model}

Only the leading edge portion of the vane is analysed in this study with 3 rows and 3 columns of jets in the suction surface and pressure surface and 1 row in the leading edge making a total of 21 jets. The model and location of jets are shown in figure 5.2. The jets are of $0.51 \mathrm{~mm}$ diameter and maintain a jet to jet spacing of $4 \mathrm{D}$ and jet to wall spacing of 2D in the span wise direction. The length of the leading edge is chosen to be $29.061 \mathrm{~mm}$, this is an arbitrary length selected to avoid any flow reversals and ensure smooth flows at the exit. Table 4 summarises the geometric parameters used.

\begin{tabular}{|l|l|}
\hline Reference length & $29.061 \mathrm{~mm}$ \\
\hline Span & $12 \mathrm{D}$ \\
\hline Jet diameter & $0.51 \mathrm{~mm}$ \\
\hline Jet Hole length to diameter (L/D) & 1.05 \\
\hline H/D & 1.588 \\
\hline
\end{tabular}

Table 4: Geometric Parameters
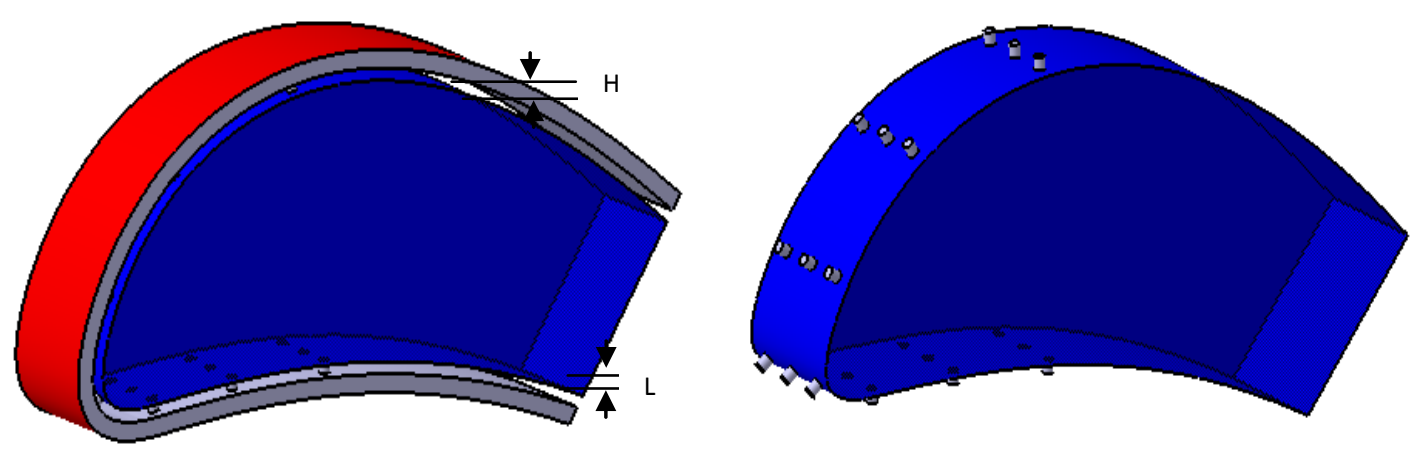

Figure 5.2: Validation model (left), Model showing jet location (right) 


\subsubsection{Micro-jet}

Micro-jet model differs from the validation model only by the diameter of the jets. The nozzle-to-target spacing and the control volume are the same. This is done to analyse only the effect of micro-jets at constant properties and spacings. The jet diameter analysec here is $0.1 \mathrm{~mm}$. Figure 5.3 shows the translucent micro jet model generated. Not many studies have been reported on the jet impingement heat transfer of realistic turbine vanes. Hence this study serves as an initial step of understanding the effectiveness of micro-jets on vanes.

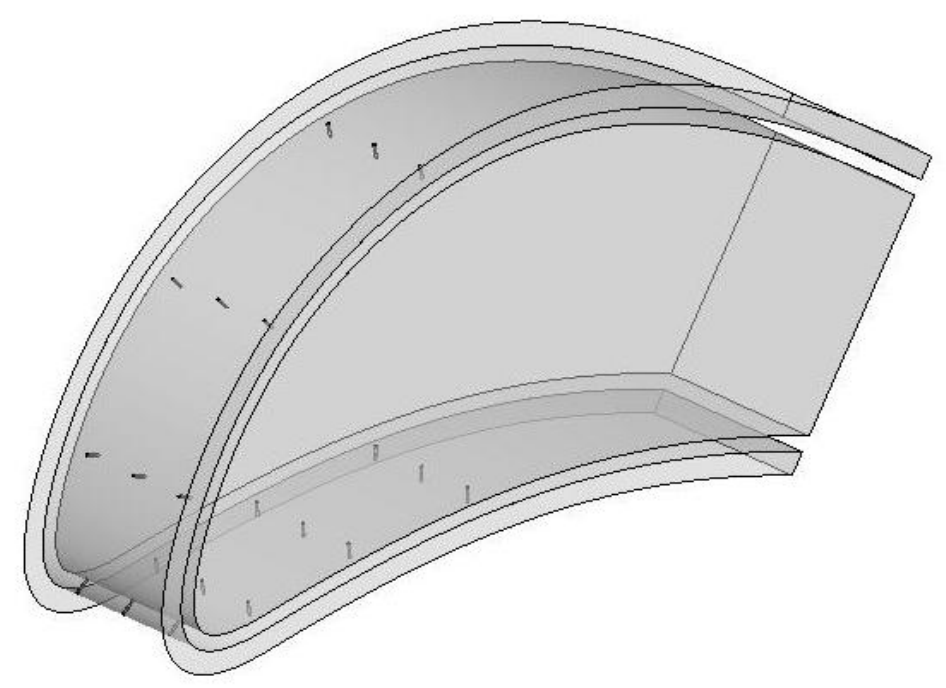

Figure 5.3: Micro-jet model with jets (Translucent view)

\section{$5.2 \quad$ Meshing}

Meshing of the models was done using ANSYS Workbench. Hybrid mesh was created on both the validation model and the micro-jet model due to geometric complexities. Automatic method with defined inflation and sizing was used in ANSYS workbench for efficient meshing.

Very fine structured mesh with $\mathrm{y}^{+}$value of 2 was created (which is within required $\mathrm{y}+$ range of viscous sub layer) normal to the target surface to capture the complex flow features. Figure 5.4 shows the mesh generated on validation model and micro jet model. The total number of nodes on the validation model and micro jet model is $8.9 \mathrm{E}+6$ and $9.1 \mathrm{E}+6$ respectively. 

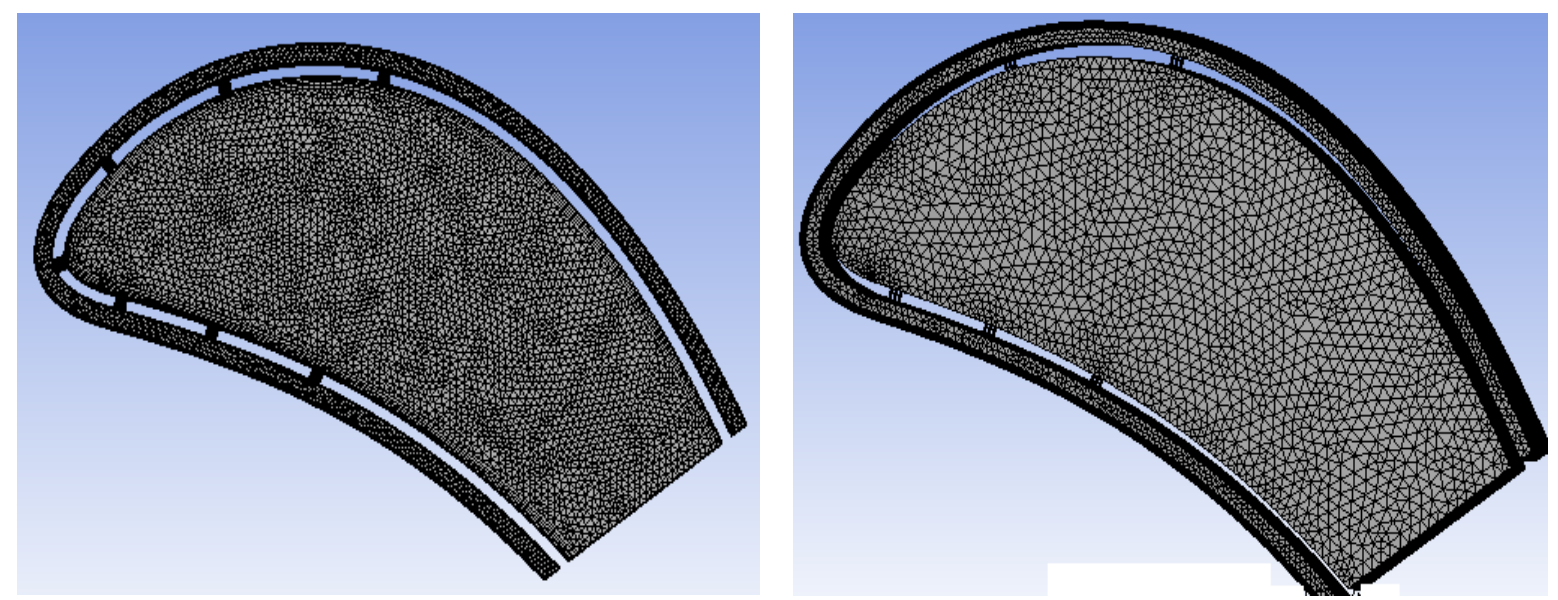

Figure 5.4: Hybrid mesh generated on validation model (left), micro jet model (right)

Figure 5.5 shows the boundary layer mesh. A very fine mesh is created near both target surface and interior surface. The latter was done to capture the cross flow generation and visualization.

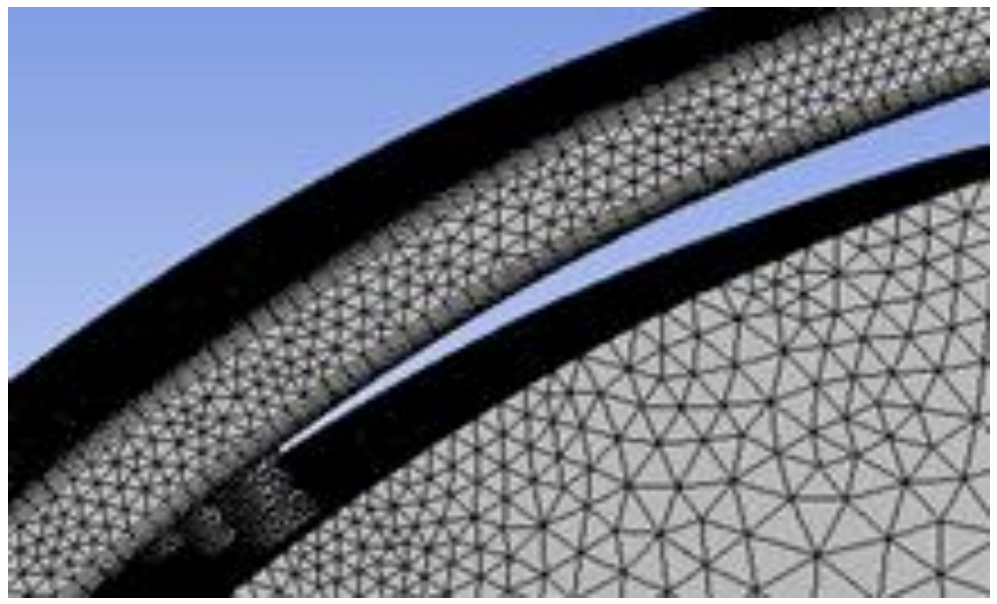

Figure 5.5: Boundary layer inflation

\subsection{Numerical Aspects}

\subsubsection{Boundary conditions}

The validation model and the micro jet model are compared by imposing a constant mass flow per unit heated area (G) at the inlet. Hence velocity inlet boundary condition is set for inlet. Inlet velocity of $1.2266 \mathrm{~m} / \mathrm{s}$ corresponding to the value of $\mathrm{G}=4.5 \mathrm{~kg} / \mathrm{m}^{2} \mathrm{~s}$ is used which indicates a mach number of $<0.5$. 
This disregards the compressibility effects. The exit was set to outflow condition. The plenum wall interior surface, plenum surface, jet walls and the sidewalls are considered as adiabatic walls. The target surface is set with a constant temperature of $300 \mathrm{~K}$ while the ambient pressure and temperature are set to $1.435 \mathrm{MPa}$ and $500 \mathrm{~K}$ respectively. This inverse of conditions is defined to avoid convergence issues at high Reynolds numbers (Leon De Paz [34]). The flow directions and boundary conditions are shown in figure 5.6, white and red arrows show the velocity inlet and pressure outlet respectively. The direction of flow entry is not realistic and assumed only for this study.

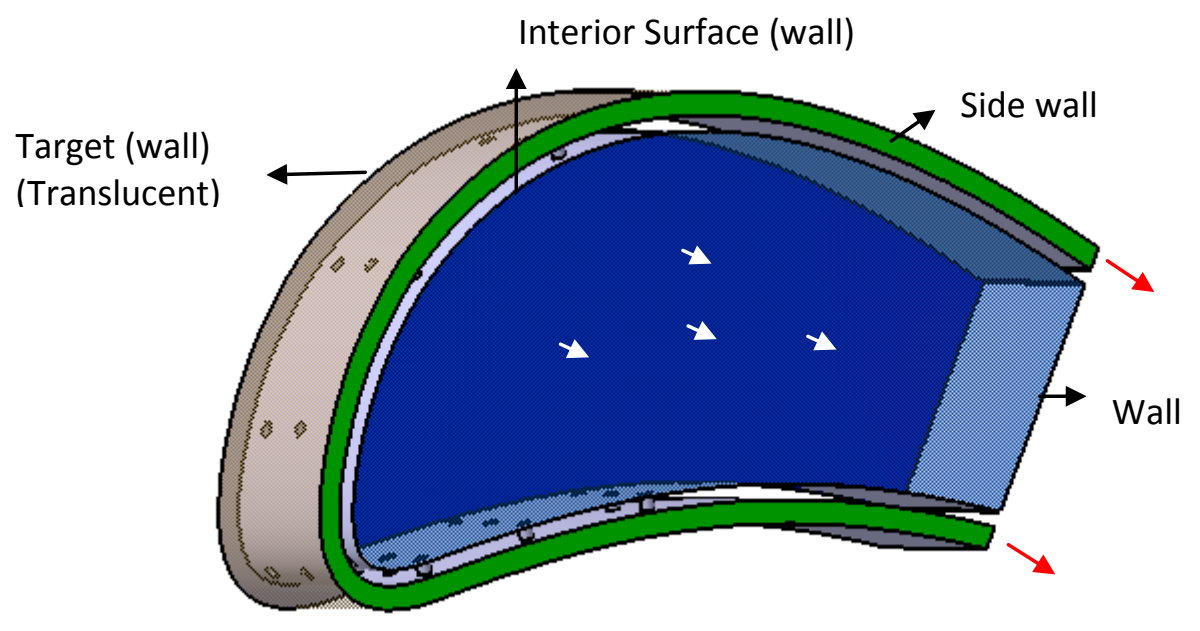

Figure 5.6: Model showing flow directions and Boundary conditions

Unless otherwise stated the flow and boundary conditions are the same for validation model and microjet model.

\subsubsection{Simulation Setup}

Numerical simulations were carried out using fluent. Parallel solvers were used with a total of 12 processors. Table 5 shows the flow conditions.

Implicit pressure based solver with SIMPLE scheme of pressure-velocity coupling was used which involves calculation of initial velocity components from an assumption of pressure and then updates the values after correction satisfying continuity equation. Second order upwind scheme was used to discretize momentum and energy equations for higher accuracy and the convergence level for all residuals apart from energy equation was set to $10^{-4}$. Energy equation was set at $10^{-6}$. These levels of convergence were set to ensure that the variables of interest have reached a stable value and imbalances are below $1 \%$. Specification of turbulence was defined by turbulence intensity and hydraulic 
diameter for both cases. $\mathrm{k}-\omega \mathrm{SST}$ turbulence model is chosen for this study based on the analysis work of [35]. Turbulence intensity (I) was calculated based on equation 4.2.

\begin{tabular}{|l|l|}
\hline Density, $\rho\left(\mathrm{kg} / \mathrm{m}^{3}\right)$ & Incompressible ideal gas \\
\hline Specific Heat, $\mathrm{Cp}(\mathrm{J} / \mathrm{kg} \mathrm{K})$ & 1030.305 \\
\hline Thermal Conductivity, $\mathrm{k}(\mathrm{W} / \mathrm{m} \mathrm{K})$ & 0.040284 \\
\hline Viscosity, $\mu(\mathrm{kg} / \mathrm{ms})$ & $2.6375 \times 10^{-5}$ \\
\hline
\end{tabular}

Table 5: Flow conditions at $500 \mathrm{~K}$

\subsubsection{Grid Independence}

Grid independence study of the proposed model was carried out with three levels of grids. The stream wise Nusselt number distribution extracted along mid plane of jets, on the pressure surface, is plotted against the chord length for three grids showing only minor variations in the stagnation Nusselt number peaks between fine and medium grids whereas the coarse show significant variations in the stagnation Nusselt peak and downstream wall jet region (Fig 5.7). Hence the medium grid was chosen for further analysis to save computational space and time.

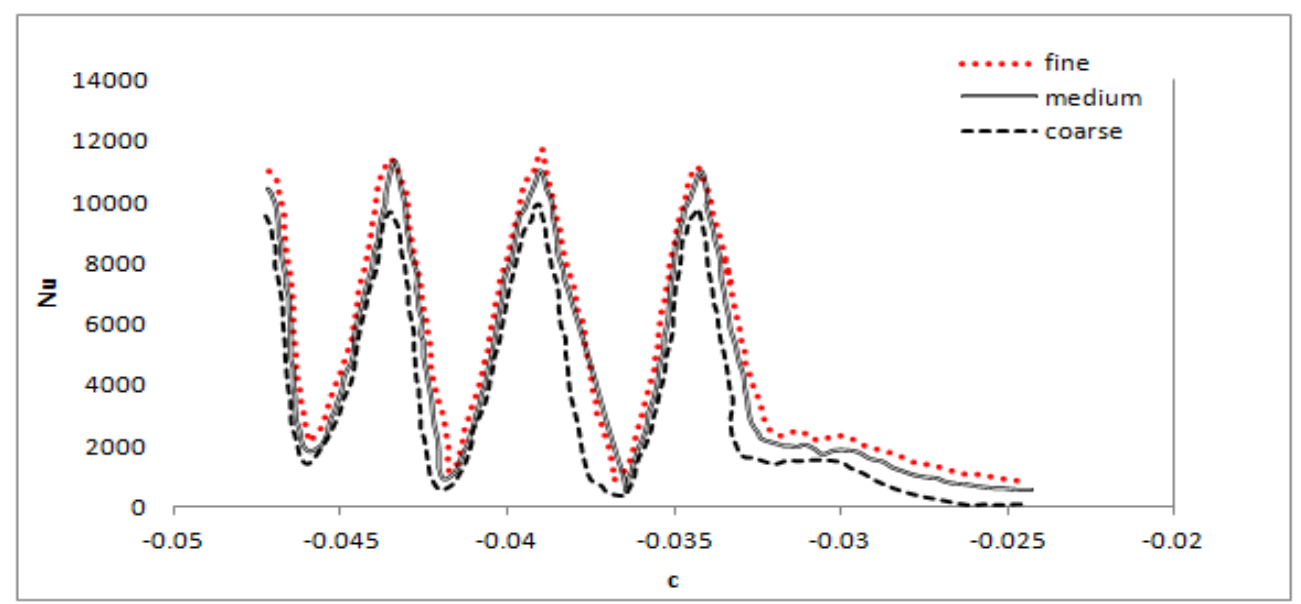

Figure 5.7: Mesh sensitivity of stream wise Nusselt distribution on pressure surface

Figure 5.8 shows the Nusselt number distribution reported by Anand [9] with a total of 42 jets on the full geometry of second stage vane. It is seen that the Nusselt values obtained by current study is quite lesser in magnitude than the values obtained by Anand [9]. This may be attributed to the considered model of only leading edge and the boundary condition. 


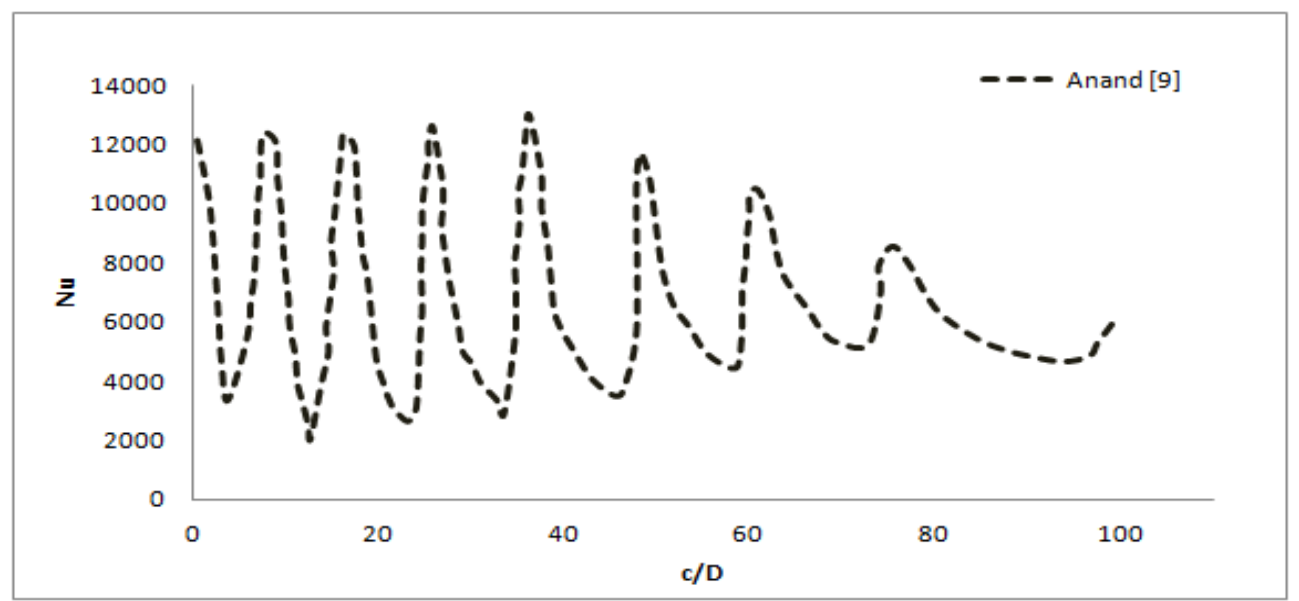

Figure 5.8: Stream wise nusselt distribution on pressure surface for full vane geometry by [9]

Further to this, grid sensitivity analysis based on the method proposed by Roache [45] was carried on for three grids to determine the Grid convergence index $(\mathrm{GCl})$. Table 2 shows the average Nusselt values of three grids and the calculated zero spacing value.

\begin{tabular}{|l|c|c|}
\hline \multicolumn{1}{|c|}{ Grid } & $\overline{N u}$ & Zero Spacing Nu Value \\
\hline Coarse & 5000.60 & \multirow{2}{*}{6217.29} \\
\cline { 1 - 2 } Medium & 6088.20 & \\
\hline Fine & 6150.84 & \\
\hline
\end{tabular}

Table 5: Average Nu values for different grids and zero spacing value

Table 7 shows the calculated $\mathrm{GCl}$ indices. Due to the use of unstructured grid on the validation and micro jet models a refinement factor of ' $r$ ' cannot be defined and hence the effective refinement factor proposed by Roache [45] is used for this $\mathrm{GCl}$ calculation.

$$
R_{\text {effective }}=\left(\frac{N_{1}}{N_{2}}\right)^{1 / D}
$$

Where $\mathrm{N} 1$ and $\mathrm{N} 2$ are the total no of nodes on fine and coarse grid respectively. $\mathrm{D}$ is the jet diameter for this study.

\begin{tabular}{|l|l|}
\hline$R_{\text {Effective }}$ & 2.1 \\
\hline $\mathrm{GCl}$ Coarse (\%) & 1.75 \\
\hline $\mathrm{GCl}$ Fine (\%) & 0.08 \\
\hline
\end{tabular}

Table 6: Calculated GCI index

$0.08 \%$ is the maximum discretization error in predicting the average heat transfer on the target surface. 


\subsection{Results and Discussion}

Tecplot 360 software was used to do extract and plot datas along the mid plane of the plane due to the complexity of the same in Fluent. Figure $\mathbf{5 . 7}$ shows the velocity plot in the mid section of the vane. An increase in velocity is observed along the stream wise direction which is more prominent in the suction surface. This is accounted to the cross flow effects enhanced by the build up of jets upstream and the curvature in the geometry. Hence higher nu values are noted for the last row of jets in the suction surface.

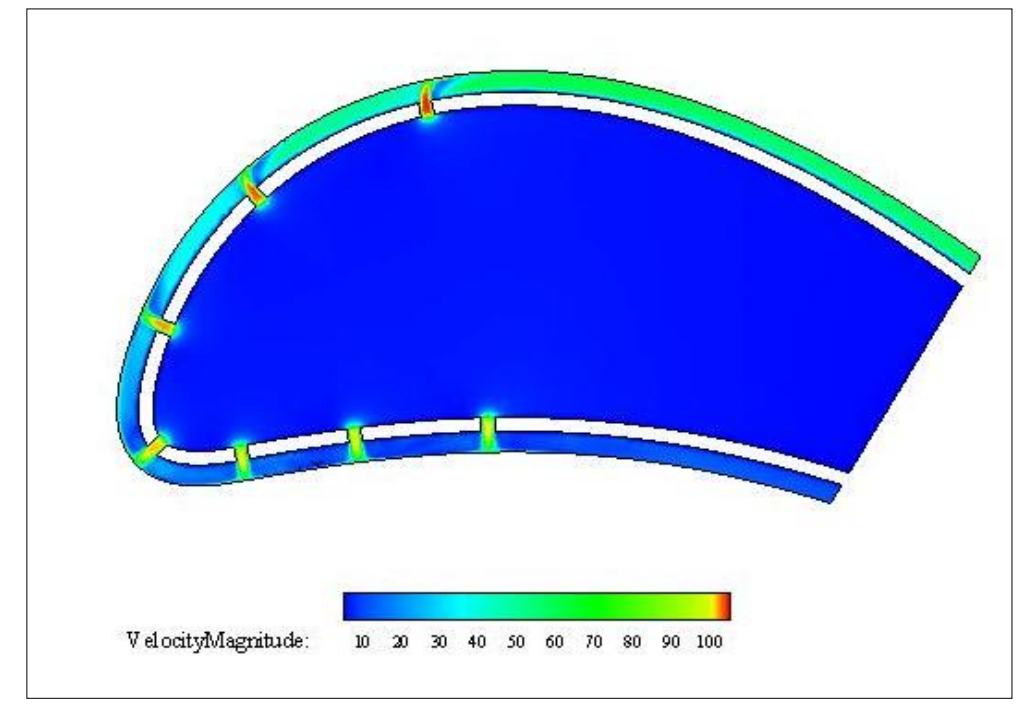

Figure 5.9: Velocity distribution on the vane mid plane of validation model

Figure 5.8 shows the Nusselt number distribution on the heated (target) surface of the validation model. The direction of the jets and the cross flow effects is visually interpreted. High heat transfer rates are observed in the center of the jets. 


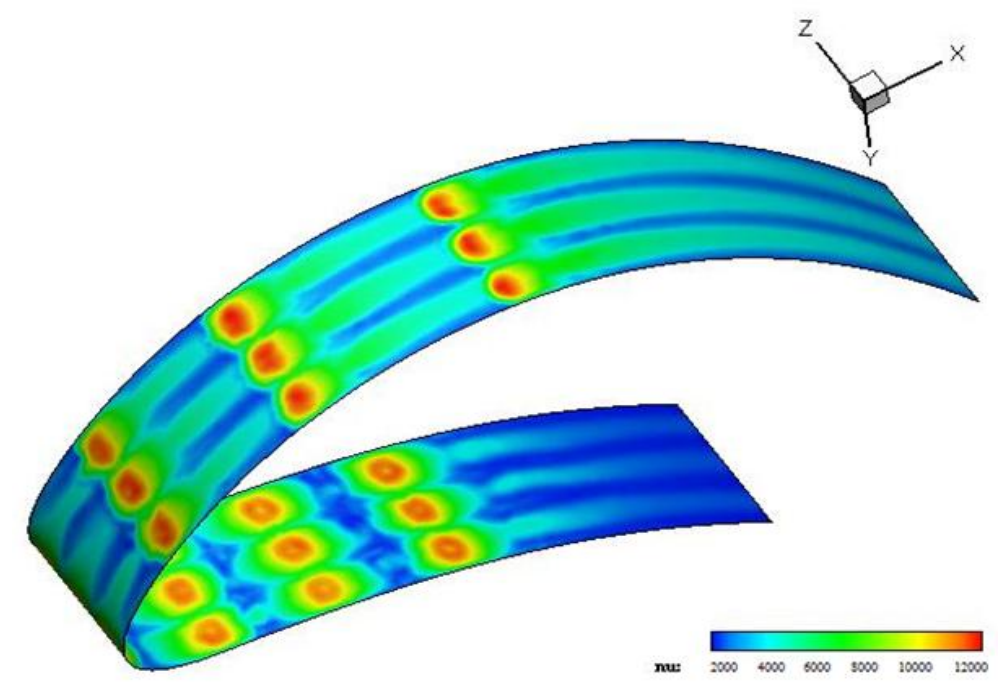

Figure 5.10: Local Nusselt contour on target surface

Figures 5.11 shows the recirculation zones near the jets in the pressure surface and the upstream jet build up and cross flow in the suction surface. Stream lines are drawn using Tecplot 360 software on the mid plane section of the turbine vane to better project the flow features.
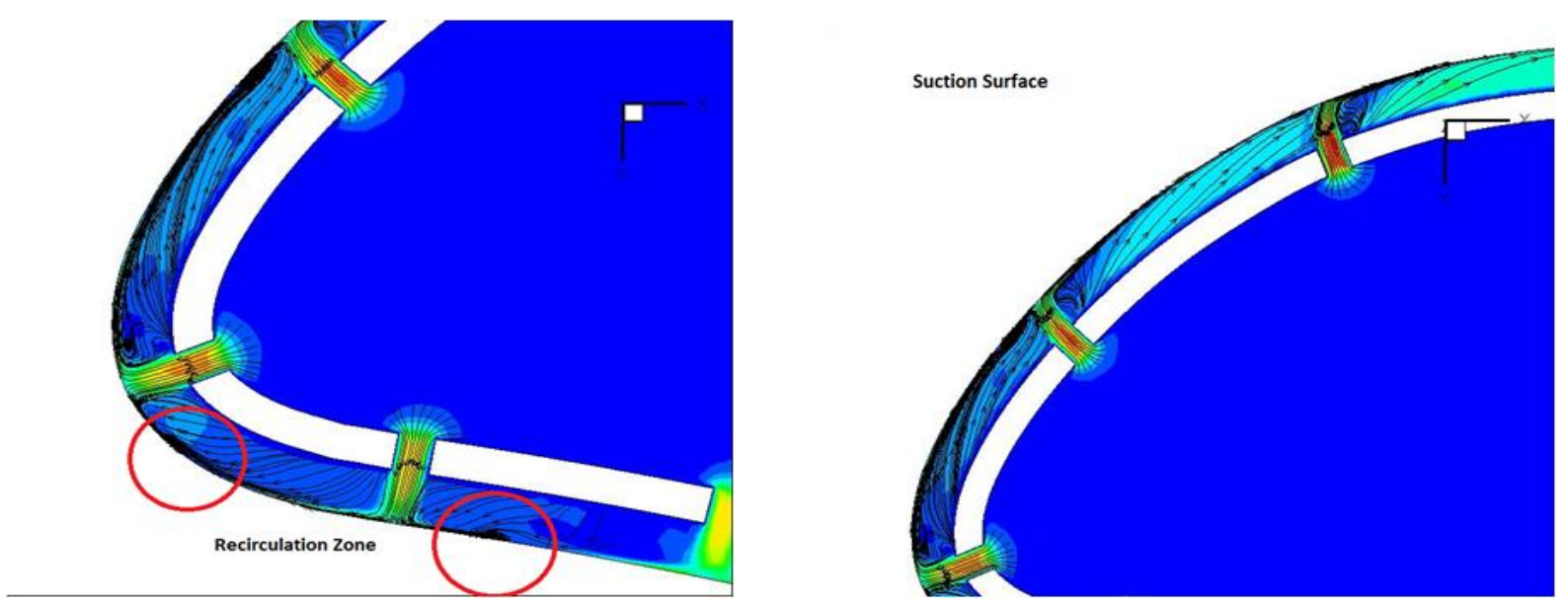

Figure 5.11: Streamlines representing recirculation zones and the cross flow

Cross flow effects tends to deflect the jet and hence a shift in stagnation point will be observed. This effect is projected more for the jets present downstream [34]. The leading edge portion considered in the present study is less affected by that phenomenon. 
An attempt has been made to study the effect of micro-jet impingement on the turbine vane. This variation in the jet diameter resulted in drastic improvement in the heat transfer characteristics of the jet. Figure 5.12 shows the velocity magnitude contour at the mid plane of the vane which indicates a very high velocity jet exiting the nozzles. This increase in velocity is due to decrease in the jet diameter.

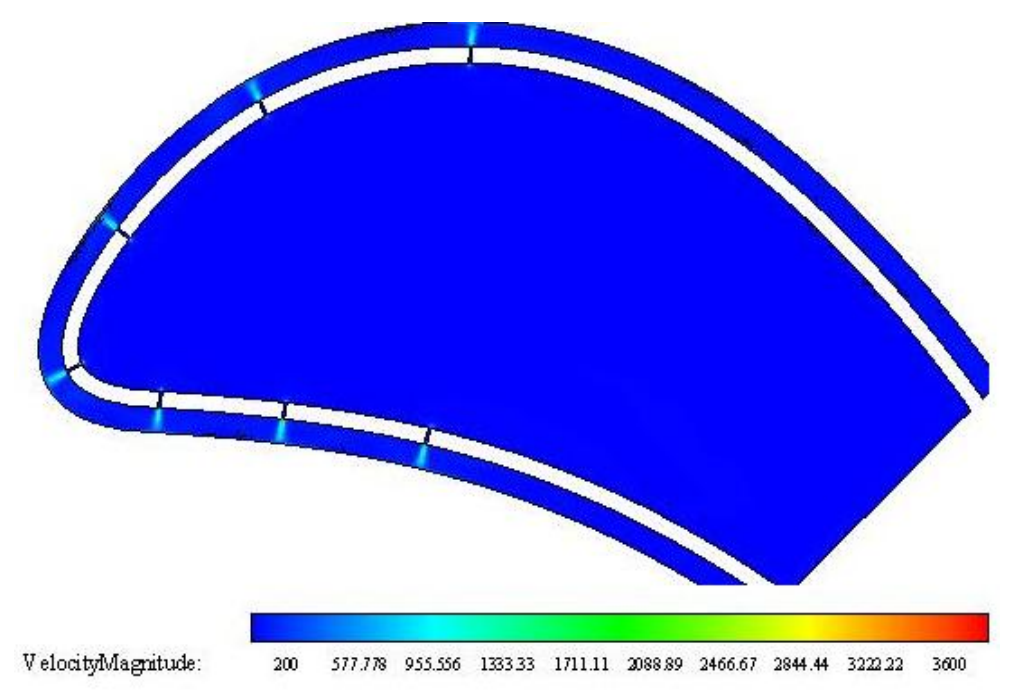

Figure 5.12: Velocity distribution on the vane mid plane of micro-jet model

An added advantage of cross flow is that it reduces the effects of cross flow there by concentrating on the impingement surface. The plot of Nusselt number distribution along the chord length for micro-jet model shows drastic shoot up of Nusselt values compared to the validation model (Fig 5.12). Hence a reduction of jet diameter by $0.4 \mathrm{~mm}$ gives almost $65 \%$ increase of the heat transfer rate. A similar trend has been shown by Anand [9] and Leon De Paz [34].

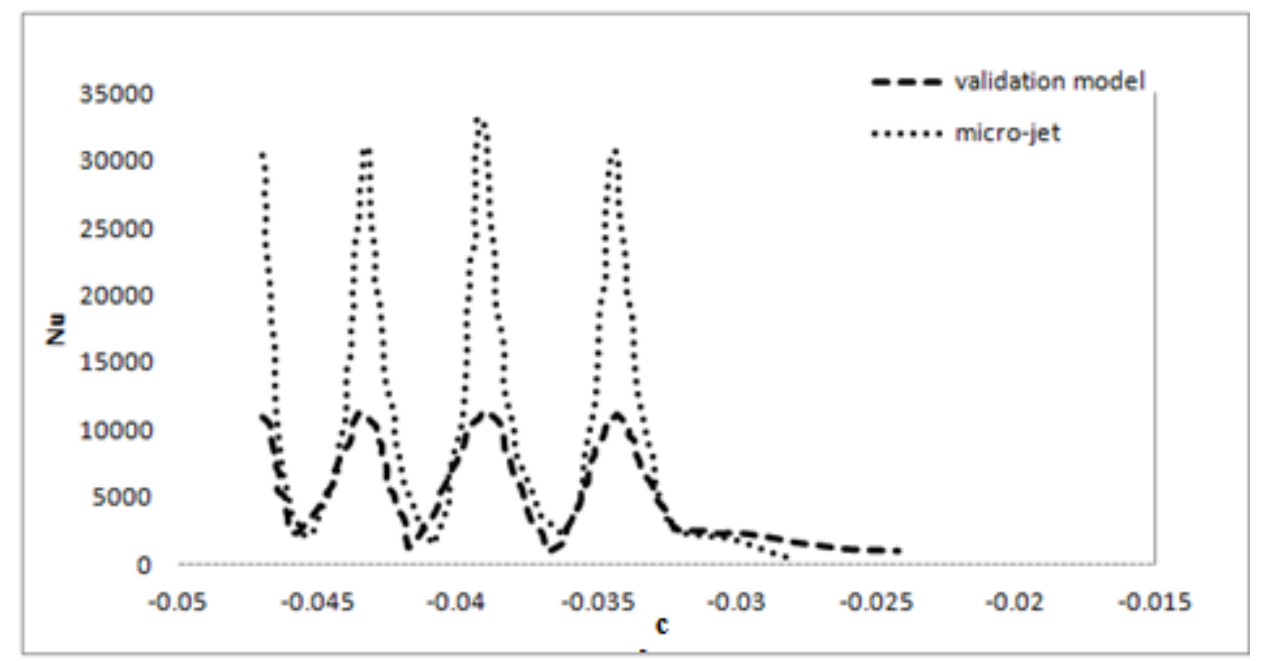

Figure 5.13: Stream wise Nusselt distribution on pressure surface 


\section{Conclusion}

\subsection{Summary}

The detailed study on different aspects of single jet and jet arrays impingement heat transfer on a heated target has led to the understanding of different trends and conclusions.

The selection of turbulence model depends on particular case, turbulence and flow characteristics rather than a general theory. From the current study it is revealed that k-epsilon RNG and K-omega SST yielded better results and agreement with experimental data though none of the turbulence models could better predict the secondary peaks.

The radial distribution of Nusselt number described a smooth curve with maximum value at the stagnation and minimum near the exit. Secondary peaks were noted to be part of low H/D ratios and high Reynolds numbers.

For a jet diameter of $0.2 \mathrm{~mm}$ of the single round jet model, the high Nusselt value was obtained at the stagnation point and for an $H / D$ ratio of 3 . A rise in stagnation Nusselt number was noted for an increase of $h / D$ up to 3 and then drop of Nusselt values was observed. Reduction of nozzle diameter to $0.1 \mathrm{~mm}$ showed $50 \%$ increase in heat transfer rates. The analysis of Reynolds number effect proved the trend of increase in local heat transfer distribution with the Reynolds number proposed by many other researchers.

Impingement heat transfer by jet arrays on leading edge part of HPT second stage vane of $E^{3}$ was studied. The analysis showed the cross flow effects and reduction of heat transfer in the downstream jets due to jet build up in the upstream. A maximum Nusselt value was obtained in the stagnation points of the jets which decayed radially and was carried away by the cross flow.

Effectiveness of micro-jet in realistic turbine vane was assessed and it is apparent that significant improvement in heat transfer rates is achieved by smaller jet diameters.

In a nutshell, jet impingement proved to be an effective method of cooling and micro-scale jets proved its efficacy for both single jet and jet arrays.

\subsection{Drawbacks of micro-scale jets}

The major drawback of using micro-jets in cooling techniques is manufacturing, blockage and deterioration of components strength. Micro-jets are highly prone to blockage which leads to building of thermal stress. The intensity of the micro-jets is so high that there is complexity involved in using the same at all points due to structural limits of the component. Thus finding a feasible solution to blockage would be the best recommendation for future work. 


\section{References}

[1] HIH. Saravanamuttoo, G. Rogers and H. Cohen, "Gas Turbine Theory," Prentice Hall, 2006.

[2] Kenneth W. Van Treuren, "Impingement Flow Heat Transfer Measurements of Turbine Blades Using a Jet Array," Doctoral Thesis , University of oxford, , 1994.

[3] E. E. Halila, D. T. Lenahan and T. T. Thomas, "Energy Efficient Engine: High Pressure Turbine Test Hardware Detailed Design Report," 1982.

[4] Osama. M. Al-aqal, "Heat Transfer distributions on the walls of a narrow channel with jet impingement and cross flow," Doctoral Thesis, University of Pittsburgh, 2003.

[5] K. Jambunathan, E. Lai, M. A. Moss and B. L. Button, "A review of heat transfer data for single circular jet impingement," International Journal of Heat and Fluid Flow, Vol. 13, No. 2, pp. 106-115, June 1992.

[6] Martin Draksler and Bostjan Koncar, "Analysis of heat transfer and flow characteristics in turbulent impinging jet"," Nuclear engineering and design, pp. 1254-1258, 2011.

[7] Mirko Bovo, "On the numerical modelling of impinging jets heat transfer," Chalmers University of Technology, Sweden, 2011.

[8] D. Lytle and B.W.Webb, "Air jet impingement heat transfer at low nozzle-plate spacings," International Journal of Heat and Mass transfer, Vol. 37, No. 12, pp. 1687-1697, 1994.

[9] Karan Anand, " Numerical heat transfer analysis of micro-scale jet impingement cooling in a high pressure turbine vane,"MASc Thesis, Ryerson University, 2011.

[10] Jung-Yang San and Wen-Zheng Shiao, " Effects of jet plate size and plate spacing on the stagnation Nusselt number for a confined circular air jet impinging on a flat surface," International Journal of Heat and Mass Transfer, Vol. 49, pp. 3477-3486, 2006.

[11] R. J Goldstein and A. I. Behbahani, " Impingement of a circular jet with and without cross flow," International Journal of Heat and Mass transfer, Vol. 25, No.9, pp. 1377-1382, April 1982.

[12] Jungho Lee and Sang-Joon Lee, "Stagnation region heat transfer of a turbulent axisymmetric jet impingement," International Journal of Heat and Mass transfer, pp. 3497-3509, 1999. 
[13] Naseem Uddin, Syef Olaf Neumann, Bernhard Weigand and Bassam A. Younis, "Large eddy simulations and heat flux modelling in a turbulent impinging jet," Numerical Heat Transfer, Part A, 55, pp. 906-930, 2009.

[14] S Ashforth-Frost, K.Jambunathan, C. F. Whitney and S. J. Ball, "Heat transfer from a flat plate to a turbulent axisymmetric impinging jet," Proceedings of the Institution of Mechanical Engineers, pp. 167-172, 1997.

[15] Vadiraj Katti and S.V.Prabhu "Experimental study and theoretical analysis of local heat transfer distribution between smooth flat surface and impinging air jet from a circular straight pipe nozzle," Indian Institute of Technology, pp. 4480-4494.

[16] R. J. Goldstein and W.S. Seol, " Heat transfer to a row of impinging circular air jets including the effect of entrainment," International Journal of Heat and Mass transfer, Vol. 34, No.8, pp. 21332147, 1991.

[17] Colin Glynn and D. B. Murray, "Jet impingement cooling in microscale," ECl International Conference on Heat Transfer and Fluid Flow in Microscale, September 2005.

[18] Dae Hee Lee, J. Song and M. Chan Jo "The Effects of Nozzle Diameter on Impinging Jet Heat Transfer and Fluid Flow," ASME, Vol. 126, pp. 554-55, August 2004.

[19] M. Behnia, S. Parneix, Y. Shabany and P. A. Durbin, " Numerical study of turbulent heat transfer in confined and unconfined impinging jets," International Journal of Heat and Fluid Flow, 1999.

[20] Leon F. G. Geers, Mark J. Tummers and Kemal Hanjalic, "Experimental investigation of impinging jet arrays," Experiments in Fluids, pp.946-958, 2004.

[21] John E. Leland and R. Ponnappan, "Experimental Investigation of an Air Microjet Array Impingement Cooling Device," Journal of Thermophysics and Heat Transfer, Vol. 16, No. 2, pp. 187192, 2002.

[22] Jr.-Ming Miao, Cheng-Yuan Wu and Ping-Hei Chen, "Numerical investigation of confined multiplejet impingement cooling over a flat plate at different crossflow orientations," Numerical heat transfer, Part A, 55, pp. 1019-1050, 2009.

[23] U. Uysal, P.-W. Li, M. K. Chyu and F. J. Cunha, "Heat Transfer on Internal Sufaces of a Duct Subjected to Impingement of a Jet Array with Varying Jet Hole-Size and Spacing," ASME, Vol. 128, pp. 158-165, 2006. 
[24] Y. -T. Yang and C. -H. Hwang, "Numerical simulations on the hydrodynamics of a turbulent slot jet imoinging on a semicylindrical convex surface," Numerical Heat Transfer, Part A, 46, pp. 995-1008, 2010.

[25] N. Souris, H. Liakos and M.Founti, "Impinging Jet Cooling on Concave Surfaces," American Institute of Chemical Engineers, Vol 50, No.8, August 2004.

[26] Je-Chin Han, "Advanced turbine cooling, Heat transfer and Aerodynamic studies", 1995.

[27] D. G. Ainley, " The high temperature turbojet engine," 1956.

[28] Zhao Liu and Zhenping Feng, " Numerical simulation on the effect of jet nozzle position on impingement cooling of gas turbine blade leading edge," International Journal of Heat and Mass Transfer, Vol. 54, pp. 4949-4959, 2011.

[29] R. E. Chupp, H. E. Helms, Peter W. Mcfadden and Tony R. Brown "Evaluation of internal heat transfer coefficients for impingement cooled turbine airfoils," AIAA, Vol. 6, No. 3, pp.203-208, 1969.

[30] I.G.Currie, "Fudamental mechanics of fluid", Third Edition, 1993.

[31] M.Angioletti, E. Nino and G. Ruocco, "CFD turbulent modelling of jet impingement and its validation by particle image velocimetry and mass transfer measurements," International Journal of Thermal Sciences, Vol. 44, pp. 349-356, 2005.

[32] Chougule N.k., Parishwad G.V., Gore P. R., Pagnis S., and Sapali S. N., "CFD Analysis of Multi-jet Air impingement on flat plate," Proceedings of the world congress on Engineering, Vol III, July 2011.

[33] D.Cooper, D. C. Jackson, B. E. Launder and G. X. Liao, "Impinging jet studies for turbulence model assessment -I. Flow-field experiments," International Journal of Heat and Mass Transfer, Vol. 36, No. 10, pp. 2675-2684, 1993.

[34] Marcel Leon De Paz and B.A. Jubran, "Numerical modeling of multi micro jet impingement cooling of a three dimensional turbine vane," Heat mass transfer, Vol. 47, pp. 1561-1579, 2011.

[35] Frank M. White, Fluid Mechanics, $5^{\text {th }}$ Ed. Boston: McGraw Hill, 2003.

[36] Jonas Berdberg, "On the Wall Boundary Condition for Turbulence Models," Chalmers University of Technology, Goteborg, Sweden, 2000. 
[37] FLUENT Inc. (2003) Fluent 6.1 Users Guide. FLUENT Inc.

[38] J. W. B. Baughn and S.Shimizu, "Heat transfer measurements from a surface with uniform heat flux and an impinging jet," ASME J. Heat Transfer, 1989.

[39] Yan, X., Baughn, J.W., Mesbah, M., "The Effects of Reynolds number on the heat transfer distribution from a flat plate to an impinging jet," ASME, Vol. 226, November 1992.

[40] R. Viskanta, "Heat transfer to impinging isothermal gas and flame jets," Experimental thermal and fluid science, Vol. 6, pp. 112-134, September 1992.

[41] R. J. Goldstein and J. -P. Bouchez, "Impingement cooling from a circular jet in a cross flow," International Journal of Heat and Mass Transfer, Vol. 18, pp. 719-730, 1975.

[42] G. Liping, Z. Jingwei, H. Feifei and Yang Mo, "Numerical study on flow field and heat transfer characteristics of rectangular impinging jets," 2011.

[43] S. V. Garimella and B. Nenaydykh, "Nozzle geometry effects in liquid jet impingement heat transfer," International Journal of Heat and Mass Transfer, Vol. 39, No. 14, pp. 2915-2923, 1996.

[45] P. J. Roache, " Perspective: A method for uniform reporting of grid refinement studies," Journal of Fluids Engineering, Vol. 116, pp. 405-413, September 1994. 